\title{
ipen
}

Instituto de Pesquisas Energéticas e Nucleares Autarquia associada à Universidade de São Paulo

\section{ESTUDO DO PROCESSO DE ESFEROLIZAÇÃO DE PARTÍCULAS VÍTREAS VISANDO À APLICAÇÃO EM RADIOTERAPIA INTERNA SELETIVA}

\section{ERALDO CORDEIRO BARROS FILHO}

Dissertação apresentada como parte dos requisitos para obtenção do Grau de Mestre em Ciências na Área de Tecnologia Nuclear-Materiais

Orientador:

Prof. Dr. José Roberto Martinelli

São Paulo

2012 
Dedico este trabalho às mulheres da minha vida: minha namorada Rose, minha mãe Darcy, minha irmã Isabel e minha avó Antonieta.

Dedico também ao meu pai Eraldo Barros "in memoriam". 


\section{AGRADECIMENTOS}

Ao Prof. Dr. José Roberto Martinelli pela orientação, dedicação e valiosos ensinamentos durante o desenvolvimento deste trabalho.

Ao Dr. Frank Ferrer Sene pelo seu caráter e pelas valiosas discussões e colaborações durante o desenvolvimento deste trabalho.

Ao Dr. João Alberto Osso Jr. e Peterson Squair pelas irradiações de nêutrons e importantes esclarecimentos.

Ao grupo LAVICOM: José Mario Prizon, Heveline Vieira, Juliana, Carla, Vilma e Rebeca, que de muitos modos contribuíram para realização deste trabalho.

Aos técnicos Celso Vieira, Flavia e Glauson Machado pelas análises de microscopia eletrônica de varredura.

Ao Técnico Renê Ramos de Oliveira pela análise de DRX.

À Dra. Sizue Rogero pelas discussões e prestação de auxílio durante a realização dos testes de citotoxicidade.

Ao Prof. Dr. Reginaldo Mucillo pelas análises de DRX e disponibilização dos laboratórios.

À Prof. Dra. Eliana Mucillo pelas valiosas discussões e esclarecimentos.

Ao Dr. Hidetoshi Takiishi pela disponibilização dos laboratórios.

À CAPES pela bolsa de estudos e ao IPEN pela oportunidade para realização deste trabalho.

Ao Centro de Radiofarmácia do IPEN e à Agência Internacional de Energia Atômica pelo apoio financeiro.

À Magali Barbieri e Fernando Moreira pela atenção e dedicação nos assuntos burocráticos.

Ao amigo Ricardo de Araújo pelas discussões e revisão do texto.

Aos amigos que conheci no IPEN e que contribuíram com discussões importantes para o trabalho: Alan, Julio, José Hélio, Silvio, Railson, Charles entre outros e em especial ao Lucas pela amizade, discussões e auxílio durante o desenvolvimento do trabalho.

À todos que de alguma forma ajudaram-me no desenvolvimento deste trabalho.

Aos meus amigos pela confiança e amizade e à minha mãe, minha irmã e minha namorada pela paciência e por sempre acreditarem em mim. 
"Aprenda como se fosse viver para sempre, viva como se fosse morrer amanhã"

(Mahatma Ghandi).

"A mente que se abre a uma nova ideia jamais voltará ao seu tamanho original"

(Albert Einstein) 


\title{
ESTUDO DO PROCESSO DE ESFEROLIZAÇÃO DE PARTÍCULAS VÍTREAS VISANDO À APLICAÇÃO EM RADIOTERAPIA INTERNA SELETIVA
}

\author{
Eraldo Cordeiro Barros Filho
}

\section{RESUMO}

A radioterapia interna seletiva é uma alternativa para o tratamento do carcinoma hepatocelular. Nesta terapia, microesferas de vidro contendo radionuclídeos são introduzidas no fígado por meio de um cateter acoplado à artéria hepática dos pacientes e são retidas em regiões microvasculares que alimentam o tecido lesado. Estas micropartículas aniquilam as células cancerosas por meio da radiação $\beta^{-}$, e, quando simultaneamente emitem raios $\gamma$, podem também ser utilizadas para imageamento do tumor. As partículas vítreas devem possuir o formato esférico para não provocar hemorragias desnecessárias e também diâmetro adequado para otimizar o bloqueio efetivo da alimentação do tumor e evitar a migração para outros órgãos que poderia causar doses em tecidos sadios. Além disso, devem ter durabilidade química adequada e não serem citotóxicas. A distribuição do tamanho de microesferas depende de muitos parâmetros como a razão de aspecto, formação de aglomerados, e temperatura de processamento. No presente trabalho é apresentado um estudo do processo de esferolização de partículas vítreas caracterizadas por difração de raios X, espectrometria de fluorescência de raios X por energia dispersiva, área superficial específica, teste de citotoxicidade e calorimetria exploratória diferencial. Foram determinadas a taxa de dissolução do vidro em água destilada a $90^{\circ} \mathrm{C}\left(\mathrm{DR} \sim 10^{-8} \mathrm{~g} \cdot \mathrm{cm}^{-2} \cdot \mathrm{min}^{-1}\right)$, densidade $\left(2,79 \mathrm{~g} . \mathrm{cm}^{-3}\right)$, viscosidade e granulometria. A morfologia das microesferas foi avaliada por microscopia eletrônica de varredura antes e após os testes de dissolução em SBF e irradiação por feixe de nêutrons. Propõem-se o peneiramento para seleção das microesferas apropriadas para o tratamento pretendido e testes "in vivo" visando a sua aplicação em radioterapia interna seletiva. 


\title{
STUDY OF THE SPHEROIDIZATION PROCESS OF GLASS PARTICLES FOR SELECTIVE INTERNAL RADIOTHERAPY.
}

\section{Eraldo Cordeiro Barros Filho}

\begin{abstract}
The selective internal radiotherapy is an alternative method to treat hepatocellular carcinoma. Glass microspheres containing radionuclides are introduced in the liver through the hepatic artery, and they are housed preferentially in the region where the cancer cells are located. The microspheres are trapped in the arterioles which feed the tumors, and the $\beta^{-}$particles annihilate the cancer cells. When these particles simultaneously emit $\gamma$ rays, they can also be used to provide images of the tumor. The glass particles must be spherical to avoid unnecessary bleeding, and the particle size must be restricted to a range which is appropriated to trap them and avoid the migration to other parts of the body. Furthermore, they must have a good chemical durability and be nontoxic. The particle size distribution of microspheres is not easily predicted based on the original irregular particles since the variation of the aspect ratio and the presence of agglomerates can influence the final result. In the present work, the spheroidization process to obtain microspheres for radiotherapy treatment was studied. The glass microspheres were characterized by X-rays diffraction, Energy Dispersive X-rays Fluorescence Spectroscopy, Differential Scanning Calorimetry, Specific Superficial Area and cytotoxicity test. The dissolution rate in distilled water at $90^{\circ} \mathrm{C}\left(\mathrm{DR} \sim 10^{-8} \mathrm{~g} . \mathrm{cm}^{-}\right.$ $\left.{ }^{2} \cdot \mathrm{min}^{-1}\right)$, density $\left(2.79 \mathrm{~g} . \mathrm{cm}^{-3}\right)$, viscosity, and size particle distribution were determined. The surface morphological aspect was evaluated by Scanning Electron Microscopy before and after the chemical durability tests in SBF and after the neutron irradiation. It is proposed that the produced material should be sieved to select the most suitable microspheres, and to allow "in vivo" tests aiming its application in selective internal radiotherapy.
\end{abstract}




\section{SUMÁRIO}

Página

1 INTRODUÇÃ

2 OBJETIVOS

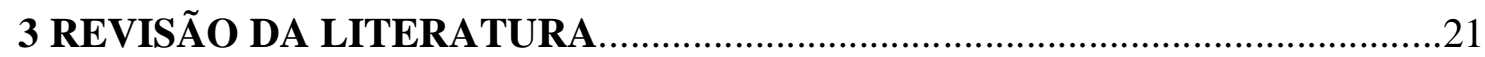

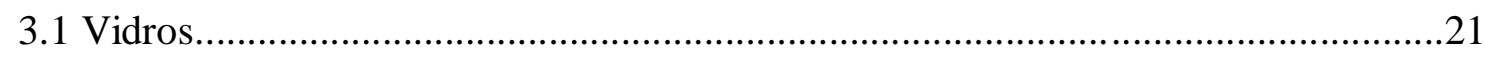

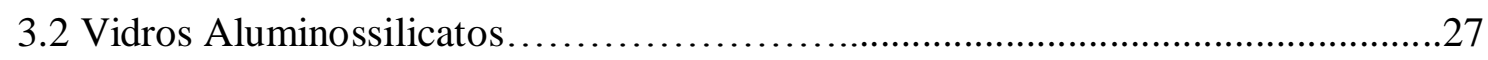

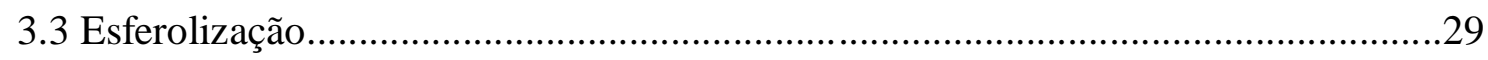

3.4 Seção de Choque para Absorção de Nêutrons.........................................................33

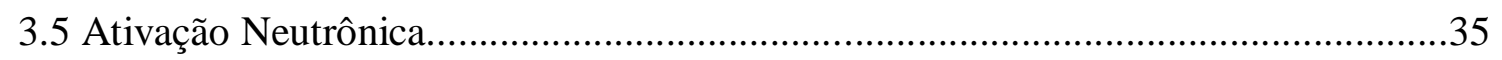

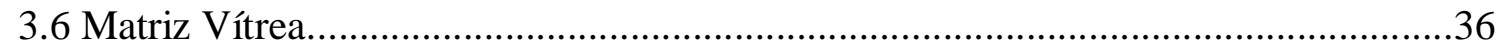

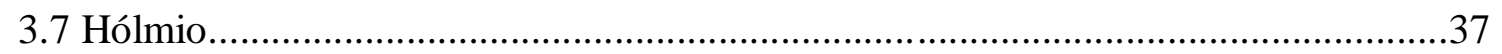

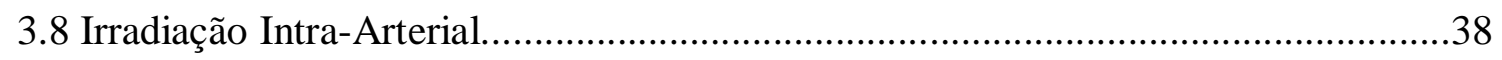

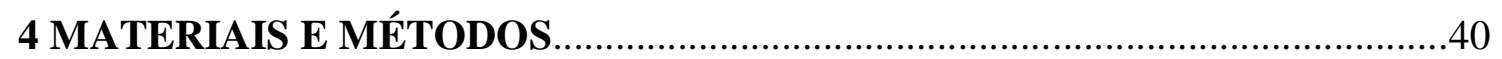

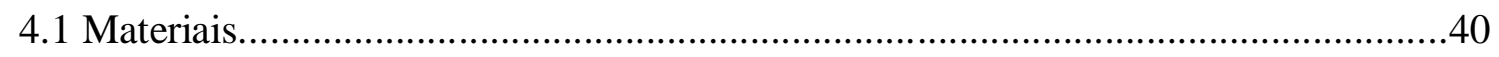

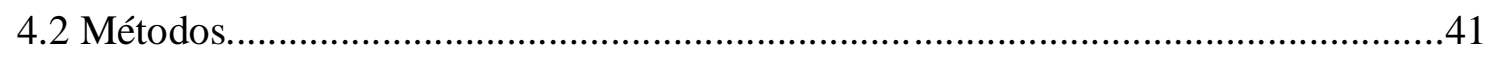

4.2.1 Determinação da Área Superficial Específica.....................................................41

4.2.2 Calorimetria Exploratória Diferencial (DSC)....................................................42

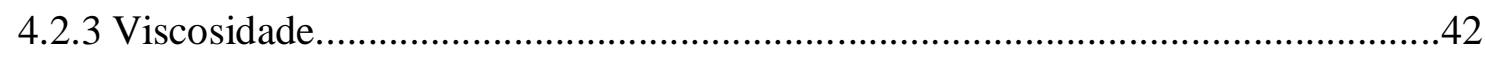

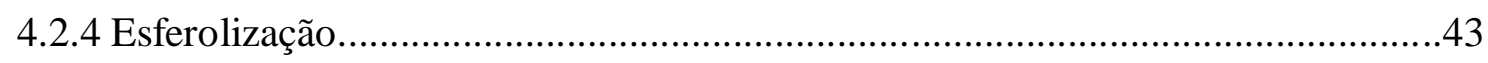

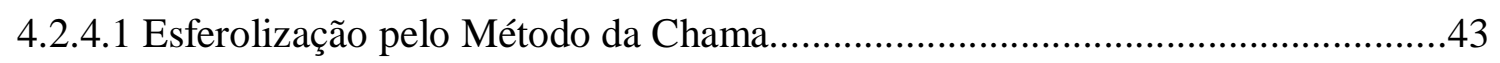


4.2.4.2 Esferolização por Queda Gravitacional...............................................................44

4.2.4.2.1 Eliminação de Finos por Decantação..................................................................46

4.2.4.2.2 Eliminação de Finos por Agitação, Ultrassom e Decantação............................46

4.2.5 Microscopia Eletrônica de Varredura e Distribuição do Tamanho de Partículas...47

4.2.6 Irradiação por Nêutrons para Avaliação dos Danos Causados pela Radiação.......47

4.2.7 Aumento do Teor de Hólmio.....................................................................................4

4.2.8 Espectrometria de Fluorescência de raios X por Energia Dispersiva.....................48

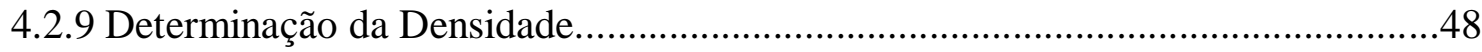

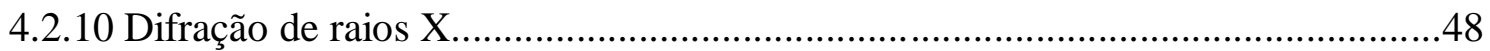

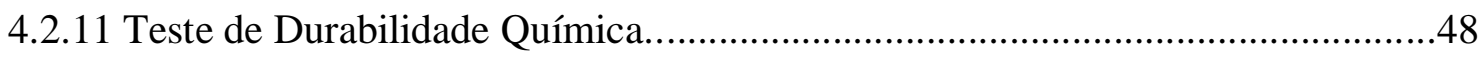

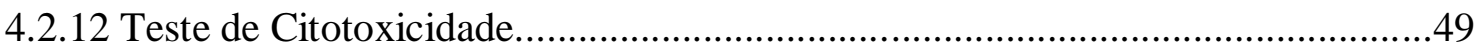

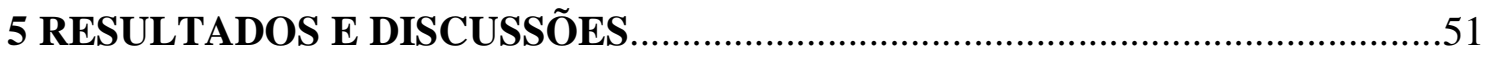

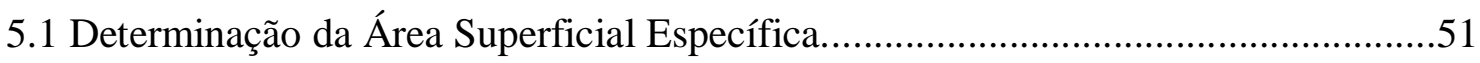

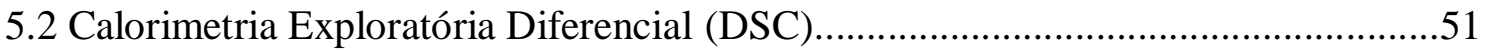

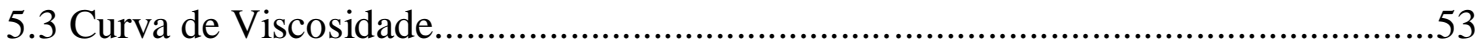

5.4 Espectrometria de Fluorescência de raios X por Energia Dispersiva ........................54

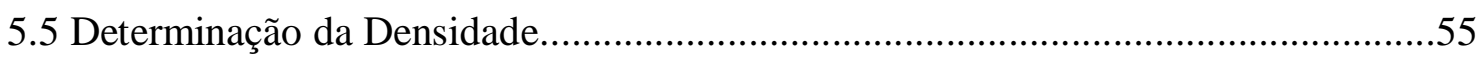

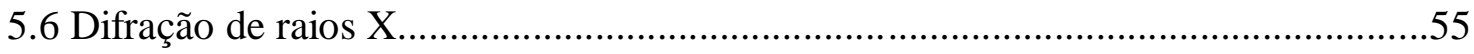

5.7 Análises Granulométricas e Microscopia Eletrônica de Varredura...........................56

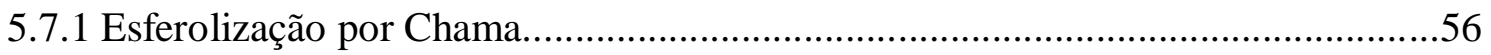

5.7.1.1 Distribuição Granulométrica do Material Precursor...........................................60

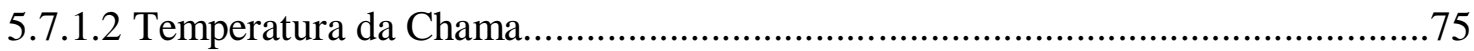

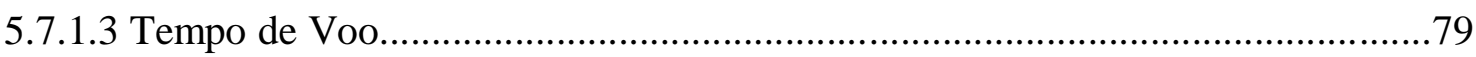

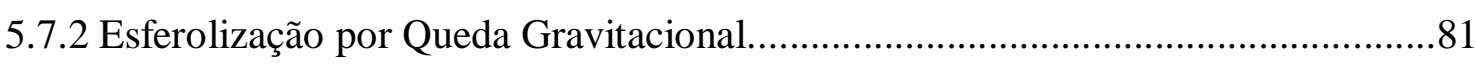

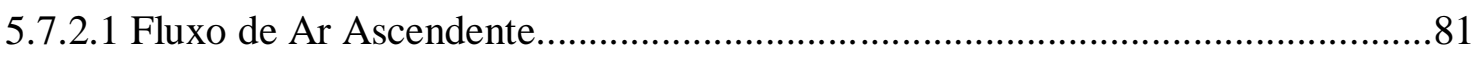

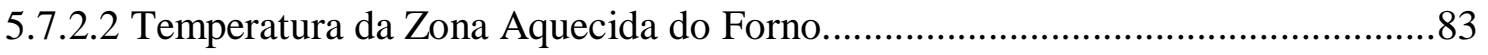

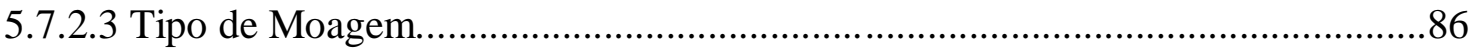

5.7.2.4 Eliminação de Finos por Decantação...............................................................92

5.7.2.5 Eliminação de Finos por Agitação Mecânica, Ultrassom e Decantação..............95

5.8 Avaliação dos Danos Superficiais após Irradiação por Nêutrons.............................98

5.9 Aumento do Teor de Hólmio...................................................................................99

5.10 Avaliação da Durabilidade Química em SBF por Meio de MEV.........................102

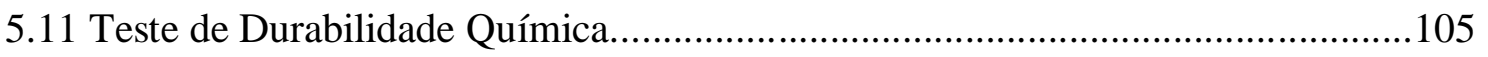




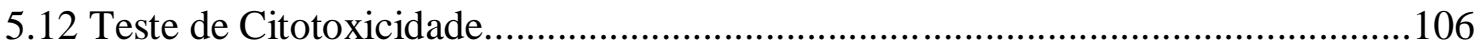

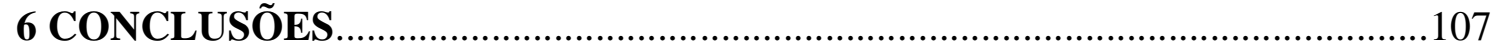

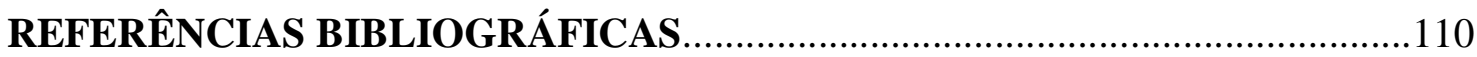


LISTA DE TABELAS

TABELA 1: Composição química da solução Ringer $\mathrm{pH}=7$

Página em $1 \mathrm{~L}$ de água deionizada. 49

TABELA 2: Composição química obtida por EDX (\%massa).........................................54

TABELA 3: Densidade média obtida por picnometria...................................................55

TABELA 4: Distribuição do tamanho de partículas por meio de difração a laser. .59

TABELA 5: Distribuição do tamanho de microesferas....................................................72

TABELA 6: Distribuição do tamanho de partículas.........................................................73

TABELA 7: Distribuição do tamanho de microesferas em

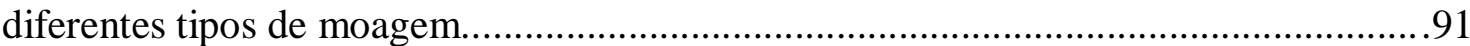

TABELA 8: Distribuição do tamanho de partícula em

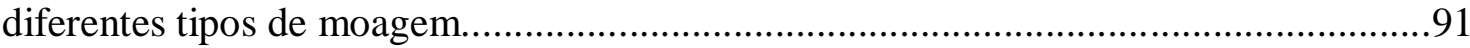

TABELA 9: Composição real de vidros contendo $25 \%$ (nominal) em peso de $\mathrm{Ho}_{2} \mathrm{O}_{3}$

TABELA 10: Composição real de vidros contendo $37 \%$ (nominal) em peso de $\mathrm{Ho}_{2} \mathrm{O}_{3}$.

TABELA 11: Taxa de dissolução de vidros aluminossilicatos contendo hólmio em função do tempo de imersão à $90^{\circ} \mathrm{C}$. 


\section{LISTA DE FIGURAS}

Página

FIGURA 1: Variação do volume específico em relação à temperatura de um vidro e de um cristal.

FIGURA 2: Representação bidimensional idealizada por Zachariasen

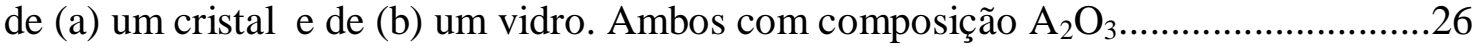

FIGURA 3: Estrutura de vidros aluminossilicatos com o $\mathrm{Al}^{+3}$ como modificador da rede e possuindo coordenação octaédrica .28

FIGURA 4: a) representação de uma molécula no interior de um líquido

b) representação de uma molécula na superfície de um líquido.

FIGURA 5: Representação das forças atuantes em um hemisfério de uma gota líquida.

FIGURA 6: A pressão de vapor do líquido varia com a superfície de curvatura

FIGURA 7: Feixe de nêutrons atravessando uma lâmina de matéria.

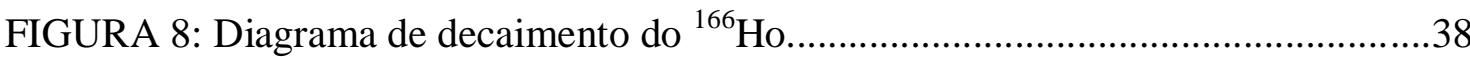

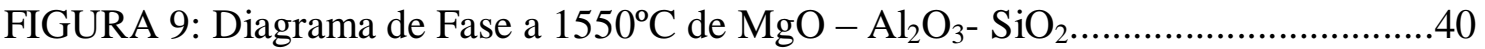

FIGURA 10: Aparato experimental utilizado para obtenção de microesferas pelo método da chama.

FIGURA 11: Aparato experimental para obtenção de microesferas

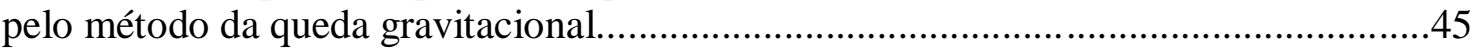

FIGURA 12: Curva DSC de partículas vítreas irregulares e microesferas....................51

FIGURA 13: Amolecimento das microesferas de vidro na

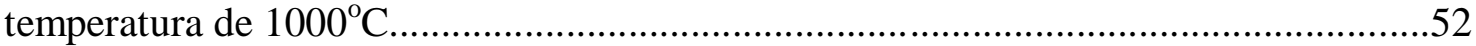

FIGURA 14: Curva da viscosidade em função da temperatura....................................53

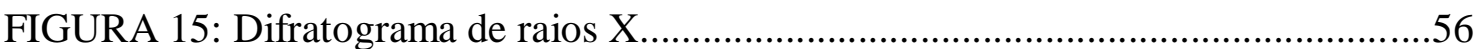

FIGURA 16: Microesferas (a) MEV; (b) Distribuição granulométrica. 
FIGURA 17: Material Precursor (a) MEV; (b) Distribuição granulométrica. .58

FIGURA 18: Microesferas obtidas a partir do material precursor com granulometria entre $0<\Phi<38 \mu \mathrm{m}$ (a) MEV; (b) Distribuição granulométrica.

FIGURA 19: Material precursor com granulometria entre $0<\Phi<38 \mu \mathrm{m}$

(a) MEV; (b) Distribuição granulométrica.

FIGURA 20: Microesferas obtidas a partir de material precursor com granulometria entre $40 \mu \mathrm{m}<\Phi<53 \mu \mathrm{m}$ (a) e (b) MEV;

(c) Distribuição granulométrica.

FIGURA 21: Material precursor com granulometria entre

$40 \mu \mathrm{m}<\Phi<53 \mu \mathrm{m}$ (a) MEV; (b) Distribuição granulométrica.

FIGURA 22: Microesferas obtidas a partir de material precursor com granulometria entre $45 \mu \mathrm{m}<\Phi<56 \mu \mathrm{m}$ (a) e (b) MEV;

(c) Distribuição granulométrica.

FIGURA 23: Material precursor com granulometria entre

$45 \mu \mathrm{m}<\Phi<56 \mu \mathrm{m}$ (a) MEV; (b) Distribuição granulométrica.

FIGURA 24: Microesferas obtidas a partir de material precursor com granulometria entre $45 \mu \mathrm{m}<\Phi<63 \mu \mathrm{m}$ (a) e (b) MEV;

(c) Distribuição granulométrica.

FIGURA 25: Material precursor com granulometria entre

$45 \mu \mathrm{m}<\Phi<63 \mu \mathrm{m}$ (a) e (b) MEV; (c) Distribuição granulométrica.

FIGURA 26: Microesferas obtidas a partir de material precursor com granulometria entre $56 \mu \mathrm{m}<\phi<63 \mu \mathrm{m}$ (a) e (b) MEV;

(c) Distribuição granulométrica.

FIGURA 27: Material precursor com granulometria entre

$56 \mu \mathrm{m}<\Phi<63 \mu \mathrm{m}$ (a) MEV; (b) Distribuição granulométrica

FIGURA 28: Microesferas obtidas a partir de material precursor com granulometria entre $63 \mu \mathrm{m}<\Phi<106 \mu \mathrm{m}$ (a) MEV;

(b) Distribuição granulométrica. . .70

FIGURA 29: Material precursor com granulometria entre

$63 \mu \mathrm{m}<\Phi<106 \mu \mathrm{m}$ (a) MEV; (b) Distribuição granulométrica.

FIGURA 30: Dependência do diâmetro médio das microesferas com

a granulometria do material precursor.

FIGURA 31: Micrografias (MEV) das microesferas produzidas

em chama "fria" com pressão de saída de $1,5 \mathrm{kgf} / \mathrm{cm}^{2}$ do gás GLP e

$1,0 \mathrm{kgf} / \mathrm{cm}^{2}$ do comburente $\left(\mathrm{O}_{2}\right)$.

FIGURA 32: Micrografias (MEV) de microesferas produzidas em chama "fria" com pressão de saída de $2,4 \mathrm{kgf} / \mathrm{cm}^{2}$ do gás GLP e de $1,5 \mathrm{kgf} / \mathrm{cm}^{2}$ do comburente $\left(\mathrm{O}_{2}\right)$...... 
FIGURA 33: Microesferas produzidas em chama "quente" com pressão de saída de $1,35 \mathrm{kgf} / \mathrm{cm}^{2}$ do gás GLP e de $2,5 \mathrm{kgf} / \mathrm{cm}^{2}$ do comburente $\left(\mathrm{O}_{2}\right)$.

(a) MEV (b) Distribuição granulométrica. .76

FIGURA 34: Microesferas produzidas em chama "quente" com pressão de saída de $1,5 \mathrm{kgf} / \mathrm{cm}^{2}$ e de $3,0 \mathrm{kgf} / \mathrm{cm}^{2}$ do comburente $\left(\mathrm{O}_{2}\right)$

(a) MEV (b) Distribuição granulométrica.

FIGURA 35: Microesferas coletadas na primeira metade do percurso total considerado a microesfera mais afastada

(a) MEV (b) Distribuição granulométrica.

FIGURA 36: Microesferas coletadas na segunda metada do percurso total considerado a microesferas mais afastada

(a) MEV (b) Distribuição granulométrica.

FIGURA 37: Micrografias (MEV) das microesferas produzidas

sob fluxo gasoso "fraco".

FIGURA 38: Micrografias das microesferas produzidas sob fluxo gasoso "razoável".

FIGURA 39: Micrografias das microesferas produzidas sob fluxo gasoso "forte".

FIGURA 40: Micrografias das "microesferas" produzidas à temperatura de $1200{ }^{\circ} \mathrm{C}$

FIGURA 41: Micrografias das microesferas produzidas à temperatura de $1380^{\circ} \mathrm{C}$

FIGURA 42: Micrografias das microesferas produzidas à temperatura de $1460^{\circ} \mathrm{C}$

FIGURA 43: Micrografias das microesferas produzidas à temperatura de $1490^{\circ} \mathrm{C}$

FIGURA 44: Microesferas produzidas a partir de material precursor moído em moinho planetário de bola de tungstênio.

(a) (b) e (c) MEV (d) Distribuição granulométrica.

FIGURA 45: Material precursor moído em moinho planetário de

bola de Tungstênio (a) (b) e (c) MEV (d) Distribuição granulométrica

FIGURA 46: Microesferas produzidas a partir de material precursor moído em moinho de facas (a) (b) e (c) MEV (d) Distribuição granulométrica.

FIGURA 47: Material precursor moído em moinho de facas

(a) (b) e (c) MEV (d) Distribuição granulométrica .90

FIGURA 48: Material precursor obtido após processo de decantação simples

(a) (b) e (c) MEV (d) Distribuição granulométrica

FIGURA 49: Microesferas obtidas após processo de decantação simples.

(a) (b) e (c) MEV (d) Distribuição granulométrica

FIGURA 50: Material precursor obtido após processo de decantação/ agitação/ ultrassom (a) (b) e (c) MEV (d) Distribuição granulométrica....96 
FIGURA 51: Microesferas obtidas após processo de decantação/agitaçao/ultrassom (a) (b) e (c) MEV (d) Distribuição granulométrica......97

FIGURA 52: Micrografias de microesferas após ativação neutrônica. .98

FIGURA 53: Microesferas obtidas contendo 25\% de óxido de hólmio m peso. (a) e (b) MEV (c) Distribuição granulométrica. 100

FIGURA 54: Microesferas obtidas contendo 37\% de óxido de hólmio em peso. (a) e (b) MEV (c) Distribuição granulométrica. 101

FIGURA 55: Microesferas contendo 5\% de óxido de hólmio (a) antes (b) após 7 dias em SBF (c) após 14 dias em SBF. 102

FIGURA 56: Microesferas contendo 25\% de óxido de hólmio (a) antes (b) após 7 dias em SBF (c) após 14 dias em SBF.

FIGURA 57: Microesferas contendo 37\% de óxido de hólmio (a) antes (b) após 7 dias em SBF (c) após 14 dias em SBF 104

FIGURA 58: Perda de massa normalizada em função do tempo. 105

FIGURA 59: Viabilidade celular de amostras de vidros aluminossilicatos contendo hólmio em função da concentração do extrato. 


\section{INTRODUÇÃO}

O câncer é uma das principais causas de mortalidade entre os seres humanos, devido às restrições nas terapias disponíveis, dada a sua agressividade ao tecido sadio. Apesar de todo o avanço tecnológico alcançado na medicina clínica preventiva, o câncer continua sendo uma ameaça oculta, de surgimento inesperado [1].

A evolução da medicina, ao longo do último século, promoveu uma importante alteração neste prognóstico desfavorável, permitindo que um grande percentual dos portadores de câncer tenha atualmente a oportunidade de cura ou significativo aumento da qualidade de vida [1].

A acentuada redução da mortalidade por câncer é consequência de vários fatores, destacando-se o desenvolvimento de políticas de saúde que visam à prevenção, o avanço nos métodos de diagnóstico e métodos cirúrgicos e o desenvolvimento de novos agentes quimio e radioterápicos vetorizados [1].

Um dos tipos de cânceres que podem ser tratados com métodos alternativos ao método cirúrgico é o carcinoma hepatocelular ( $\mathrm{CHC}$ ) ou câncer de figado primário, que é o $5^{\circ}$ tipo de câncer mais comum no mundo, com uma estimativa de mais de 500.000 novos casos anualmente. É o $3^{\circ}$ que mais mata no mundo com $80 \%$ dos novos casos ocorrendo em países em desenvolvimento (a maioria dos enfermos morrem dentro de um ano) observando-se ainda o aumento destes índices [2-5]. É o $5^{\circ}$ tipo de câncer mais comum entre os homens e o $8^{\circ}$ entre as mulheres.

Há muitos fatores de risco que contribuem para o aparecimento deste tipo de câncer como, por exemplo, infecções por vírus de hepatite $\mathrm{B}$ ou $\mathrm{C}$, cirrose, exposição à aflatoxinas (AFB1), transtornos metabólicos hereditários, consumo excessivo de álcool entre outros [2,3]. Apesar da grande incidência de tumores originários no próprio fígado, geralmente ocorre metástase originária de outros órgãos que são drenados pela 
veia porta hepática, por exemplo, metástases originadas de câncer de colo retal, com aproximadamente 1 milhão de novos casos por ano [6].

$\mathrm{O}$ tratamento do $\mathrm{CHC}$ é um desafio terapêutico, pois o único tratamento curativo é o procedimento cirúrgico, em geral seguido de transplante para remoção completa do tumor, que dependerá da localização e tamanho do mesmo, idade do paciente, grau de cirrose entre outros. Tendo em vista o diagnóstico tardio, pois o desenvolvimento dos nódulos é lento e assintomático, somente 10 a $15 \%$ dos pacientes são eletivos para procedimentos cirúrgicos ou transplante $[3,6]$ enquanto que apenas $7 \%$ dos demais superam os 5 anos de sobrevida [7]. Em geral, após o aparecimento dos sintomas do tumor, o tempo de sobrevivência é de aproximadamente 6 meses [2,3]. Novas opções de terapia são necessárias para pacientes inoperáveis e muitas delas têm salvado vidas como a radioterapia, quimioterapia, hipertermia e imunoterapia, mas, destas modalidades, nenhuma delas por si só consegue a erradicação total do tecido tumoral maligno e, além disso, usualmente causam efeitos colaterais que reduzem a qualidade de vida dos pacientes como a quimioterapia e a quimioembolização, que frequentemente produzem náuseas e perda de cabelo. Como resultado, há a necessidade de novos tratamentos que ofereçam uma diminuição dos indesejados efeitos colaterais $[8]$.

Uma possibilidade para o tratamento de CHC é o uso de hipertermia, no qual microesferas de vidro que apresentam propriedades ferromagnéticas são injetadas nos pacientes por meio da artéria hepática e, como consequência da hipervascularização da região lesada, migram preferencialmente para esta região, apresando-se nas arteríolas que alimentam o tumor. O tecido lesado é temporariamente aquecido quando as microesferas de vidro com propriedades ferromagnéticas são expostas a um campo magnético externo e variável, causando vibrações e consequentemente produzindo calor e conduzindo à destruição do tecido canceroso, pois este tecido é mais sensível ao calor em comparação ao tecido sadio $[9,10]$, no entanto, é bastante difícil manter aquecido somente o tumor sem que haja danos em regiões sadias.

Outra possível terapia disponível, e que apresenta resultados promissores para o tratamento deste tipo de lesão, é a radioterapia interna seletiva ou radioembolização. Alguns pesquisadores afirmam que mais de $80 \%$ dos casos de câncer hepático deveriam ser tratados com o uso de radionuclídeos [11]. Esta terapia utiliza microesferas contendo radionuclídeos emissores de partículas $\beta^{-}$produzidos em um reator nuclear por bombardeamento de um feixe de nêutrons e introduzidas no fígado 
por meio de um cateter acoplado à artéria hepática. O tecido sadio do fígado é nutrido pela artéria hepática e, principalmente, pela veia porta hepática, enquanto o tecido canceroso do fígado é nutrido predominantemente pela artéria hepática [4]. Quando as microesferas migram para o fígado, elas são apresadas em sua maioria nos pequenos vasos sanguíneos e arteríolas que alimentam o tumor. A emissão de partículas $\beta^{-}$ depositando altas doses diretamente no tumor e o bloqueio das vias que o alimentam impedem o crescimento do mesmo causando a aniquilação das células cancerosas. Logo, tanto a forma das partículas vítreas, preferencialmente esféricas para evitar arestas cortantes, impedindo danos nos tecidos sadios e hemorragias desnecessárias durante o translado na corrente sanguínea, como o tamanho das partículas são muito importantes para o sucesso da radioembolização. Esta terapia também requer algumas propriedades que os materiais constituintes das microesferas devem possuir, como:

- Biocompatibilidade e ausência de efeitos citotóxicos

- Alta durabilidade química aos fluidos corpóreos para que não haja desprendimento do radionuclídeo incorporado a matriz.

- Sendo o radionuclídeo produzido por ativação neutrônica, os demais componentes do vidro devem possuir baixa seção de choque para absorção de nêutrons para que não sejam produzidos radionuclídeos indesejáveis.

- A concentração do radionuclídeo produzido por ativação neutrônica deve ser tal que ele possua uma atividade específica requerida para o tratamento desejado. Essa concentração varia com o elemento ativado, o órgão tratado, o fluxo de nêutrons e o tempo de ativação.

- Capacidade das partículas serem formadas dentro do tamanho e forma desejadas. O tamanho e a forma das partículas dependem das características do órgão que será tratado [7].

A radioterapia interna seletiva já está sendo utilizada em vários países. Microesferas de vidro estão disponíveis comercialmente (MDS Nordion Canadá (Theraspheres ${ }^{\circledR}$ )) assim como microesferas poliméricas (Sirtex, Medical Ltda, Austrália (SIR-Sphere $\left.{ }^{\circledR}\right)$ ); ambas utilizam o radionuclídeo ${ }^{90} \mathrm{Y}\left({ }^{90} \mathrm{Y}: \mathrm{E}_{\beta}=2,28 \mathrm{MeV} ; \quad \mathrm{t}_{1 / 2}=\right.$ $64,1 \mathrm{~h} ; \sigma=1,25$ barns) como exclusivo emissor $\beta^{-}$e que possui um alcance médio de 2,5mm e máximo de $11 \mathrm{~mm}$ no tecido humano. Essa terapia possui um relativo sucesso como relatado na literatura $[12,13]$, porém o uso de radionuclídeos alternativos está 
sendo investigado para uso combinado $\operatorname{com}{ }^{90} \mathrm{Y}$ como o ${ }^{177} \mathrm{Lu}\left({ }^{177} \mathrm{Lu}: \mathrm{E}_{\beta}=497 \mathrm{keV}\right.$; $\mathrm{E} \gamma_{1}=113 \mathrm{keV}, 6,4 \% ; \mathrm{E} \gamma_{2}=208 \mathrm{keV}, 11 \% ; \mathrm{t}_{1 / 2}=6,71 \mathrm{~d} ; \sigma=2100$ barns) [14] ou em substituição ao ${ }^{90} \mathrm{Y}$ como: ${ }^{32} \mathrm{P}\left({ }^{32} \mathrm{P}: \mathrm{E}_{\beta}=1,71 \mathrm{MeV} ; \mathrm{t}{ }_{1 / 2}=14,3 \mathrm{~d} ; \sigma=0,17\right.$ barn $)$ $[15,16],{ }^{188} \operatorname{Re}\left({ }^{188} \operatorname{Re}: \mathrm{E}_{\beta}=2,11 \mathrm{MeV} ; \mathrm{t}_{1 / 2}=17 \mathrm{~h} ; \sigma=90\right.$ barns $)$ [17]; e em especial o ${ }^{166}$ Ho $\left({ }^{166} \mathrm{Ho}: \mathrm{E}_{\beta}=1,77-1,85 \mathrm{MeV} ; \mathrm{E} \gamma=81 \mathrm{keV}, 6,56 \% ; \mathrm{t}{ }_{1 / 2}=26,8 \mathrm{~h} ; \sigma=64\right.$ barns $)$ produzido por meio da reação nuclear ${ }^{165} \mathrm{Ho}(\mathrm{n}, \gamma){ }^{166} \mathrm{Ho}$, cuja emissão $\beta^{-}$tem um alcance máximo de $8,5 \mathrm{~mm}$ no tecido humano, alta energia e meia vida relativamente curta $[6,18,19]$. O ${ }^{165}$ Ho tem alta seção de choque para absorção de nêutrons possibilitando a ativação neutrônica em reatores de baixa potência e baixo fluxo de nêutrons térmicos como é o caso do reator nuclear do IPEN, IEA-R1, além de ser emissor combinado $\beta^{-}$e $\gamma$, sendo por isso potencialmente usado para produção de imagens por tomografia computadorizada por emissão de fótons. O hólmio também é altamente paramagnético possibilitando a produção de imagens por ressonância magnética [4]. Estas modalidades de imageamento são úteis para a avaliação da biodistribuição da dose terapêutica no tecido lesionado e permitem a dosimetria através de análises quantitativas de cintilografia e imagens de ressonância magnética [8]. Além disso, o hólmio tem uma abundância de $100 \%$ na natureza e possui seção de choque para absorção de nêutrons de 64 barns, permitindo obter uma atividade de 344mCi ( 12GBq) (reator IEA-R1, 60

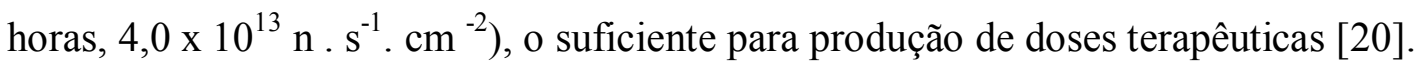

As técnicas de radioembolização disponíveis no Brasil ainda não abrangem a utilização de microesferas vítreas para o tratamento de tumores hepáticos e não há produção e caracterização deste tipo de material para aplicações radioterápicas.

A disponibilidade da radioterapia interna seletiva utilizando microesferas para o tratamento de carcinoma hepatocelular com o radionuclídeo ${ }^{90} \mathrm{Y}$ no Brasil esbarra em duas dificuldades: o custo relativamente alto (estimado ente US\$15.000 a US\$20.000 por aplicação) e a importação requer uma logística de transporte custosa, considerando a meia vida do radionuclídeo ${ }^{90} \mathrm{Y}$ relativamente curta $(64,1 \mathrm{~h})$. Considerando-se estes aspectos, o uso do ${ }^{166}$ Ho como radionuclídeo permitiria a implantação deste tipo de tratamento no Brasil. Há um grande interesse da área de medicina nuclear brasileira na aplicação deste tipo de radioterapia, a qual contribuiria nos casos em que outras terapias não têm apresentado resultados relevantes. 
Microesferas poliméricas foram obtidas usando o radionuclídeo ${ }^{166} \mathrm{Ho}$ como um dos elementos constituintes e resultados promissores foram reportados [4,8,21]. A obtenção de microesferas de vidro contendo hólmio em uma matriz vítrea de óxidos de alumino-silicato-magnésio para a utilização em radioterapia interna seletiva é um tema ainda não completamente explorado. A escolha dos componentes do vidro deve estar baseada na baixa seção de choque para absorção de nêutrons destes elementos, inviabilizando a presença de radiosótopos indesejáveis após a ativação por nêutrons [7]. Microesferas de vidro apresentam como vantagens em relação às poliméricas uma durabilidade química superior, simplicidade do processo de produção e maior estabilidade mecânica e química em relação à radiólise quando expostas a um feixe de nêutrons [4,22].

A produção de microesferas de vidro para este propósito é feita a partir da transformação de material particulado com formato irregular por meio de dois métodos: esferolização por chama ou esferolização por queda gravitacional [23].

O processo de preparação de microesferas de vidro a partir de partículas vítreas com formas irregulares parte do princípio da conformação das partículas por meio da redução da viscosidade do vidro em função do aumento da temperatura. Portanto, a passagem de partículas de vidro através de uma zona quente favorecerá a esferolização das partículas. A produção de microesferas de vidro a partir de partículas com formato irregular requer a deformação do vidro em temperaturas adequadas e num intervalo de tempo que evite a cristalização do material.

Em trabalhos previamente realizados [10], notou-se que a distribuição granulométrica do produto final depende do método de esferolização. A princípio não era possível prever a distribuição final do tamanho das microesferas apenas conhecendo a distribuição do tamanho de partículas irregulares inicial, pois fatores como razão de aspecto, variação dos parâmetros de processo, e aglomeração das partículas poderiam influenciar a distribuição final. Faz-se necessário estabelecer uma correlação entre a distribuição granulométrica do material particulado com formato irregular e a distribuição de tamanho das microesferas. 


\section{OBJETIVOS}

O objetivo deste trabalho é avaliar as variáveis dos processos de esferolização por chama e por queda gravitacional de partículas vítreas visando à obtenção de microesferas contendo hólmio com morfologia e dimensões adequadas para aplicação em radioterapia interna seletiva. Como objetivo complementar, propõem-se a caracterização física, a determinação da durabilidade química, a resistência à radiação e o estudo das propriedades citotóxicas destes materiais. 


\section{REVISÃO DA LITERATURA}

\subsection{Vidros}

A presença de vidros no nosso cotidiano é tão comum que raramente nos impressionamos com sua beleza e pelo fato da maioria deles serem transparentes à luz. A importância comercial e tecnológica dos vidros é de valor inestimável na sociedade atual e, desde tempos remotos, o homem faz uso destes materiais, pois podem ser produzidos naturalmente pelo resfriamento rápido de alguns tipos de rochas vulcânicas ou artificialmente por vários métodos.

A primeira produção artificial de vidros é de data e origem incertas, porém, segundo o historiador romano Plínio (23-79 d.C), os primeiros vidros foram sintetizados artificialmente de modo casual há 7000 anos a.C. pelos fenícios quando desembarcaram na costa da Síria e improvisaram fogões, usando blocos de salitre sobre areia, observando que, passado algum tempo, escorria-se uma substância brilhante que se solidificava rapidamente [24-26]. Após essa descoberta, os fenícios fizeram pequenos aperfeiçoamentos na técnica de obtenção de vidros e difundiram esse conhecimento pelo Egito e Mesopotâmia, sendo desenvolvida e consolidada em todos os continentes [24]. Mas vidros transparentes eram raros e sempre continham pequenas bolhas e estrias como consequência do uso de temperaturas inadequadas de fusão do material de partida e inomogeneidades no líquido. Com a invenção da técnica de sopragem de vidros entre o fim e o início da era Cristã, foi possível obter peças de vidro ocas em que o vidreiro poderia dar formas das mais variadas aos objetos vítreos e deste modo expandiu-se a utilização destes materiais, antes puramente decorativos e luxuosos, causando a queda dos preços e popularizando-os [26-28]. Em Alexandria, em torno de 100 d.C., foram produzidos os primeiros vidros incolores pela adição de óxido de manganês em sua composição. No Império Romano Ocidental, o desenvolvimento da obtenção de vidros continuou sua escalada e os objetos vítreos tornaram-se comuns na vida diária. Mesmo 
depois da queda do Império Romano Ocidental, as técnicas desenvolvidas de produção de vidros foram levadas ao Império Romano Oriental [27, 29].

No mundo islâmico em torno de 780 d.C, além do uso como decoração, os vidros eram utilizados como padrões de alta precisão para pesagem. Após a queda do Império Romano Oriental, Veneza tornou-se famosa pela produção de vidros de altíssima qualidade e estimulada pela igreja desenvolveu métodos para coloração de vidros a base de inserção de óxidos [26,27]. O ponto alto do vidro veneziano foi a criação de um vidro cristal extraordinariamente puro. A produção de vidros usando as técnicas desenvolvidas em Veneza espalhou-se para outros países da Europa nos séculos seguintes [29].

Em 1600, a arte de cortar vidros foi desenvolvida e muitos objetos de admirável beleza foram produzidos usando esta técnica. O livro "Arte Vertraria", publicada no ano de 1612 por Antonni Néri, em Pisa, apresentava todos os conhecimentos da época sobre os vidros e pela primeira vez foram estabelecidos critérios sistemáticos e um estilo moderno nos fundamentos e tecnologias de processamento dos vidros. O conhecimento empírico dos vidros foi disseminado por vários países [26,27] e o vidro "Flint" composto por silicato de chumbo, possuindo baixo número de Abbe e apresentando um alto índice de refração e alto poder de dispersão da luz em relação ao vidro "Crown”, composto por silicato de sódio e cálcio, foi desenvolvido no ano de 1675 na Inglaterra [26, 29,30].

Em 1830, tem início o estudo científico dos vidros com Michael Faraday definindo-os como sendo "materiais mais aparentados a uma solução de diferentes substâncias do que a um composto em si” [24].

Durante o século XIX, o processo de produção de vidros foi aprimorado com o uso de matérias-primas selecionadas e de alta pureza e com o desenvolvimento de fornos mais potentes e estáveis. Novos tipos de vidros foram criados e aperfeiçoados, conhecidos como vidros ópticos e que possuíam as seguintes características: propriedades ópticas bem definidas, performance óptica homogênea e ausência de bolhas, estrias, tensões e inclusões [30]. No ano de 1880, Otto Schott começou o desenvolvimento específico de novos vidros ópticos propostos por Ernst Abbe para o desenvolvimento de sistemas de lentes com alta qualidade para confecção de microscópios e outros instrumentos ópticos.

No século XX, a revolução na produção vidreira ocorreu com a mecanização industrial, em que o processo manual foi substituído por máquinas e onde 
foram obtidos vidros planos até então muito difíceis de serem produzidos [29]. No entanto, todo o desenvolvimento da tecnologia do vidro ocorria no campo empírico e somente nos anos 30 do século XX os estudos científicos dos vidros levando-se em consideração suas propriedades físicas, químicas e estruturais tiveram avanços significativos. Pode-se dizer que somente após a segunda guerra mundial houve uma forte interação entre a tecnologia dos vidros e pesquisas científicas [27]. Desde então os cientistas tentam entender o estado vítreo e muitas teorias foram criadas para explicá-lo.

Para o estudo destes materiais, enfrentou-se o primeiro desafio de classificálos em relação ao estado de agregação da matéria. A princípio os vidros são materiais com viscosidade elevada (acima de $10^{13}$ Poise à temperatura ambiente) e propriedades semelhantes às dos sólidos cristalinos como a rigidez e forma própria não dependente do recipiente em que está inserido, mas submetendo-os a análises de difração de raios $\mathrm{X}$ notou-se que o arranjo atômico dos constituintes dos vidros não apresenta uma periodicidade a longo alcance, ou seja, não há um ordenamento (repetição) entre os átomos e seus vizinhos distantes e conclui-se que, microscopicamente, a estrutura assemelha-se à dos líquidos [26]. Esta dificuldade de classificá-los quanto ao seu estado de agregação deu margem a uma proposição de um quarto estado da matéria: o estado vítreo; porém esta proposição não encontrou uma aceitação generalizada por parte da comunidade científica [26]. Outro desafio era a própria definição de vidro, pois se verificou a existência de outros tipos de materiais, como alguns tipos de polímeros, que também apresentavam a ausência de ordenamento da estrutura atômica, porém com outras propriedades muito diferentes dos vidros, como as propriedades mecânicas [26].

Não há uma definição unânime por parte da comunidade científica a respeito dos vidros, pois nenhuma definição mostrou-se completamente satisfatória. Uma definição operacional de vidro definida pela American Society for Testing Materials (ASTM) é: "Um vidro é um sólido inorgânico obtido pelo resfriamento rápido de um líquido sem ocorrência da cristalização" [27, 29-33]. No entanto, esta definição é restritiva, pois é possível obter vidros orgânicos e metálicos e também o processo de fusão/resfriamento não é o único meio de produzir vidros [32]. Os processos de deposição de vapor, sol-gel e a irradiação de nêutrons em materiais cristalinos são outros processos por meio dos quais é possível a obtenção de vidros [25].

Os vidros são materiais frágeis, duros e geralmente transparentes à luz, mas o notável é que todos os vidros encontrados e produzidos naturalmente ou artificialmente possuem duas características comuns: ausência de um arranjo atômico 
periódico de longo alcance e exibição de um comportamento dependente do tempo conhecido como comportamento de transição vítrea. Em 1997, vidros foram definidos como sendo sólidos amorfos, ou seja, não possuem um arranjo atômico periódico a longo alcance e exibem uma relaxação atômica na região de transição vítrea [25]. Em 2006, vidros foram definidos como sólidos não-cristalinos e que apresentam uma transição vítrea [34].

O comportamento de transição vítrea é tradicionalmente investigado com base no diagrama do volume específico ou da entalpia ou de alguma grandeza termodinâmica extensiva em função da temperatura tal qual mostrado na FIG. 1, que mostra o volume específico como grandeza termodinâmica extensiva em função da temperatura.

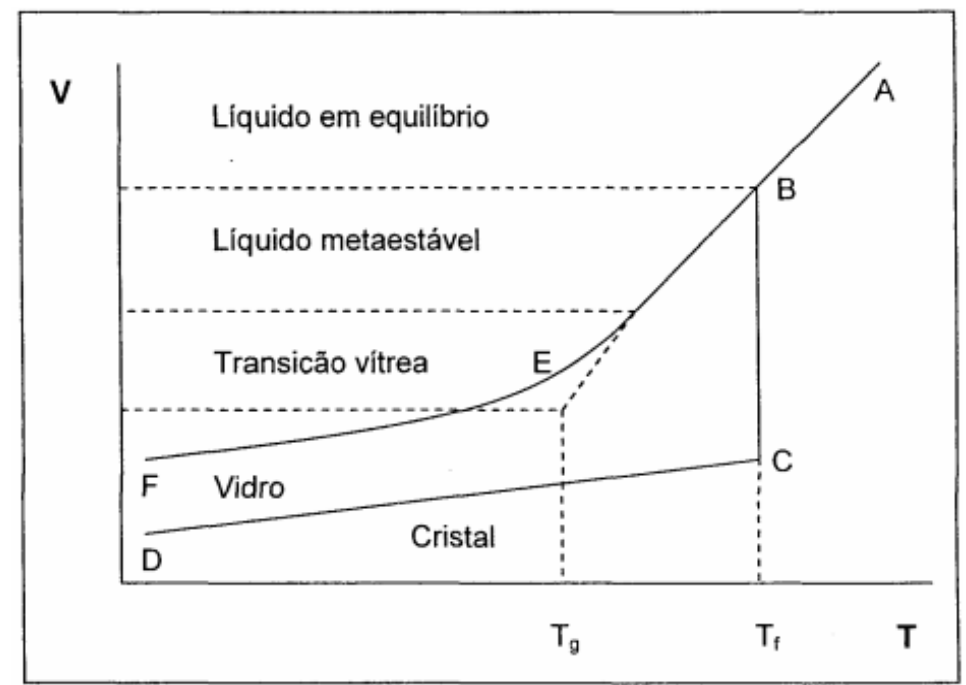

FIGURA 1 - Variação do volume específico em relação à temperatura de um vidro e de um cristal [35].

Quando um material é mantido acima do ponto de fusão, o seu estado é de um líquido em equilíbrio. Conforme mostrado na FIG. 1, se este líquido for resfriado gradualmente no segmento $\mathrm{A}$ até $\mathrm{C}$, haverá a formação de cristais abaixo do ponto de solidificação $\mathrm{T}_{\mathrm{f}}$ adquirindo uma estrutura atômica periódica de longo alcance, tornandose um sólido cristalino. No segmento $\mathrm{C}$ até $\mathrm{D}$, este sólido se contrairá de acordo com o seu coeficiente de expansão térmica e consequentemente, o volume específico diminuirá abruptamente no segmento B a C. Se o líquido for resfriado rapidamente, tal que não ocorra à cristalização, conforme o perfil de resfriamento representado na FIG. 1 pelo segmento B a E, então temos um líquido super-resfriado ou metaestável. O movimento translacional dos átomos no líquido continua na medida em que a temperatura diminui, todavia sem que ocorra o rearranjo periódico da estrutura e a redução abrupta do 
volume específico e, portanto, sem descontinuidades na curva da FIG.1. A viscosidade deste líquido começa a aumentar e os átomos começam a perder mobilidade. A curva do diagrama na FIG. 1 começa a desviar-se da linha de equilíbrio seguindo até o ponto E, diminuindo seu coeficiente angular até que a viscosidade torna-se tão grande que a posição atômica se torna fixa e os átomos perdem sua mobilidade translacional. Ao reduzir a temperatura até o ponto $\mathrm{F}$ do diagrama, o material, agora denominado vidro, assume o seu estado final. Os limites de temperatura em que a curva da FIG.1 começa a desviar-se da linha de equilíbrio até atingir o líquido "congelado", determinam a região de transição vítrea $[25,26,32,33,36]$.

Como a temperatura de transição vítrea não é bem definida, pois depende da história térmica do vidro, é conveniente definirmos uma temperatura que nos permita diferenciar dois vidros com diferentes taxas de resfriamentos. Essa temperatura é a temperatura fictícia e é definida como a intersecção entre a linha extrapolada do líquido metaestável e do vidro [25, 27, 32, 37].

A teoria de formação estrutural de vidros teve início com Goldschmidt, que baseado na observação postulou que compostos com a formula geral AnOm formavam vidros mais facilmente quando a razão entre o raio iônico do cátion $\mathrm{A}$ e do oxigênio estivesse entre 0,2 e 0,4, correspondendo ao arranjo tetraédrico dos oxigênios ao redor do cátion; no entanto alguns compostos como o $\mathrm{BeO}$ não seguiam esta regra [25,38,39]. Poucos anos depois, Zachariasen publicou seu artigo no ano de 1932 [38] estabelecendo considerações que o levaram a regras empíricas para formação vítrea. Zachariasen considerou:

1. As forças de ligação interatômica em vidros e em cristais devem ser similares devido às similaridades entre as propriedades mecânicas dos dois tipos de sólidos.

2. Como nos materiais cristalinos, o vidro consiste em uma estrutura com rede tridimensional, porém com caráter difuso como mostra o espectro de difração de raios X. A rede não é simétrica e periódica como em um cristal (não há ordem a longo alcance).

A rede pode ser comparada a uma única molécula ou sistema com uma célula unitária gigante. A desordem estrutural explicaria o fato da energia contida em um vidro ser maior que em um cristal [27]. Na FIG. 2, é representada a idealização bidimensional da estrutura de um cristal e de um vidro com a mesma composição $\mathrm{A}_{2} \mathrm{O}_{3}$ feita por Zachariasen. 


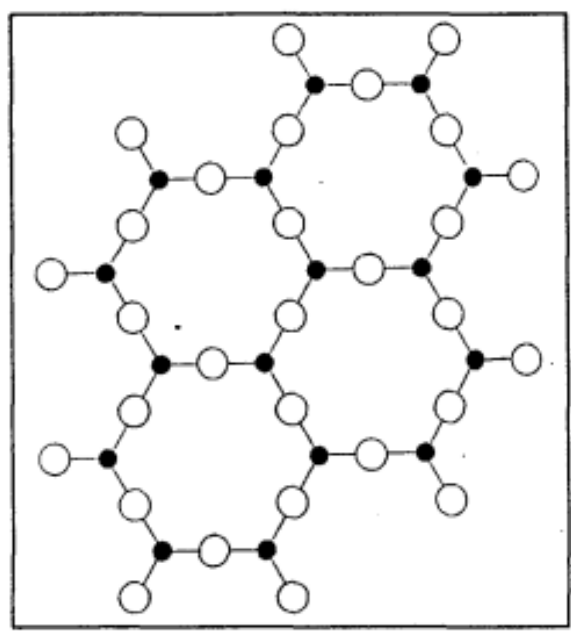

(a)

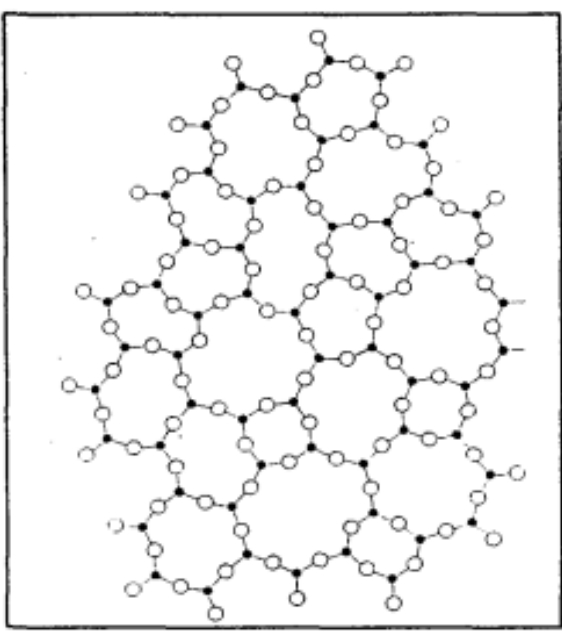

(b)

FIGURA 2 - Representação bidimensional idealizada por Zachariasen de (a) um cristal e de (b) um vidro. Ambos com composição $\mathrm{A}_{2} \mathrm{O}_{3}$ [38].

A partir dessas considerações, Zachariasen formulou as seguintes regras para formação vítrea:

1. O átomo de oxigênio deve estar ligado a não mais que dois cátions;

2. O número de oxigênios que circundam o cátion deve ser pequeno;

3. As estruturas poliédricas formadas por estes átomos não devem compartilhar as arestas ou faces, mas somente os vértices;

4. Cada poliedro deve compartilhar, ao menos, três vértices com outros poliedros;

A partir dessas regras, Zachariasen classificou os óxidos em formadores, intermediários e modificadores de rede.

Os formadores de vidro são aqueles que participam da estrutura fundamental do vidro sendo responsáveis pela formação da rede tridimensional e possuem a tendência covalente em suas ligações químicas como $\mathrm{SiO}_{2}, \mathrm{~B}_{2} \mathrm{O}_{3}$ e $\mathrm{P}_{2} \mathrm{O}_{5}$. Os modificadores são aqueles que modificam algumas propriedades dos vidros como temperatura de fusão e viscosidade facilitando a obtenção do vidro e apresentam ligações iônicas com ânions da rede vítrea. Como exemplos, podem-se citar os cátions $\mathrm{K}^{+}, \mathrm{Na}^{+}, \mathrm{Fe}^{2+}$ e $\mathrm{Ca}^{2+}$. Finalmente os intermediários são aqueles que atuam como modificadores e formadores. $\mathrm{O} \mathrm{Be}^{+2}, \mathrm{Zn}^{+2}, \mathrm{Sn}^{+4}$ e $\mathrm{Ga}^{+3}$ são alguns exemplos de intermediários. 


\subsection{Vidros Aluminossilicatos}

Vidros aluminossilicatos são comumente comercializáveis e utilizados em diversas aplicações como em lâmpadas de alta durabilidade nos automóveis, isolamento com fibras de vidro resistentes à hidrólise, lã de vidro (isolamento térmico), fabricação de filtros, usados como louças e objetos de decoração, visualização de radiografias entre outras aplicações. Alguns tipos de vidros aluminossilicatos são considerados biovidros, pois são inertes quando em contato com tecidos humanos. Vidros aluminossilicatos também podem ser utilizados como hospedeiros de radionuclídeos, pois seus elementos constituintes apresentam baixa seção de choque para absorção de nêutrons [40]. Eles podem possuir quantidades moderadas de óxidos alcalinos e alcalinos terrosos como $\mathrm{MgO}$ ou $\mathrm{CaO}$ que possuem a função de modificadores segundo a classificação de Zachariasen e alteram propriedades do vidro como o aumento significativo do módulo de elasticidade e resistência à corrosão química [24,32].

Quando o óxido de alumínio é adicionado à composição de vidros silicatos, o vidro resultante torna-se menos viscoso em temperaturas elevadas. Apesar do alumínio por si só não ser um formador de vidros, em vidros aluminossilicatos ele assume a coordenação tetraédrica similar ao silício. Como o alumínio é trivalente e o silício é tetravalente, o tetraedro formado pelas ligações $\mathrm{Al}$ - $\mathrm{O}$ diminui o número de oxigênios não ponte, aumentando a coesão da estrutura vítrea. Portanto, estes vidros podem ser aquecidos a altas temperaturas sem ocorrência de deformações como ocorrem em vidros soda-cal e borossilicatos. Isto explica o amplo uso comercial destes vidros [41].

A estrutura destes vidros tem sido estudada por vários autores usando diversos métodos como a ressonância magnética nuclear (RMN) [42, 43], difração de raios X e de nêutrons [44], espectroscopia no infravermelho e Raman [45] entre outras.

Em materiais cristalinos, o alumínio frequentemente aparece em sua estrutura com coordenação tetraédrica e octaédrica, e, nos vidros, formando tetraedros com os átomos de oxigênio. Esses tetraedros podem substituir diretamente os tetraedros formados por silício e oxigênio, no entanto a ligação entre $\mathrm{Al}$ - $\mathrm{O}$ é muito mais fraca em comparação com a ligação covalente entre o $\mathrm{Si}$ - O [40]. Nesses casos em que o alumínio, apesar de não ser um formador de vidro isoladamente, mas podendo facilmente ocupar o lugar do silício na rede vítrea e comportar-se como um óxido formador e modificador concomitantemente, é atribuído o conceito de óxido 
intermediário. No entanto, o íon de alumínio trivalente nem sempre age como um formador e a configuração estrutural do vidro dependerá da razão $\left[\mathrm{Al}_{2} \mathrm{O}_{3} / \mathrm{M}_{2} \mathrm{O}\right]$ em que $\mathrm{M}_{2} \mathrm{O}$ representa o modificador que compõe o vidro. Em geral, quando esta razão é menor que 1, o íon $\mathrm{Al}^{+3}$ age como formador de rede possuindo uma coordenação tetraédrica [32].

O tetraedro formado pela ligação de alumínio com quatro átomos de oxigênio ponte possui um excesso de carga negativa -1, e um cátion alcalino deve estar presente na vizinhança de cada tetraedro para manter a neutralidade local. Dessa forma, muitos tetraedros de silício e alumínio são polimerizados e formam sítios de oxigênios pontes por ligações $\mathrm{Si}-\mathrm{O}-\mathrm{Si}, \mathrm{Si}-\mathrm{O}-\mathrm{Al}$, e $\mathrm{Al}-\mathrm{O}-\mathrm{Al}$ com pequenas quantidades de oxigênios não ponte [46]. Esta população de sítios representa a desordem estrutural e afeta as propriedades do vidro como a capacidade calorífica, entropia e viscosidade. Podemos pensar no tetraedro de alumínio-oxigênio como um grande ânion com carga efetiva -1 distribuída em todo o ânion. O cátion alcalino modificador pode estar localizado em qualquer lugar na vizinhança imediata deste ânion. A compensação da carga via íon de elementos alcalinos terrosos com carga +2 requer que dois tetraedros de alumínio-oxigênio ocupem sítios próximos de modo que um único cátion possa simultaneamente compensar a carga de dois tetraedros [25].

Quando a razão $\left[\mathrm{Al}_{2} \mathrm{O}_{3} / \mathrm{M}_{2} \mathrm{O}\right]=1$, não há oxigênios não ponte na estrutura, mas quando $\left[\mathrm{Al}_{2} \mathrm{O}_{3} / \mathrm{M}_{2} \mathrm{O}\right]>1$, o íon $\mathrm{Al}^{+3}$ entra na rede como um modificador com coordenação octaédrica e apresenta três oxigênios ponte e três não ponte como mostrado na FIG. 3:

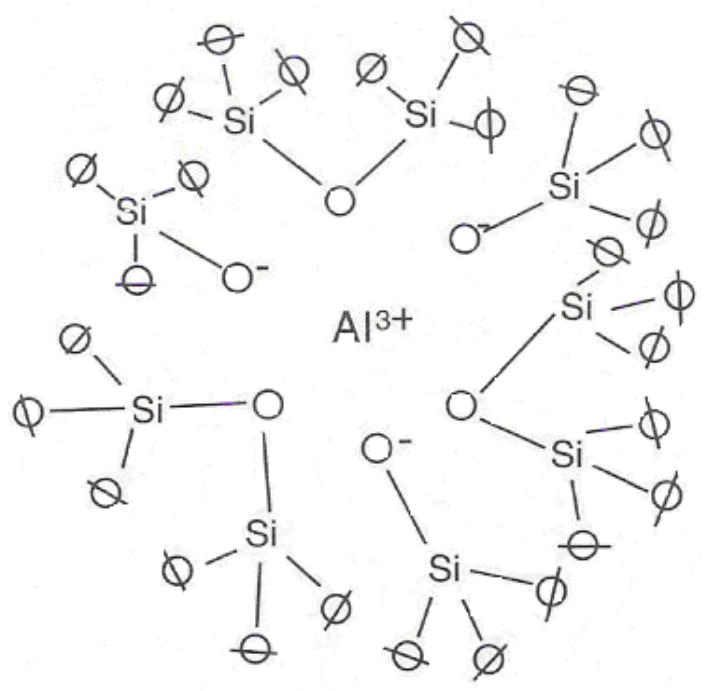

FIGURA 3 - Estrutura de vidros aluminossilicatos com o $\mathrm{Al}^{+3}$ como modificador da rede e possuindo coordenação octaédrica [32]. 


\subsection{Esferolização}

Líquidos são incapazes de expandir-se livremente e formam uma interface com um segundo líquido ou gás [47]. Eles tendem a minimizar sua área superficial e seu volume interno de modo que o número máximo de moléculas fique no interior da fase líquida [48] causando um aumento da pressão interna e consequentemente em $\Delta \mathrm{P}$ (diferença de pressão interna e externa devido à tensão superficial que aparece em líquidos) $[47,49]$. A tensão superficial em termos termodinâmicos é definida como:

$$
\gamma=\left(\frac{\partial G}{\partial A}\right)_{P, T, N_{i}}
$$

no qual $\mathrm{G}$ é a energia livre de Gibbs do sistema, A é a área superficial, P é a pressão, T é a temperatura e $\mathrm{N}_{\mathrm{i}}$ é o número de constituintes do sistema.

Do ponto de vista molecular, a tensão superficial surge devido à interação atrativa entre as moléculas da superfície do líquido. Na FIG. 4 a) é mostrada uma molécula dentro do líquido que interage com outras moléculas vizinhas em todas as direções e a resultante dessas interações pode ser considerada nula. Na FIG. 4 b) é mostrada uma molécula da superfície do líquido interagindo com suas moléculas vizinhas, porém, como não existem moléculas na parte superior da superfície do líquido, aparece uma resultante nesta camada interfacial direcionada para baixo [50] gerando tensão na superfície. Estas forças atrativas causam, na superfície do líquido, uma contração de sua área superficial até um valor mínimo e são responsáveis por reter uma gota em uma barra, limita o tamanho da gota que pode ser retida e faz com que pequenas gotículas de um spray ou pulverizador adquiram o formato esférico [50]. Como a esfera apresenta uma área superficial mínima para um determinado volume, ou seja, a relação superfície/volume é mínima, na ausência ou desprezando forças externas, o líquido assumirá o formato esférico [48,51]. Entretanto, devem-se considerar as forças externas que competem contra a tendência do líquido para adquirir esta forma ideal, em particular a força gravitacional terrestre que tende a achatar as esferas líquidas em poças e oceanos [48]. 


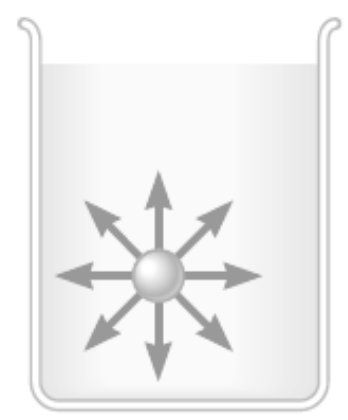

(a)

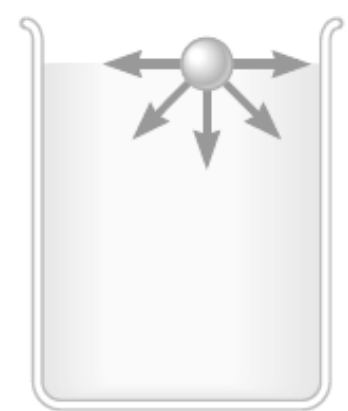

(b)

FIGURA 4 - a) Representação de uma molécula no interior de um líquido

b) Representação de uma molécula na superfície de um líquido [41].

Se considerarmos a pressão interna $\mathrm{P}_{\alpha}$ no equilíbrio com sua pressão de vapor $\mathrm{P}_{\beta}$ a temperatura $\mathrm{T}$ de uma gota líquida esférica de raio $\mathrm{r}$, como a tensão superficial age para minimizar a área superficial, então a diferença de pressão ( $\Delta P=P_{\alpha}-P_{\beta}$ ) da gota agirá para aumentar seu volume e no equilíbrio teremos que o trabalho de contração $\triangle \mathrm{PdV}$ será igual a diminuição da energia livre de superfície $\gamma \mathrm{dA}$ e temos:

$$
\Delta P 4 \pi r^{2} d r-\gamma 8 \pi r d r=0
$$

E consequentemente:

$$
\Delta P=\frac{2 \gamma}{r}
$$

A equação 3 é um caso especial da equação de Young-Laplace [51] e mostra que a diferença entre as pressões tende a zero quando o raio de curvatura tende a infinito (quando a superfície é plana) [48] e também pode ser deduzida considerando um hemisfério de uma gota onde a resultante das forças de tensão superficial é dada por 2 $\pi$ r. $\gamma$ onde $2 \pi \mathrm{r}$ é a circunferência do hemisfério e $\gamma$ é a tensão superficial. A força devido à diferença de pressão é dada por $\left(P_{\alpha}-P_{\beta}\right) \cdot \pi r^{2}$ onde $\pi r^{2}$ é a projeção da área do hemisfério considerado da gota. Desta forma, no equilíbrio, estas forças devem ser iguais e então teremos:

$$
\left(P_{\alpha}-P_{\beta}\right) \cdot \pi r^{2}=2 \pi r \gamma
$$

Que se reduz à equação de Young-Laplace (3) demonstrada a partir de um hemisfério de uma gota. A FIG. 5 representa as forças atuantes em um hemisfério de uma gota. 


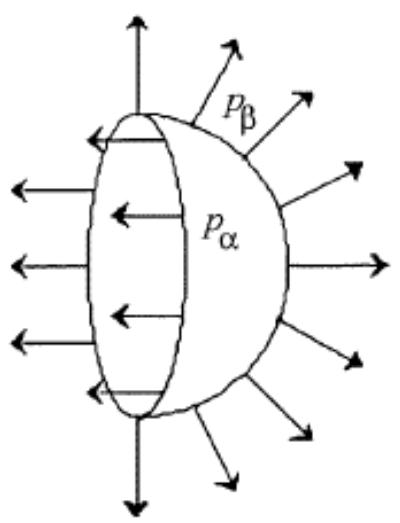

FIGURA 5 - Representação das forças atuantes em um hemisfério de uma gota líquida [49].

Podemos usar este resultado para predizer o aumento de pressão dentro de uma bolha composta de um filme fino de líquido possuindo duas interfaces com ar, uma interna e outra externa aproximadamente com o mesmo raio $r$ [47]:

$$
\Delta P_{\text {bolha }} \approx 2 \cdot \Delta P_{\text {gota }}=\frac{4 \gamma}{r}
$$

Nota-se que a pressão interna em uma bolha é duas vezes a pressão da gota com o mesmo tamanho.

Para o caso geral de uma superfície arbitrariamente curvada com raio principal $r_{1}$ e raio secundário $r_{2}$ a equação de Young - Laplace é dada por:

$$
\Delta P=\gamma\left(\frac{1}{r_{1}}+\frac{1}{r_{2}}\right)
$$

O raio será negativo caso a curvatura seja côncava e a pressão neste lado, interno, sempre será maior do que a pressão no lado convexo, externo. As superfícies consideradas são interfaces entre um sólido ou um líquido e seu vapor. Uma consequiência do efeito de curvatura da superfície será que a pressão de equilíbrio P será função da tensão superficial e temperatura dada pela equação de Kelvin:

$$
\ln \frac{P}{P_{o}}=\frac{2 \gamma V_{m o l}}{r R T}
$$

onde $\mathrm{V}_{\text {mol }}$ é o volume molar da fase condensada na temperatura $\mathrm{T}$ e P/Po é a pressão de vapor acima da superfície curva relativa à superfície planar. Na FIG. 6, é mostrado como a superfície de curvatura do líquido varia em relação à pressão de vapor. 


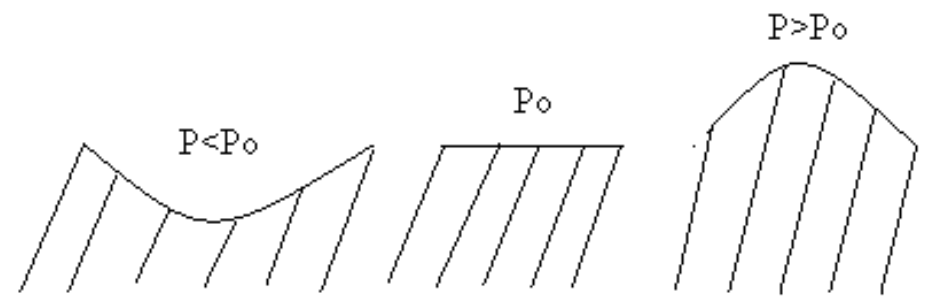

FIGURA 6 - A pressão de vapor do líquido varia com a superfície de curvatura [51].

Quando partículas vítreas irregulares passam por uma zona quente durante uma queda livre através de uma distância suficientemente longa, estas partículas começam a se comportar como líquidos devido à redução da viscosidade e assumirão o formato esférico antes da solidificação [25]. Isto é possível quando partículas de vidro são introduzidas em um forno vertical ou quando introduzidas em uma chama de um maçarico. 


\subsection{Seção de choque para absorção de nêutrons}

Consideremos um feixe paralelo de nêutrons atravessando uma lâmina de matéria, como está mostrado na FIG. 7.

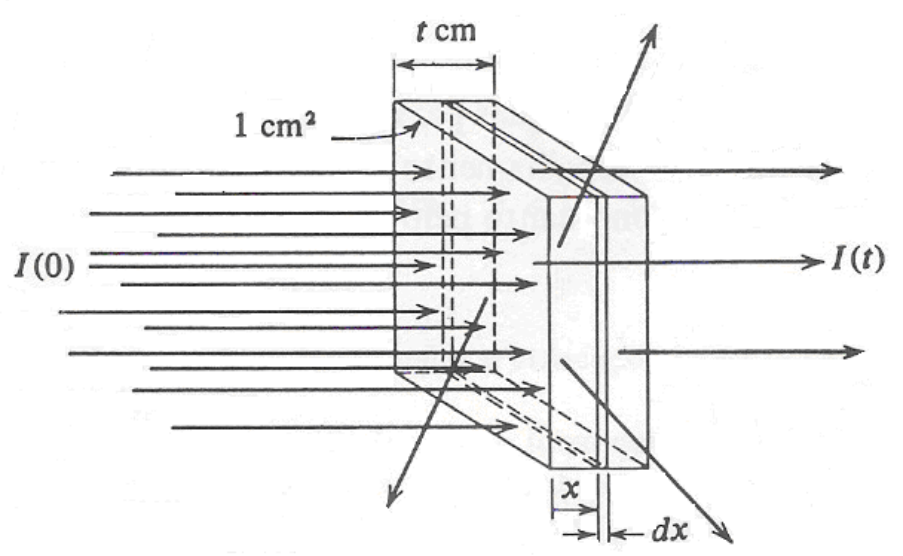

FIGURA 7 - Feixe de nêutrons atravessando uma lâmina de matéria [53].

Os nêutrons podem interagir com o núcleo dos átomos da lâmina sofrendo espalhamento elástico ou inelástico, podem ser absorvidos e consequentemente provocar reações nucleares diversas. Além disso, da mesma maneira que os fótons, nêutrons podem atravessar diversas camadas atômicas sem que haja qualquer interação, pois a força nuclear forte tem alcance muito curto e só atua entre o nêutron e o núcleo [52]. A questão sobre quais são as probabilidades de ocorrência desses processos, para determinadas condições, tem considerável importância teórica e prática como no projeto da blindagem e funcionamento de um reator nuclear ou escolha dos elementos constituintes de radiofármacos. A resposta a essa questão é expressa em termos de quantidades chamadas de seções de choque. A probabilidade de um nêutron com uma dada energia ser absorvido ao passar pela lâmina é dada pelo valor da seção de choque de absorção de nêutrons $\sigma_{\text {An }}[53,54]$. Em geral, quanto maior a energia dos nêutrons, maior será sua penetração nos materiais, pois a seção de choque de boa parte das interações diminui com o aumento da energia cinética [52]. Esta medida da probabilidade de ocorrência de absorção de nêutrons é definida de forma que o número de absorções neutrônicas $\mathrm{N}_{\text {An }}$ que ocorrem seja dado por:

$$
N_{A n}=\sigma_{A n} \cdot I \cdot N
$$

quando um feixe de nêutrons I incide sobre uma lâmina que contém $\mathrm{N}$ átomos por 
unidade de área. Supõe-se aqui que a lâmina é suficientemente fina para que a probabilidade de um nêutron ser absorvido ao passar por ela seja muito menor que 1.

A equação (8) representa um modelo para as definições de todas as seções de choque, como no caso de uma reação de absorção de nêutrons que a desexcitação do núcleo pode envolver a emissão de partículas alfa, elétrons, pósitrons, prótons, raios $\gamma$ ou no caso de fissão, fragmentos de fissão. Pode-se associar uma seção de choque específica para estes diferentes tipos de "caminhos" de decaimento tal como $\sigma_{\alpha}$ para emissão $\alpha, \sigma_{\beta}$ para emissão beta e assim sucessivamente $[55,56]$. Desse modo, é suficientemente importante justificar uma interpretação física mais cuidadosa desta definição [57]. Inicialmente notemos que o número $\mathrm{N}_{\mathrm{An}}$ de absorções deve certamente ser diretamente proporcional ao número I de nêutrons incidentes sobre a lâmina. Outrossim, se a lâmina é fina, no sentido especificado anteriormente, seus átomos não farão "sombra" uns aos outros, relativamente ao feixe incidente. Então, o número $\mathrm{N}_{\mathrm{An}}$ também deve ser diretamente proporcional ao número $\mathrm{N}$ de átomos por unidade de área da lâmina. Portanto:

$$
N_{A n} \propto I \cdot N
$$

Se essa proporcionalidade for expressa na forma de uma igualdade, chamando à constante de proporcionalidade de $\sigma_{\mathrm{An}}$, obtém-se a equação que define a seção de choque. Portanto, a seção de choque de absorção neutrônica, cujo valor depende tanto da energia do nêutron quanto do tipo de átomo, afere o quanto esses átomos são efetivos na absorção de nêutrons. Como as quantidades $\mathrm{N}_{\mathrm{An}}$ e I são adimensionais, e $\mathrm{N}$ tem dimensão de $\left(\right.$ área) ${ }^{-1}$ fica claro que $\sigma_{\mathrm{An}}$ deve ter dimensão de área, o que justifica a sua denominação. As definições e interpretações das seções de choque para outros processos de absorção e espalhamento de radiações são completamente análogas às considerações acima.

As seções de choque são freqüentemente expressas em termos da unidade $10^{-24} \mathrm{~cm}^{2}$, e esta unidade é chamada de "barn", sendo abreviada como b [55,57]. Freqüentemente, é dada uma interpretação geométrica à seção de choque, imaginandose que um círculo de área $\sigma_{\mathrm{An}}$, centrado em cada átomo da lâmina e no plano desta, tem a propriedade de que todo nêutron que passa por ele é absorvido pelo átomo. Essa interpretação geométrica é conveniente para visualização e mesmo para cálculos, mas não deve ser tomada como literalmente verdadeira, pois seções de choque nucleares apresentam valores na faixa de frações de barns até centenas de milhares de barns e 
estes valores podem diferir bastante da seção de choque geométrica [57]. Uma seção de choque é na verdade apenas uma maneira de expressar numericamente a probabilidade de que certo tipo de átomo faça com que o nêutron, de dada energia, sofra um determinado processo.

\subsection{Ativação neutrônica}

A ativação neutrônica é o processo por meio do qual é possível obter uma determinada espécie radioativa bombardeando o núcleo estável de um átomo colocado na direção de um feixe de nêutrons. O tempo de interação é geralmente muito grande, variando em função de alguns parâmetros desejados e, assim mesmo, nem sempre o isótopo obtido é radioativo [58]. Na ativação, a seção de choque de absorção de nêutrons é importante e aumenta à medida que diminui a velocidade do nêutron. Quando os nêutrons são dispersos num dado meio, podem atingir um estado energético tal que numa nova colisão tanto podem perder quanto ganhar energia. Quando esse estado é atingido, dizemos que o nêutron se acha em equilíbrio térmico com o meio e sua probabilidade de ganhar ou perder energia numa outra colisão é igual para todos os nêutrons, que passam a ser denominados de nêutrons térmicos. Estes nêutrons são extremamente importantes para a ativação, pois possuem baixa velocidade e como a seção de choque de absorção de nêutrons é inversamente proporcional à velocidade $\mathrm{V}$, ela assumirá valores consideráveis dependendo do átomo bombardeado. Temos que:

$$
\sigma_{a} \propto \frac{1}{V}
$$

Para nêutrons térmicos temos:

$$
\sigma_{a_{0}} \propto \frac{1}{V_{0}} \therefore \frac{\sigma_{a}}{\sigma_{a_{0}}}=\frac{V_{0}}{V}
$$

em que $\sigma_{a_{0}}$ é a seção de choque térmica de absorção.

Supondo um feixe de nêutrons bombardeando um material, cada nêutron absorvido produz um novo isótopo e o número de isótopos produzidos na unidade de tempo é proporcional ao fluxo de nêutrons, a seção de choque de absorção e a densidade de átomos da amostra, logo:

$$
\frac{d N_{a}}{d t}=n(V) \cdot V \cdot N \cdot \sigma_{a}
$$


em que n(V).V é o fluxo de nêutrons.

Se nos interessar somente isótopos produzidos por nêutrons térmicos (baixa

velocidade), deve-se substituir $\sigma_{a}$ por $\sigma_{a_{0}}$ e então temos que :

$$
d N_{a}=n(V) \cdot V_{0} \cdot N \cdot \sigma_{a_{0}} \cdot d t
$$

É o número de isótopos produzidos no intervalo de tempo dt [58]. No entanto, temos também que considerar o decaimento do isótopo filho. Se o número do radioisótopo filho na amostra é $\mathrm{N}_{\mathrm{a}}$ e a constante de decaimento $\lambda$, então a taxa de perda dos radioisótopos filho será $\lambda \mathrm{N}_{\mathrm{a}}$. Desse modo temos que:

$$
\frac{d N_{a}}{d t}=n(V) \cdot V_{0} \cdot N \cdot \sigma_{a_{0}}-\lambda N_{a}
$$

As reações nucleares que produzem núcleos radioativos também chamadas de reações de transmutação apresentam os seguintes mecanismos [55]:

- Reação de captura de um nêutron por um núcleo acompanhado de emissão gama:

$$
{ }_{67}^{165} \mathrm{Ho}+n \rightarrow{ }_{67}^{166} \mathrm{Ho}+\gamma
$$

- Reações de troca entre um nêutron e um próton:

$$
{ }_{7}^{14} \mathrm{~N}+n \rightarrow{ }_{6}^{14} \mathrm{C}+p_{(16)}
$$

- Produção de radiosótopos:

$$
{ }_{13}^{27} \mathrm{Al}+n \rightarrow{ }_{11}^{24} \mathrm{Na}+{ }_{2}^{4} \mathrm{He}(17)
$$

Uma notação conveniente e bastante usada destas reações é mostrada a seguir, representando a reação de captura neutrônica seguida de emissão gama do hólmio-165 transmutando-se para hólmio-166:

$$
{ }_{67}^{165} \mathrm{Ho}(n, \gamma){ }_{67}^{166} H_{\text {o }}(18)
$$

\subsection{Matriz Vítrea}

O óxido formador escolhido para produção de microesferas de vidro foi a sílica, o intermediário foi a alumina, e o modificador foi a magnésia. Esta escolha baseia-se no fato que os elementos constituintes da matriz vítrea usada para incorporação do hólmio devem apresentar baixa seção de choque para absorção de nêutrons e obviamente formar vidro. A seção de choque do oxigênio, alumínio, silício e 
magnésio é respectivamente igual a 0,00028; 0,230; 0,17; e 0,063 barn. Desse modo, esses elementos praticamente não formam radiosótopos indesejáveis durante a ativação neutrônica e ainda que os formem em baixíssimas quantidades, tais radionuclídeos possuem meia vida da ordem de dezenas de segundos e, portanto, podem ser usados para produção da matriz vítrea das microesferas [7,59]. A formação de vidros aluminossilicatos já foi amplamente estudada [60] e é relativamente fácil sua obtenção.

\subsection{Hólmio}

O hólmio é um elemento químico de número atômico 67 pertencente à série dos lantanídeos (terras-raras) e seu isótopo estável ${ }^{165}$ Ho constitui $100 \%$ de abundância na natureza. Na forma metálica, apresenta-se relativamente macio e maleável, de cor prateada e brilhante. Foi descoberto em 1879 por Per Theodro Cleve, químico sueco, na cidade de Estocolmo (Hólmia em latim) em seu país natal, que usou o mesmo método de busca de impurezas em óxidos de terras raras utilizado por Carl Gustaf Mosander para descobrir o lantânio, érbio e térbio [61]. Ele é encontrado na forma de óxido em minerais como gadolinita [62] e a monazita [63,64]. É um elemento trivalente e devido a suas propriedades magnéticas e térmicas incomuns, como anomalias tipo $\lambda$, que aparecem em curvas do calor específico em função da temperatura, vem sendo estudado desde o final dos anos 1950 [65-68] descobrindo-se que acima de 133K torna-se altamente paramagnético possuindo um momento magnético por átomo de 10,6 $\mu_{\mathrm{B}}$ (magnéton de Bohr) [65,66]. Este efeito é mais forte a baixas temperaturas e mais fraco a altas temperaturas [69] sendo que também possibilita a obtenção de imagens por ressonância magnética.

Resultados promissores de imageamento por ressonância magnética (RM) em coelhos foram previamente reportados utilizando microesferas poliméricas marcadas com hólmio. A presença do hólmio afeta o sinal de RM e a mudança do sinal resultante é dependente do teor de hólmio. Isto permite a visualização direta das microesferas e exploração para propósitos dosimétricos [70]. Comparado com as imagens obtidas por RM convencionais, são esperadas algumas vantagens na obtenção dessas imagens a partir da radioterapia interna seletiva como possibilidade de ajuste no contraste do tecido mole, alta resolução e capacidade de imagens dinâmicas [71].

Após a ativação neutrônica deste elemento, devido a sua alta seção de choque para absorção de nêutrons, ocorre a reação de captura de nêutrons: 


$$
{ }_{67}^{165} \mathrm{Ho}+n \rightarrow{ }_{67}^{166} \mathrm{Ho}+\gamma(19)
$$

O hólmio torna-se um átomo de núcleo instável que passa a irradiar partículas $\beta^{-}$e raios $\gamma$ conforme a reação (20) abaixo:

$$
{ }_{67}^{166} \mathrm{Ho} \rightarrow{ }_{68}^{166} \mathrm{Er}+\boldsymbol{\beta}^{-}+\bar{\nu}+\gamma
$$

Pode-se representar esse decaimento conforme o diagrama abaixo:
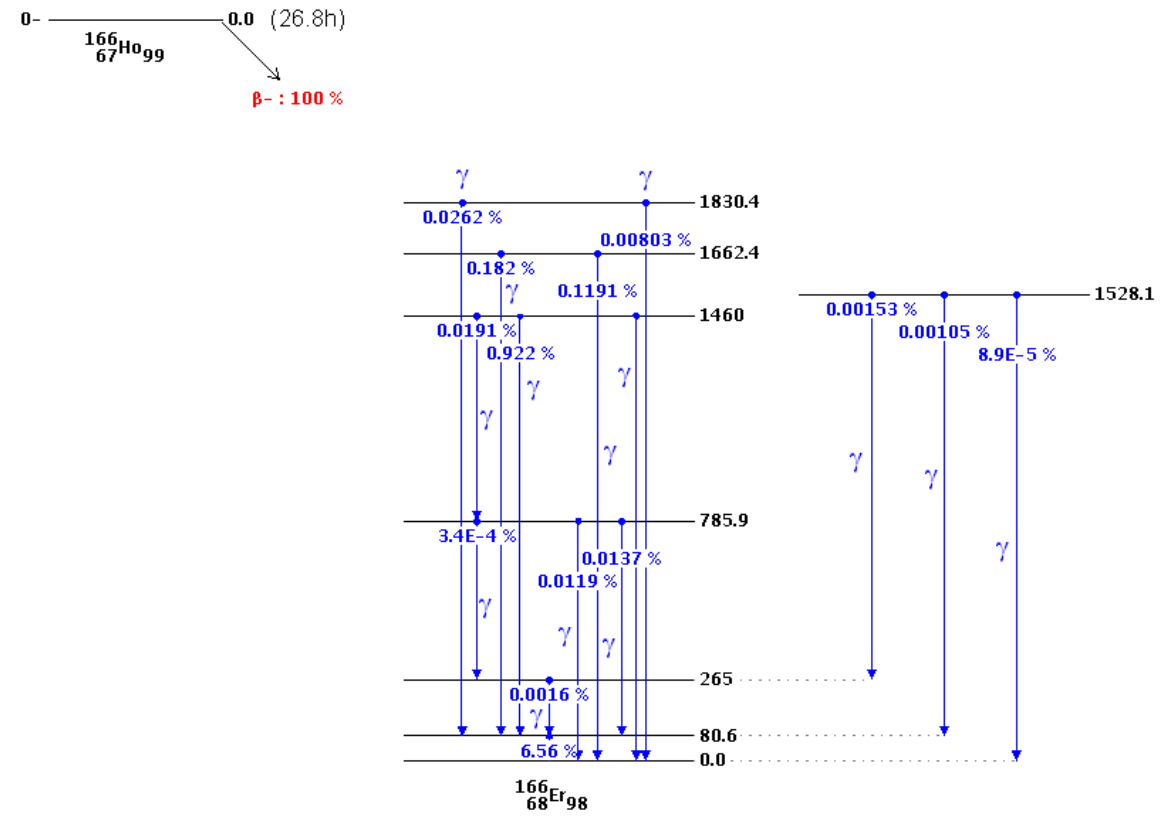

FIGURA 8 - Diagrama de decaimento do ${ }^{166} \mathrm{Ho}$ [72].

A meia-vida deste elemento é de 26,8 horas decaindo para um elemento estável $\left({ }^{166} \mathrm{Er}\right)$. As partículas $\beta^{-}$possuem alta energia e curto alcance podendo ser utilizadas para a destruição das células cancerosas e os raios $\gamma$ de baixa energia e abundância podem ser utilizados para imageamento por tomografia de emissão de fótons. Todas essas propriedades fazem do hólmio um elemento de grande interesse para aplicações em medicina nuclear e potencialmente indicado para tratamentos radioterápicos.

\subsection{Irradiação Intra-Arterial}

A irradiação intra-arterial é um efetivo modo de tratamento de alguns tipos de cânceres por meio da injeção de material radioativo diretamente na artéria nutriente do tumor ou órgão lesionado [73]. O carcinoma hepatocelular é um tipo de câncer que pode ser tratado com este tipo de terapia [73-75] principalmente para aqueles pacientes 
não indicados para o procedimento cirúrgico. Isto porque o tecido sadio do fígado é nutrido predominantemente pela veia porta hepática, enquanto o tumor é nutrido especialmente pela artéria hepática. Portanto, faz-se a administração do medicamento diretamente na artéria hepática, na qual as microesferas migram até regiões hipervaculares características das células cancerosas. Como a distribuição do fluxo sanguíneo é de 3 a 7 vezes maior no tumor do que nos tecidos sadios circundantes, haverá uma tendência de deposição das microesferas nas arteríolas que alimentam o tumor, apresando-se e bloqueando-se a alimentação do mesmo, bem como depositando dose e aniquilando as células cancerosas[76]. Para isto, o material injetado deve possuir formato esferoidal para evitar arestas cortantes que poderiam causar hemorragias desnecessárias e diâmetro entre 20 e 60 micra [77-79] para o efetivo bloqueio da alimentação do tumor e deposição de dose na área lesionada. No caso de partículas menores que $20 \mu \mathrm{m}$ pode ocorrer a migração dessas partículas pela corrente sanguínea até regiões de outros órgão sadios, o que deve ser evitado, enquanto que partículas maiores que $60 \mu \mathrm{m}$ podem ser apresadas antes da chegada até as arteríolas que alimentam o tumor. Este tipo de terapia tem se desenvolvido desde os anos 1960 [80] quando foi reportada a aplicação com sucesso de microesferas cerâmicas dopadas com ítrio $\left({ }^{90} \mathrm{Y}\right)$ em coelhos brancos, em que se observou a inibição do crescimento tumoral. Em 1969, os primeiros resultados usando microesferas metálicas dopadas com ítrio no tratamento de humanos foram reportados $[81,82]$. Apesar do estudo limitado a dois pacientes portadores de $\mathrm{CHC}$, os resultados foram favoráveis à diminuição da massa do tumor. O próximo trabalho de investigação do tratamento desta terapia ocorreu em 1982 $[78,81]$ notando-se que os pacientes mais indicados para este tipo de tratamento eram aqueles que possuíam tumores hipervascularizados, ajudando a criar um critério de seleção para pacientes submetidos a esta terapia. Em 1980, as microesferas poliméricas SIR-SPHERES foram desenvolvidas pela empresa Sirtex na Austrália e são comercializadas até os dias de hoje [83]. Também estão disponíveis no mercado microesferas de vidro desenvolvidas pela MDS Nordion do Canadá (Therespheres) [76]. Ambas usam como radionuclídeo o ${ }^{90} \mathrm{Y}$, que é um emissor $\beta^{-}$puro com energia máxima de 2,28 MeV, possui tempo de meia vida igual a 64,1 horas e seção de choque para absorção de nêutrons igual a 1,25 barns. Esta terapia possui um relativo sucesso propiciando uma melhora na qualidade de vida dos pacientes e em muitos casos tornando-os operáveis para remoção completa do tumor. 


\section{MATERIAIS E MÉTODOS}

\subsection{Materiais}

Vidros aluminossilicatos de magnésio contendo hólmio foram produzidos preliminarmente a partir da mistura e fusão de $\mathrm{Al}_{2} \mathrm{O}_{3}, \mathrm{SiO}_{2}, \mathrm{MgO}$ e $\mathrm{Ho}_{2} \mathrm{O}_{3}(5 \%$ em peso) com composição estequiométrica de $53,7 \mathrm{SiO}_{2} \cdot 9,5 \mathrm{Al}_{2} \mathrm{O}_{3} \cdot 35,8 \mathrm{MgO} \cdot 1 \mathrm{Ho}_{2} \mathrm{O}_{3}$ em $\%$ mol baseada no diagrama de fase da FIG. 9.

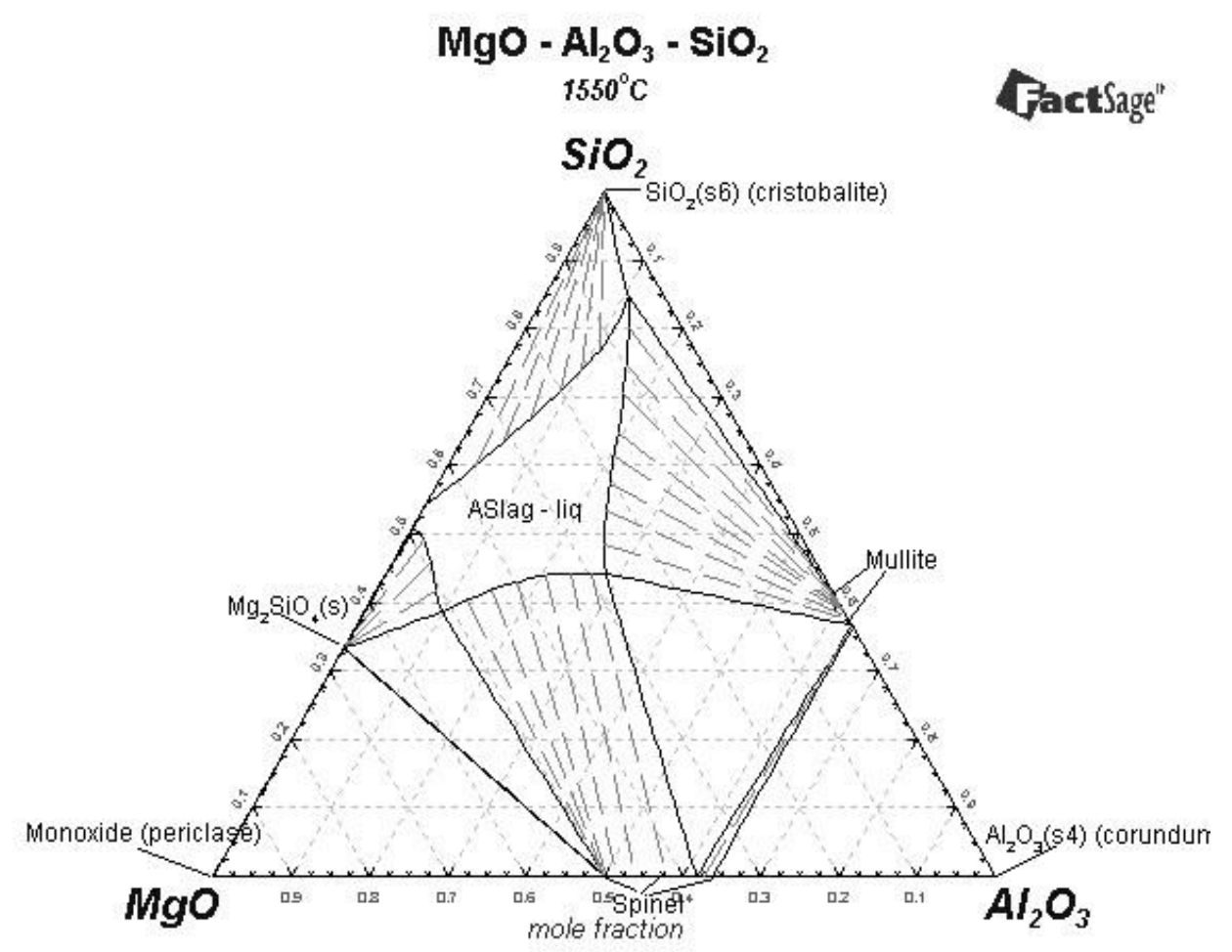

FIGURA 9 - Diagrama de fase a $1550^{\circ} \mathrm{C}$ de $\mathrm{MgO}-\mathrm{Al}_{2} \mathrm{O}_{3}-\mathrm{SiO}_{2}$ [84]

A mistura do material de partida foi realizada durante 20 minutos com o auxílio de um pistilo e gral de vidro silicato e a fusão foi realizada em um forno elétrico (Lindberg modelo Blue M) com taxa de aquecimento de $10^{\circ} \mathrm{C} / \mathrm{min}$ até a temperatura final de $1550^{\circ} \mathrm{C}$, utilizando-se um cadinho de alumina. $\mathrm{O}$ líquido foi mantido nesta temperatura durante 2 horas para homogeneização e afinagem, e agitado a cada 30 
minutos usando uma barra de sílica. O líquido foi então vertido em moldes de aço inoxidável obtendo-se barras solidificadas com dimensões de 10x10x50 mm³. Estas barras foram recozidas à temperatura de $770^{\circ} \mathrm{C}$ para alívio das tensões e cortadas (para teste de durabilidade química), maceradas e moídas (para produção de microesferas) utilizando-se 3 diferentes tipos de moinhos: 1) moinho planetário de bola de Tungstênio (Pulverizzete); 2) moinho de facas (Quimis Q2908-A); 3) dispositivo de aço-inoxidável acionado por martelo; obtendo-se partículas vítreas irregulares com diferentes morfologias que são chamadas de material precursor. Peneiras de aço inoxidável (Abronzinox) foram utilizadas para a separação das partículas em diferentes faixas granulométricas $\quad(0<\Phi<38 \mu \mathrm{m} ; 38 \mu \mathrm{m}<\Phi<63 \mu \mathrm{m} ; 45 \mu \mathrm{m}<\Phi<63 \mu \mathrm{m} ; 40 \mu \mathrm{m}<\Phi<53 \mu \mathrm{m}$; $45 \mu \mathrm{m}<\Phi<56 \mu \mathrm{m} ; 56 \mu \mathrm{m}<\Phi<63 \mu \mathrm{m}$ e $63 \mu \mathrm{m}<\Phi<106 \mu \mathrm{m}$ ) visando à investigação desta variável no processo de esferolização.

A pesquisa objetivando estudar o processo de esferolização foi realizada preliminarmente com a composição do vidro contendo $5 \%$ em peso de óxido de hólmio. Justifica-se usar esta composição devido ao alto custo do óxido de hólmio. Posteriormente, após investigações do processo de esferolização e quando estabelecido o método para obtenção de microesferas aplicáveis à radioembolização foram utilizadas composições com teores de óxido de hólmio superiores visando à otimização deste processo.

\subsection{Métodos}

Todas as análises para a caracterização físico-química dos materiais foram realizadas no Centro de Ciência e Tecnologia dos Materiais (CCTM) do IPEN. A irradiação por nêutrons foi realizada no reator nuclear IEA-R1 IPEN-CNEN/SP monitorada pelo Centro de Radiofarmácia (CR) do IPEN e o teste de citotoxicidade foi realizado no Centro de Química e Meio Ambiente (CQMA) do IPEN.

\subsubsection{Determinação da área superficial específica}

A área superficial específica das microesferas e do material precursor (partículas com formato irregular) foi determinada pela técnica B.E.T. em um aparelho (ASAP - 2010 V2), que utiliza o princípio de adsorção de um gás na superfície do sólido. O gás utilizado foi o nitrogênio e o intervalo de medida de 120 minutos. As microesferas analisadas por esta técnica foram obtidas pelo método da chama e o material precursor à esferolização foi peneirado na faixa de $38 \mu \mathrm{m}<\Phi<63 \mu \mathrm{m}$ utilizando 
o meio de moagem, um cilindro e um êmbolo de aço inoxidável acionado por um martelo. A temperatura da chama foi estabelecida mantendo a pressão de saída do combustível e comburente em $1,5 \mathrm{kgf} / \mathrm{cm}^{2}$ para o GLP e $2,5 \mathrm{kgf} / \mathrm{cm}^{2}$ para o $\mathrm{O}_{2}$.

\subsubsection{Calorimetria Exploratória Diferencial (DSC - acrônimo inglês de Differencial Scanning Calorimetry)}

A curva de calorimetria exploratória diferencial (DSC) foi obtida por um analisador e calorímetro térmico diferencial modelo Netzsch DSC 404 F3 Pegasus. A velocidade de aquecimento utilizada foi de $10^{\circ} \mathrm{C} / \mathrm{min}$. As amostras foram pesadas em uma balança com precisão de $0,01 \mathrm{mg}$, com massas variando de 40 a $54 \mathrm{mg}$ inseridas em um cadinho de alumina. As amostras foram analisadas na faixa de $20-1300^{\circ} \mathrm{C}$.

\subsubsection{Viscosidade}

A curva de viscosidade em função da temperatura foi obtida por meio da técnica de prolongamento de fibras. Fibras de vidro foram obtidas por puxamento manual e estas foram inseridas em um forno tubular (Gold Furnace Thermcraft) em uma zona quente de $20 \mathrm{~cm}$ e solicitadas a uma carga de $0,196 \mathrm{~N}$. Foram realizadas medidas na faixa de $825^{\circ} \mathrm{C}$ até $920^{\circ} \mathrm{C}$, com intervalos de $10^{\circ} \mathrm{C}$. A viscosidade $(\eta)$ foi calculada por meio da fórmula empírica (21):

$$
\eta=\frac{\mathrm{g} \cdot \mathrm{M} \cdot \mathrm{L}_{1} \cdot \mathrm{L}_{2} \cdot\left(\mathrm{t}_{2}-\mathrm{t}_{1}\right)}{3 \cdot \mathrm{V} \cdot\left(\mathrm{L}_{2}-\mathrm{L}_{1}\right)}
$$

Em que :

$$
\begin{aligned}
& \mathrm{g} \text { - aceleração da gravidade }\left(\mathrm{m} / \mathrm{s}^{2}\right) \\
& \mathrm{M} \text { - carga aplicada na fibra }(\mathrm{kg}) \\
& \mathrm{V} \text { - volume da fibra }\left(\mathrm{m}^{3}\right) \\
& \mathrm{L}_{1} \text { - comprimento inicial da fibra }(\mathrm{m}) \\
& \mathrm{L}_{2} \text { - comprimento final da fibra }(\mathrm{m}) \\
& \mathrm{t}_{2} \text { - tempo final (s) } \\
& \mathrm{t}_{1} \text { - tempo inicial (s) }
\end{aligned}
$$

A curva de viscosidade em função da temperatura foi obtida com o auxílio do software Maple 9.5, considerando que o comportamento da viscosidade obedece à equação de Arrenhius: 


$$
\eta=A \cdot e^{\frac{E}{R T}}
$$

na qual A (Pa.s) é uma constante que depende da composição do vidro, E (J/mol) é a energia de ativação por mol para ocorrência de deslizamentos dos planos atômicos, $\mathrm{R}$ (J/mol.K) é a constante universal dos gases e T $(\mathrm{K})$ é a temperatura na escala absoluta (Kelvin).

\subsubsection{Esferolização}

As partículas de vidro com formatos irregulares foram transformadas em microesferas utilizando-se dois processos de esferolização: por chama e por queda gravitacional.

\subsubsection{Esferolização pelo método da chama.}

Na FIG. 10, é mostrado um diagrama esquemático do processo de esferolização por chama.

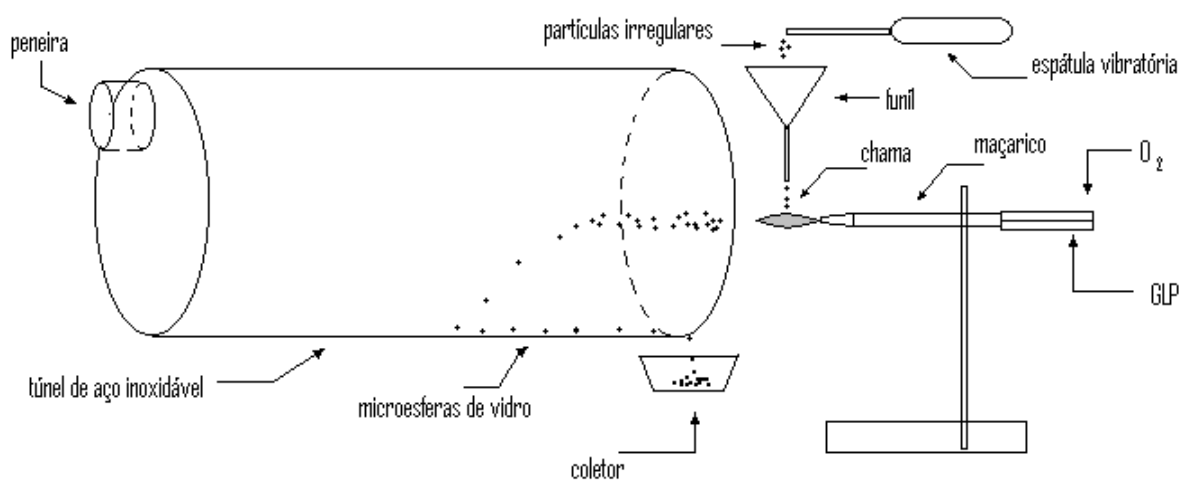

FIGURA 10 - Aparato experimental utilizado para obtenção de microesferas pelo método da chama.

Os parâmetros considerados críticos deste método foram: temperatura da chama, distribuição granulométrica do material precursor por peneiramento e tempo de voo.

A temperatura da chama foi controlada por meio da mistura de combustível (gás GLP) e comburente $\left(\mathrm{O}_{2}\right)$. Na primeira tentativa para obtenção das microesferas escolheu-se a temperatura da chama de modo que a pressão de saída foi de $1,5 \mathrm{kgf} / \mathrm{cm}^{2}$ do gás GLP e 2,5 kgf/ $\mathrm{cm}^{2}$ do gás $\mathrm{O}_{2}$. A granulometria do material precursor obtida por peneiramento foi de $38 \mu \mathrm{m}<\Phi<63 \mu \mathrm{m}$ e o meio de moagem foi um cilindro e um êmbolo de aço inoxidável acionado por um martelo. 
Variou-se a distribuição granulométrica do material precursor obtida por peneiramento nas faixas de $0<\Phi<38 \mu \mathrm{m} ; \quad 40 \mu \mathrm{m}<\Phi<53 \mu \mathrm{m} ; \quad 45 \mu \mathrm{m}<\Phi<56 \mu \mathrm{m}$; $45 \mu \mathrm{m}<\Phi<63 \mu \mathrm{m} ; 56 \mu \mathrm{m}<\Phi<63 \mu \mathrm{m}$ e $63 \mu \mathrm{m}<\Phi<106 \mu \mathrm{m}$, mantendo-se as condições iniciais constantes e investigou-se essa variável.

Variou-se a temperatura da chama do maçarico onde é lançado o material precursor controlando a pressão de saída do combustível (gás GLP) e do comburente $\left(\mathrm{O}_{2}\right)$. As pressões utilizadas foram selecionadas de acordo com os seguintes critérios: 1) pressões que em comparação com os valores preliminares tornavam a chama mais "fria" (coloração mais alaranjada da chama) na qual as pressões utilizadas foram de 1,5 $\mathrm{kgf} / \mathrm{cm}^{2}$ para o GLP e $1,0 \mathrm{kgf} / \mathrm{cm}^{2}$ para o $\mathrm{O}_{2} ; 2,4 \mathrm{kgf} / \mathrm{cm}^{2}$ para o GLP e $1,5 \mathrm{kgf} / \mathrm{cm}^{2}$ para o $\mathrm{O}_{2}$; e 2) pressões que tornavam a chama mais "quente" (coloração mais azulada da chama) na qual as pressões utilizadas foram de $1,35 \mathrm{kgf} / \mathrm{cm}^{2}$ para o GLP e $2,5 \mathrm{kgf} / \mathrm{cm}^{2}$ para o $\mathrm{O}_{2} ; 1,5 \mathrm{kgf} / \mathrm{cm}^{2}$ para o GLP e $3,0 \mathrm{kgf} / \mathrm{cm}^{2}$ para o $\mathrm{O}_{2}$. Investigou-se o tempo de voo das partículas considerando as microesferas coletadas em distâncias mais longínquas em relação à chama e separando-as em duas partes: microesferas coletadas próximo à chama e que possuíam um tempo de voo "curto" (região da primeira metade do percurso) e microesferas coletadas longe da chama que possuíam um tempo de voo "longo" (região da segunda metade até as mais afastadas). Utilizou-se o material precursor peneirado na faixa de $45 \mu \mathrm{m}<\Phi<63 \mu \mathrm{m}$ e a temperatura da chama tal que a pressão de saída do combustível e comburente foi de $1,5 \mathrm{kgf} / \mathrm{cm}^{2}$ para o GLP e 2,5 $\mathrm{kgf} / \mathrm{cm}^{2}$ para o $\mathrm{O}_{2}$.

\subsubsection{Esferolização por queda gravitacional}

A FIG. 11 mostra um diagrama esquemático do processo de esferolização por queda gravitacional: 


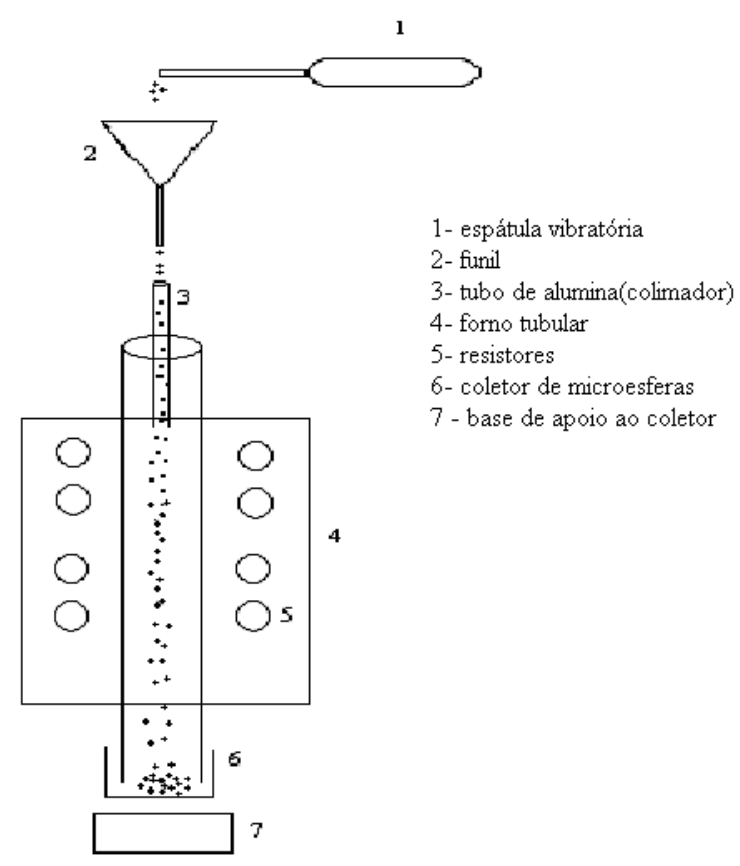

FIGURA 11: Aparato experimental para obtenção de microesferas pelo método da queda gravitacional.

Notou-se no momento da obtenção de microesferas por este método que surgia uma corrente de ar ascendente no interior do forno ocasionada pelo gradiente de temperatura nos seus extremos. Este fluxo de ar ascendente tem uma intensidade que qualitativamente denominaremos "forte". Ela pode ser bastante reduzida quando a extremidade inferior do forno é obstruída e um orifício na parte superior é aberto anulando a corrente ascendente. Denominaremos esse fluxo como "fraco". Pode-se apenas amenizá-lo diminuindo sua intensidade quando na parte superior do forno abrese um orifício sem obstruir a parte inferior do mesmo. Denominaremos esse fluxo como "médio".

Neste método de obtenção de microesferas, os parâmetros investigados foram: temperatura da zona aquecida do forno, fluxo de ar ascendente e tipo de moagem do material precursor. Inicialmente fixou-se a temperatura do forno em $1420^{\circ} \mathrm{C}$, o material precursor foi separado por peneiramento na faixa de $45 \mu \mathrm{m}<\Phi<63 \mu \mathrm{m}$ e a moagem foi realizada com um dispositivo de aço-inoxidável e martelo. Obtivemos microesferas usando as três intensidades ascendentes do fluxo de ar ("fraco", "médio" e "forte").

Em seguida, variou-se a temperatura do forno fixando-a em $1200^{\circ} \mathrm{C}$, $1380^{\circ} \mathrm{C}, 1460^{\circ} \mathrm{C}$ e $1490^{\circ} \mathrm{C}$ a fim de investigar esta variável. Foram mantidas as condições iniciais do material precursor e o fluxo de ar utilizado foi "fraco". 
Também investigou-se os efeitos causados pelo tipo de moagem analisando se a morfologia do material precursor poderia influenciar na obtenção das microesferas. As condições iniciais do experimento foram mantidas constantes $\left(\mathrm{T}=1420^{\circ} \mathrm{C}\right.$, material precursor separado por peneiramento na faixa de $45 \mu \mathrm{m}<\Phi<63 \mu \mathrm{m}$ e fluxo de ar ascendente "fraco"). As moagens investigadas foram por um moinho de facas, um moinho de bola de tungstênio e um moinho de aço inoxidável acionado por um martelo.

\subsection{Eliminação de finos por decantação simples}

Percebeu-se, por meio das micrografias do material precursor, que, na maioria dos casos, as partículas irregulares continham pequenas partículas aglomeradas sobre sua superfície (finos), as quais são denominadas partículas satélites. Estas partículas poderiam estar coalescendo com as partículas maiores e aumentando o diâmetro médio das microesferas resultantes. Um procedimento conveniente para eliminar as partículas satélites foi inserir o material precursor em um béquer contendo solução de tetrapirofosfato de sódio, que atuou como dispersante, e agitar a dispersão com uma barra de sílica durante três minutos. As partículas satélites se desagregaram das partículas mais pesadas e ficaram em suspensão enquanto houvesse a agitação. Após cessar a agitação, as partículas mais pesadas (maiores) decantaram rapidamente constituindo o corpo de chão e as mais leves continuaram suspensas no líquido. $\mathrm{O}$ líquido do béquer foi vertido eliminando as partículas satélites e as partículas maiores foram coletadas e colocadas em uma estufa a $100^{\circ} \mathrm{C}$ para secagem por 2 horas. $\mathrm{O}$ experimento foi realizado com o material precursor separado na faixa granulométrica de $45 \mu \mathrm{m}<\Phi<63 \mu \mathrm{m}$ por peneiramento, a temperatura do forno utilizada foi de $1420^{\circ} \mathrm{C}$ e o fluxo de ar ascendente "fraco".

\subsection{Eliminação de finos por agitação mecânica, ultrassom e decantação}

Visando a uma melhora no processo de decantação, a solução de tetrapirofosfato de sódio e o material precursor descritos anteriormente foram submetidos a ondas de ultrassom durante $3 \min ($ SONIC \& MATERIALS modelo V1A) após a mistura e agitados mecanicamente (FisAtom modelo 710) por $3 \mathrm{~min}$. Microesferas foram obtidas a partir desse material nas mesmas condições do experimento descrito no item acima (4.2.4.2.1). 


\subsubsection{Microscopia eletrônica de varredura e Distribuição do tamanho de partícula.}

O estudo do processo de esferolização de partículas vítreas pelo método da chama e da queda gravitacional foi realizado variando parâmetros considerados críticos para obtenção de microesferas adequadas para o tratamento radioterápico. A técnica de microscopia eletrônica de varredura foi utilizada para determinar a morfologia das partículas resultantes deste processamento.

As microesferas e o material precursor foram analisados em um microscópio eletrônico de varredura Philips modelo - XL30 onde foram aplicadas voltagens entre 5 a $25 \mathrm{kV}$. As amostras foram espalhadas sobre a superfície de uma fita dupla face de carbono e foram recobertas com ouro por meio de uma evaporadora modelo SCD 040 que continha argônio submetido a uma corrente elétrica de $\mathrm{i}=25$ mA. A distribuição do tamanho de partículas foi obtida pela técnica de espalhamento laser. O equipamento utilizado foi um analisador granulométrico CILAS modelo 1064. Foi utilizado como dispersante tetrapirofosfato de sódio dissolvido em água na razão 1:50 e foram aplicadas ondas de ultrassom durante 60 segundos antes e durante as medidas. O diâmetro médio das microesferas e o diâmetro equivalente do material precursor foram determinados por esta técnica utilizando o modelo de Fraunhofer.

\subsubsection{Irradiação de nêutrons para avaliação dos danos de radiação.}

As microesferas foram irradiadas no reator IEA-R1 IPEN-CNEN/SP durante 1 hora e com fluxo de nêutrons de $1 \times 10^{13} \mathrm{n} \cdot \mathrm{cm}^{-2} \cdot \mathrm{s}^{-1}$. A amostra contendo $23 \mathrm{mg}$ de microesferas foi inserida em um “eppendorf” e colocada em um cilindro de alumínio ("coelho") dentro do reator. Após a ativação neutrônica, as microesferas foram colocadas em recipiente blindado para espera de tempo apropriado (mais de 10 meiasvidas do ${ }^{166} \mathrm{Ho}$ ) e após este período foram realizadas análises da atividade por espectrômetro de raios $\gamma$ (Detetor Germânio de alta pureza) constatando uma baixa atividade suficiente para possibilitar a análise por MEV a fim de investigar a integridade física da superfície das microesferas mesmo após a irradiação.

\subsubsection{Aumento do teor de Hólmio}

Com a finalidade de otimizar a ativação neutrônica e após o estudo dos parâmetros dos processos de esferolização, foram produzidos vidros com teores de óxido de hólmio de $25 \%$ e $37 \%$ em peso (composição nominal baseada no diagrama de fase da FIG. 10). A composição nominal do vidro contendo $25 \%$ em peso de óxido de 
hólmio foi de $50 \mathrm{SiO}_{2} .9 \mathrm{Al}_{2} \mathrm{O}_{3} .35 \mathrm{MgO} .6 \mathrm{Ho}_{2} \mathrm{O}_{3}(\% \mathrm{~mol})$ e a composição nominal do vidro contendo $37 \%$ em peso de óxido de hólmio foi de $50 \mathrm{SiO}_{2} \cdot 7 \mathrm{Al}_{2} \mathrm{O}_{3} .35 \mathrm{MgO} .8 \mathrm{Ho}_{2} \mathrm{O}_{3}$ (\%mol). As microesferas obtidas e o material precursor foram analisados pela técnica de MEV para avaliação da morfologia. Análises granulométricas para determinação da distribuição do tamanho de microesferas e Espectrometria de Fluorescência de raios X por Energia Dispersiva para determinação da composição real dos vidros foram realizadas. A moagem foi realizada em moinho de facas e o material precursor obtido foi peneirado entre $40 \mu \mathrm{m}<\Phi<53 \mu \mathrm{m}$ sendo submetido ao processo de eliminação de finos por agitação mecânica, ultrassom e decantação. O processo de esferolização utilizado foi por queda gravitacional.

\subsubsection{Espectrometria de fluorescência de raios X por energia dispersiva (EDX)}

A análise química das amostras foi realizada por Espectrometria de Fluorescência de raios X por Energia Dispersiva utilizando um aparelho Shimadzu modelo EDX-720. As amostras foram analisadas em vácuo na forma de pó e os colimadores utilizados possuíam diâmetro de $5 \mathrm{~mm}$ e $10 \mathrm{~mm}$. Um filme de polipropileno de $5 \mu \mathrm{m}$ de espessura foi utilizado durante a realização das medidas. Foram obtidas cinco análises para cada amostra e o resultado foi considerado a média dos mesmos.

\subsubsection{Determinação da densidade}

A densidade das amostras foi determinada utilizando o método de picnometria a gás hélio (Quantachrome modelo Ultrapycnometer 1000). A pressão submetida foi de 17 psi e a massa analisada foi de 1,4g para ambas as amostras. Foram realizadas 10 análises para cada amostra e determinada a média aritmética dos valores obtidos.

\subsubsection{Difração de raios $X$}

As amostras foram analisadas em um difratômetro Rigaku modelo multiflex, utilizando o método do pó. A radiação utilizada para análise foi $\mathrm{CuK}_{\alpha}$ (ânodo de cobre), a tensão de $40 \mathrm{kV}$ e corrente elétrica de $20 \mathrm{~mA}$. Os ângulos varridos foram de $10^{\circ}$ até $90^{\circ}$ (velocidade $2^{\circ} / \mathrm{min}$ ).

\subsubsection{Teste de Durabilidade Química}

Amostras com dimensões de $0,1 \times 1 \times 1 \mathrm{~cm}^{3}\left(\mathrm{~A} / \mathrm{V}=20 \mathrm{~cm}^{-1}\right)$ foram preparadas a partir de barras de vidros previamente recozidas a $770^{\circ} \mathrm{C}$, posteriormente seccionadas 
em uma cortadora Isomet modelo 1000, utilizando-se um disco de diamante mantido em banho de um agente refrigerante (água destilada) e posteriormente foram lixadas progressivamente com lixas de carbeto de silício com granulação 240 e 420 mesh respectivamente. As amostras foram imersas em um extrator soxhlet conectado a um condensador de bolas e a um balão Pyrex contendo $100 \mathrm{ml}$ de água destilada e mantidas a $90^{\circ} \mathrm{C}$ por uma manta elétrica no período de 14 dias. A massa das amostras foi determinada nos intervalos de 1, 3, 7 e 14 dias.

A taxa de dissolução, $\mathrm{D}_{\mathrm{R}}$, foi calculada utilizando-se a equação abaixo:

$$
\mathrm{D}_{\mathrm{R}}=\Delta \mathrm{W} /(\mathrm{A} \cdot \mathrm{t})(23)
$$

Na qual A é a superfície total da amostra $\left(\mathrm{cm}^{2}\right)$, $\mathrm{t}$ o tempo (min) em que a amostra permanece imersa na solução a $90^{\circ} \mathrm{C}$ e $\Delta \mathrm{W}$ é a diferença de massa entre a massa inicial (g) e a massa no tempo $\mathrm{t}(\mathrm{g})$. O ensaio foi baseado na norma MCC-1P [85].

Testes de durabilidade química utilizando-se Fluido Corpóreo Simulado (SBF-acrônimo inglês de simulated body fluid) foram realizados à temperatura de $37^{\circ} \mathrm{C}$ em microesferas com 5, 25 e 37\% em peso de óxido de hólmio. Estas microesferas foram analisadas por MEV após 7 e 14 dias imersas em SBF tendo em vista investigar a integridade morfológica da superfície.

Para os ensaios em SBF, foi preparada a solução Ringer de $\mathrm{pH}$ igual a 7, cuja composição se apresenta na TAB 1.

TABELA 1: Composição química da solução Ringer $\mathrm{pH}=7$ em 1L de água deionizada.

\begin{tabular}{cc}
\hline \hline Componente & $\mathbf{g} / \mathbf{L}$ \\
\hline Cloreto de cálcio & 0,48 \\
Cloreto de sódio & 8,60 \\
Cloreto de potássio & 0,30 \\
\hline \hline
\end{tabular}

\subsubsection{Teste de Citotoxicidade}

Para os testes de citotoxicidade, utilizou-se a linhagem celular de NCTCclone L929 de tecido conectivo de camundongo, originária da American Type Culture Collection [ATCC-(CCL1)] e o meio de cultura foi o Meio de Eagle (MEM) com adição de $10 \%$ de soro fetal bovino, aminoácidos não essenciais e piruvato de sódio (MEM-uso).

A preparação da microplaca para o ensaio foi feita no setor de Culturas Celulares do Instituto Adolfo Lutz. O cultivo das células foi realizado em garrafas de cultura, em Meio-uso e após o crescimento das mesmas as células foram destacadas e a 
suspensão celular foi ajustada para $3,5 \times 10^{5}$ células $/ \mathrm{mL}$. Para atingir a confluência desejada, $200 \mu \mathrm{L}$ da suspensão obtida foi distribuída em cada poço da microplaca de 96 poços e a placa foi mantida em incubadora úmida a $37^{\circ} \mathrm{C}$ e atmosfera com $5 \% \mathrm{CO}_{2}$ por cerca de $24 \mathrm{~h}$.

Os extratos das amostras e dos controles foram preparados em MEM-uso, na proporção de $1 \mathrm{~cm}^{2}$ de área superficial ou $0,5 \mathrm{~g}$ por $\mathrm{mL}$ do meio de cultura, incubados em estufa $37^{\circ} \mathrm{C}$ durante $48 \mathrm{~h}$. Foi utilizada como controle negativo a alumina e como controle positivo o látex de borracha natural. Os extratos foram submetidos à diluição seriada com MEM-uso obtendo-se concentrações de $100 ; 50 ; 25 ; 12,5 ;$ e 6,25\%.

O controle negativo, material que não causa toxicidade, é utilizado para demonstrar a resposta celular e o controle positivo, material que demonstra resposta citotóxica reprodutível, é utilizado com o propósito de demonstrar uma resposta apropriada ao sistema do teste.

No ensaio propriamente dito, foram depositados $200 \mu \mathrm{L}$ de cada diluição tanto das amostras como dos controles em contato com as células aderidas em cada poço.

A placa foi mantida em estufa úmida a $37^{\circ} \mathrm{C}$ e atmosfera com $5 \% \mathrm{CO}_{2}$ por 24h. Decorrido este período os meios foram trocados por Meio-uso sem soro, contendo $50 \mu \mathrm{g}$ do corante vermelho neutro/mL e a placa foi incubada por mais $3 \mathrm{~h}$ adicionais para a incorporação do corante. Após esta etapa a placa foi lavada duas vezes com PBS e uma vez com a solução de lavagem e em seguida cada poço recebeu $200 \mu \mathrm{L}$ da solução de extração. Após agitação por $10 \mathrm{~min}$ foi feita a leitura da densidade óptica da microplaca em espectrofotômetro leitor de ELISA, em 540nm.

Este procedimento está em conformidade com a norma ISO 10993-5 (2009)[86]. 


\section{RESULTADOS E DISCUSSÕES}

\section{1 Determinação da área superficial específica.}

O valor da área superficial específica para as microesferas é $0,90(15) \mathrm{m}^{2} / \mathrm{g}$ e para o material precursor 1,63 (20) $\mathrm{m}^{2} / \mathrm{g}$. Comparando os resultados obtidos, verificouse que a área superficial específica do material precursor é muito maior comparado com o valor das microesferas. Essa diminuição da área superficial para menos de $55 \%$ do valor inicial indica que houve uma possível coalescência de algumas partículas irregulares durante o processo de esferolização.

\subsection{Calorimetria Exploratória Diferencial (DSC)}

As curvas DSC do material precursor e das microesferas para a composição $53,7 \mathrm{SiO}_{2} .9,5 \mathrm{Al}_{2} \mathrm{O}_{3} .35,8 \mathrm{MgO} .1 \mathrm{Ho}_{2} \mathrm{O}_{3}$ são mostradas na FIG. 12:

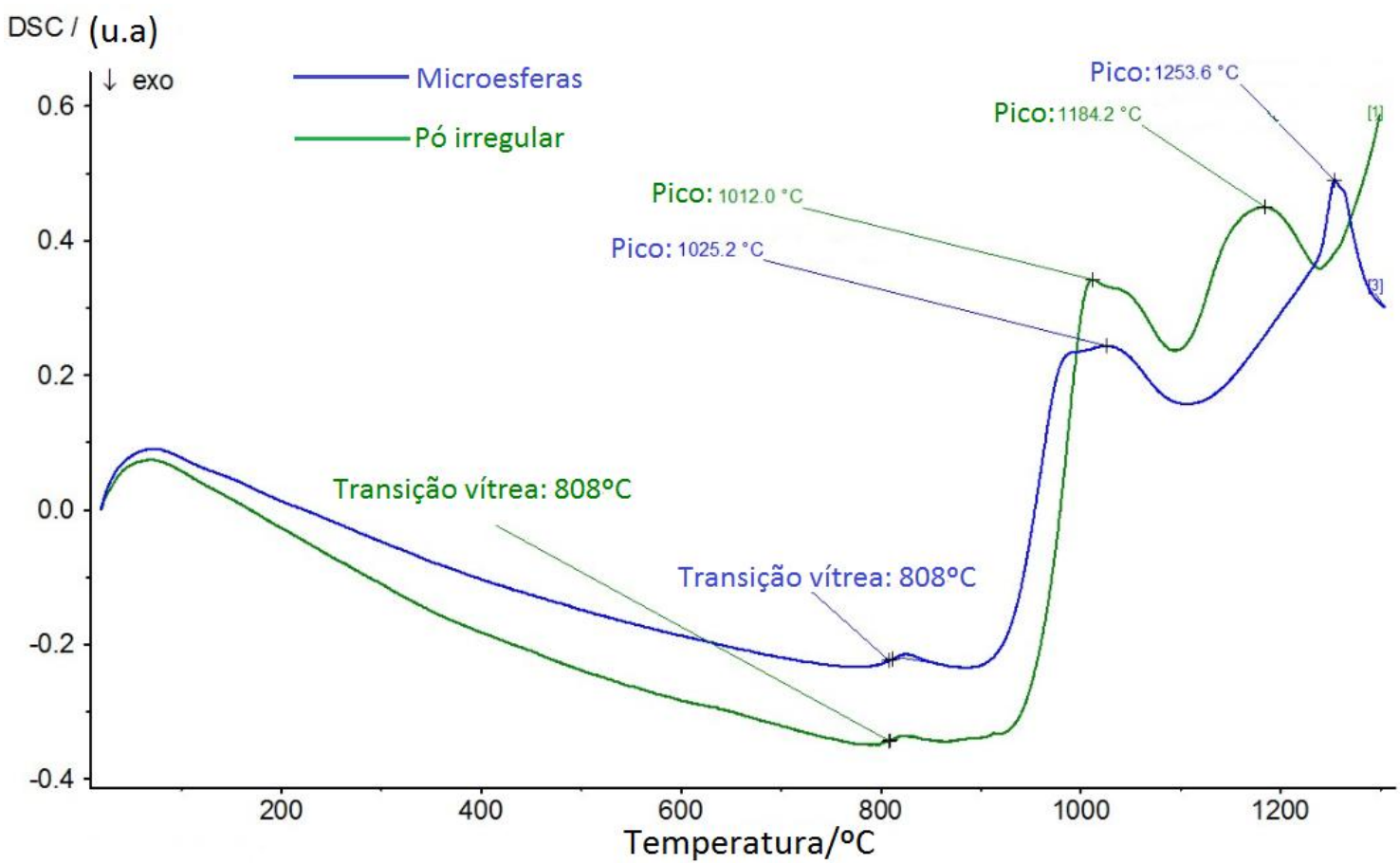

FIGURA 12 - Curva DSC do material precursor (partículas vítreas irregulares) e microesferas. 
Para ambas as curvas, foram observados um evento endotérmico correspondente à temperatura de transição vítrea $(\mathrm{Tg})$ em $808^{\circ} \mathrm{C}$. Um evento endotérmico correspondente ao amolecimento de uma fase vítrea foi encontrado em $1012^{\circ} \mathrm{C}$ para o material precursor e $1025^{\circ} \mathrm{C}$ para as microesferas. Um evento endotérmico foi encontrado em $1184^{\circ} \mathrm{C}$ e $1253^{\circ} \mathrm{C}$ para o material precursor e para as microesferas, respectivamente, correspondendo ao amolecimento de uma fase vítrea secundária. A proposta que estes fenômenos endotérmicos estejam relacionados ao amolecimento e consequente sinterização de partículas vítreas pode ser confirmado com a observação destas partículas em microscopia eletrônica de varredura. Na FIG. 13 a) é mostrado o amolecimento das microesferas de vidro à temperatura de $1000^{\circ} \mathrm{C}$ e na FIG. 13 b) o mesmo fenômeno para o material precursor.

(a)

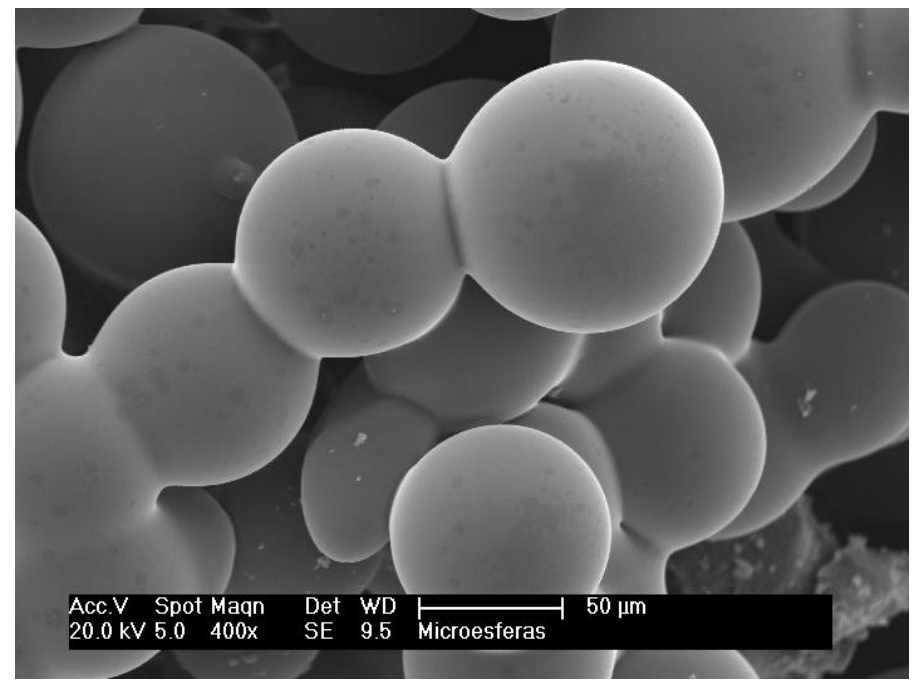

(b)

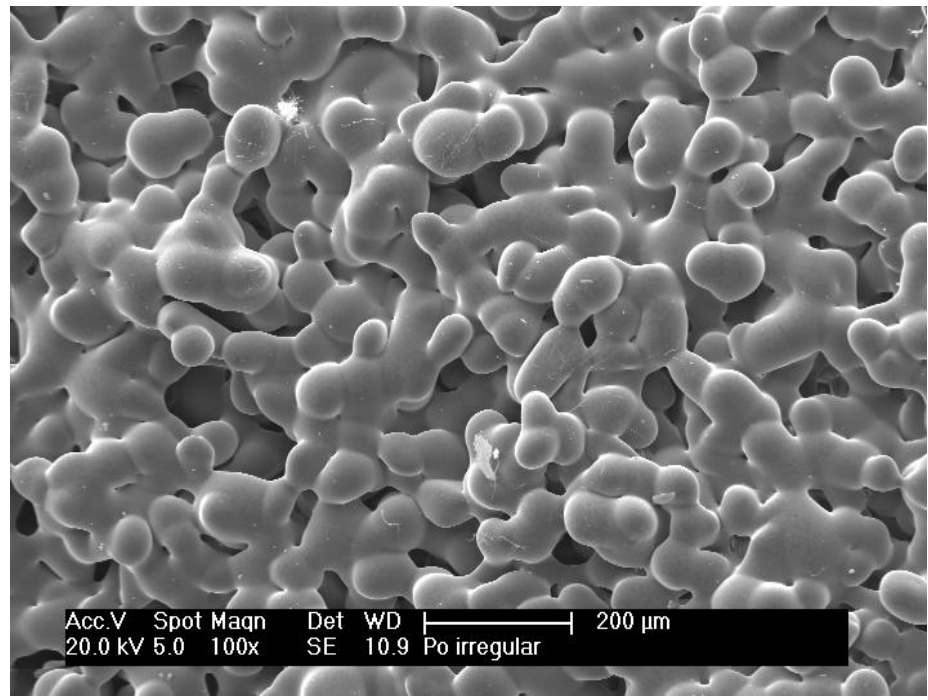

FIGURA 13: (a) Amolecimento das microesferas de vidro à temperatura de $1000^{\circ} \mathrm{C}$ (b) Amolecimento do material precursor à temperatura de $1000^{\circ} \mathrm{C}$. 
Observa-se na FIG. 13 a) a formação de pescoços nas interfaces das microesferas, e na FIG. 13 b) o mesmo fenômeno nas interfaces das partículas com formato irregular, além do início de um processo de esferolização destas partículas. Estes fenômenos são característicos de um processo de sinterização por fluxo viscoso em matrizes vítreas. Não houve mudanças significativas da Tg do material precursor em comparação com as microesferas. O parâmetro de estabilidade calculado por meio da diferença entre as temperaturas de máxima cristalização $(\mathrm{Tx})$ e transição vítrea $(\mathrm{Tg})$ dado por $\Delta \mathrm{T}=\mathrm{Tx}-\mathrm{Tg}$ não pôde ser determinado, pois não foi possível encontrar $\mathrm{Tx}$, porém é possível afirmar que estes vidros possuem alta estabilidade contra a cristalização. O parâmetro de Hruby não pôde ser calculado, pois não foi possível determinar a temperatura de fusão de uma possível fase cristalina, já que não é conclusivo por meio da curva DSC que esteja ocorrendo uma cristalização.

\subsection{Curva de Viscosidade}

A curva de viscosidade para o vidro com composição $53,7 \mathrm{SiO}_{2} .9,5 \mathrm{Al}_{2} \mathrm{O}_{3} .35,8 \mathrm{MgO} .1 \mathrm{Ho}_{2} \mathrm{O}_{3}$ foi determinada com o auxílio do software Maple 9.5, inserindo os parâmetros na equação (22) encontrados após tratamento dos dados experimentais. Na FIG. 14, é mostrada a curva com melhor ajuste e os dados experimentais.

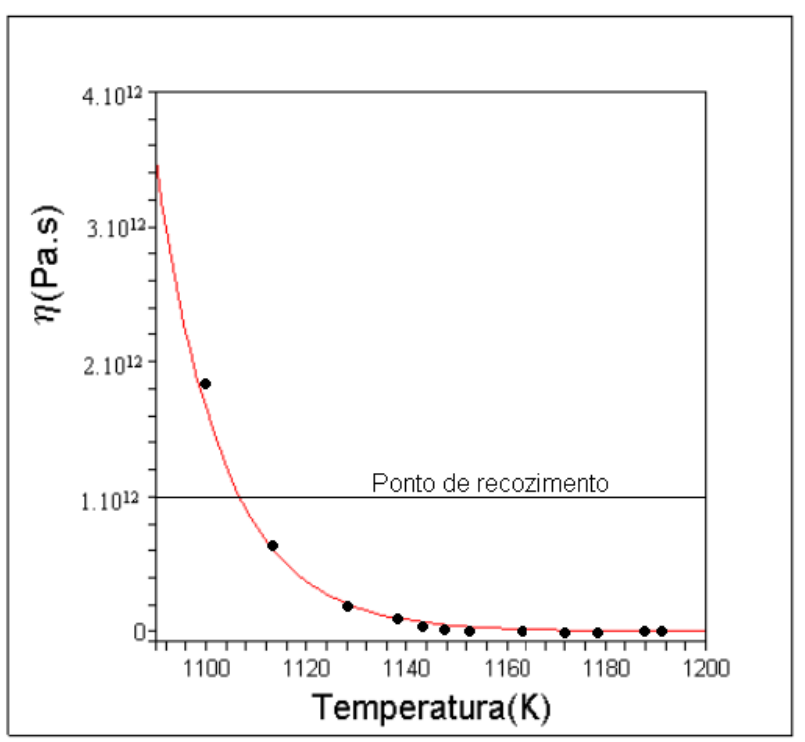

FIGURA 14 - Curva da viscosidade em função da temperatura.

Nota-se pela análise da FIG. 14 que a viscosidade deste vidro comporta-se com boa aproximação segundo a equação de Arrenhius. Utilizando este método de determinação da viscosidade foi possível encontrar o ponto de recozimento deste vidro 
$\left(834^{\circ} \mathrm{C}, 10^{12} \mathrm{~Pa} . \mathrm{s}\right)$ e pode-se afirmar que esse vidro apresenta uma viscosidade superior em relação a outros vidros. Por exemplo, a $834^{\circ} \mathrm{C}$, esse vidro apresenta uma viscosidade de $1,0 \times 10^{12}$ Pa.s, enquanto que nesta mesma temperatura os valores para vidros niobofosfato e silicatos de lítio são $2 \times 10^{10} \mathrm{~Pa} . \mathrm{s}$, e $1 \times 10^{5} \mathrm{~Pa} . \mathrm{s}$, respectivamente [87].

Este fato pode ser consequência do tipo de ligação química entre o oxigênio e o silício e alumínio presentes na composição do vidro deste estudo. Estas ligações são fortes o suficiente para aumentar a viscosidade, a dureza e a durabilidade química desses vidros.

\subsection{Espectrometria de Fluorescência de raios $X$ por energia dispersiva}

As análises da composição química das microesferas e do material precursor foram realizadas por meio de espectrometria de fluorescência de raios X por energia dispersiva. Na TAB. 2, são mostrados os valores encontrados:

TABELA 2: Composição química obtida por EDX (\%massa).

\section{Composição química obtida por EDX (\% massa)}

\begin{tabular}{ccc}
\hline Componente & Microesferas & Material precursor \\
\hline $\mathrm{SiO}_{2}$ & $53,2(7)$ & $54,2(8)$ \\
$\mathrm{Al}_{2} \mathrm{O}_{3}$ & $19,6(5)$ & $19,7(3)$ \\
$\mathrm{MgO}$ & $16,5(7)$ & $17,1(5)$ \\
$\mathrm{Ho}_{2} \mathrm{O}_{3}$ & $9,2(5)$ & $7,5(1,2)$ \\
$\mathrm{Lu}_{2} \mathrm{O}_{3}$ & $0,82(9)$ & $0,94(18)$ \\
$\mathrm{CaO}$ & $0,40(10)$ & $0,31(7)$ \\
$\mathrm{Fe}_{2} \mathrm{O}_{3}$ & $0,27(12)$ & $0,16(12)$ \\
\hline \hline
\end{tabular}

Verifica-se que não há mudanças significativas nas composições das microesferas em relação ao material precursor. A presença de óxido de lutécio deve-se a impurezas presentes no óxido de hólmio utilizado como material de partida. A presença do óxido de ferro pode ser explicada por contaminação no processo de moagem, no qual foi utilizado um dispositivo de aço inoxidável. O óxido de cálcio presente na análise são impurezas advindas do óxido de magnésio utilizado na composição dos vidros investigados. 


\subsection{Determinação da Densidade}

Na TAB. 3, são mostrados os valores médios de densidade do material precursor e das microesferas.

TABELA 3 - Densidade média obtida por picnometria.

\begin{tabular}{cc}
\hline Material & Densidade média $\left(\mathbf{g} / \mathbf{c m}^{\mathbf{3}}\right)$ \\
\hline Microesferas & $2,79(12)$ \\
Material Precursor (Pó irregular) & $2,82(3)$ \\
\hline \hline
\end{tabular}

Não se observou uma alteração significativa dos valores de densidade das microesferas comparativamente ao material precursor (pó irregular). Ainda que estes valores de densidade não sejam tão baixos quanto aqueles encontrados em microesferas poliméricas [11], eles podem ser considerados como resultados animadores, pois as microesferas vítreas comerciais que utilizam o ítrio como radionuclídeo possuem densidade média de $3,29 \mathrm{~g} / \mathrm{cm}^{3}[11]$ e isto é um inconveniente, pois pode haver deposição das microesferas nos vasos sanguíneos antes do efetivo direcionamento ao tumor.

\subsection{Difração de raios X (DRX)}

Os difratogramas de raios $\mathrm{X}$ das microesferas de vidro e do material precursor (pó irregular) mostram a presença de um halo na faixa de $2 \theta=\left(20^{\circ}-40^{\circ}\right)$ evidenciando as características amorfas das microesferas e do material precursor. Não foram observados picos relacionados à presença de fases cristalinas como mostrado no FIG. 15. 


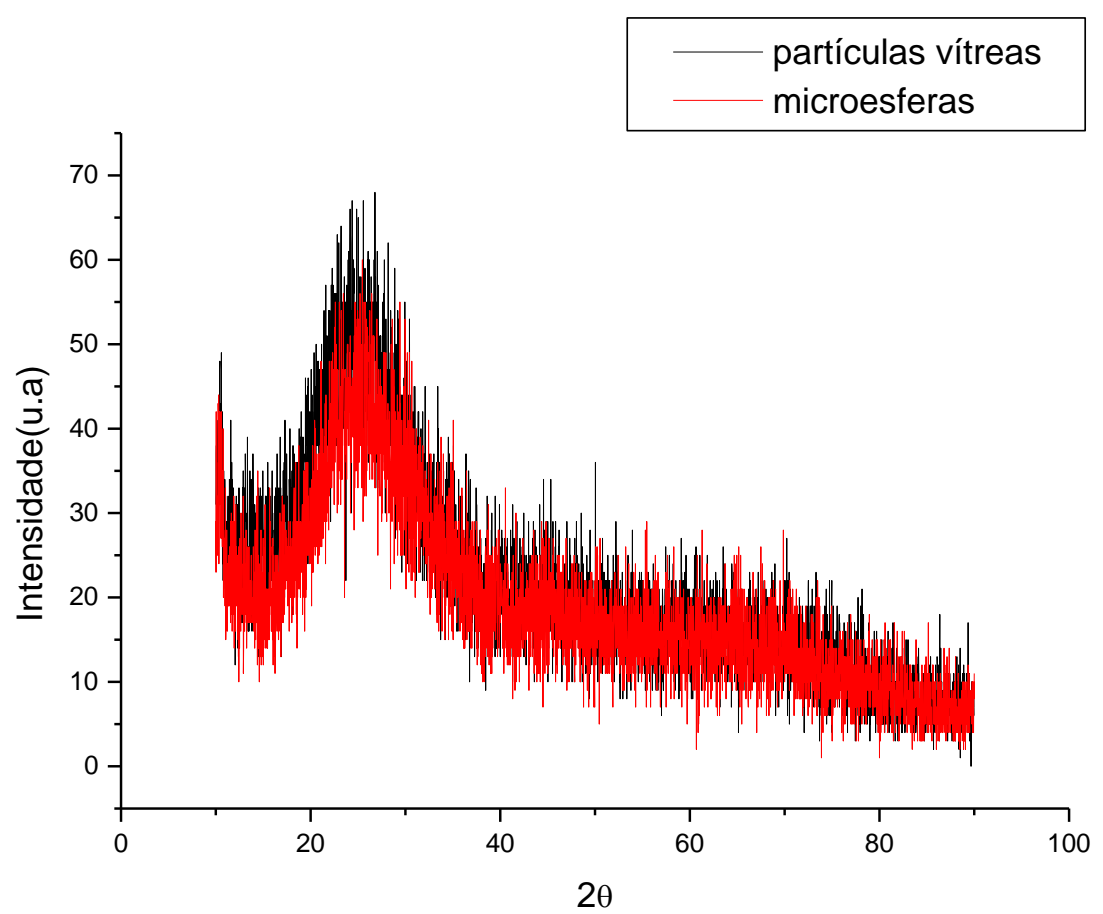

FIGURA 15: Difratograma de raios X

Não há cristalização do material submetido aos processos de esferolização. Após a ativação neutrônica por nêutrons térmicos destes materiais, espera-se que eles permaneçam amorfos [88], mantendo sua integridade física e química para a aplicação em radioterapia interna seletiva.

\subsection{Análises granulométricas e microscopia eletrônica de varredura.}

\subsubsection{Esferolização por chama}

As imagens obtidas por microscopia eletrônica de varredura e os resultados da análise granulométrica por difração a laser das microesferas e do material precursor são mostrados nas FIG. 16 e 17. Estes resultados se referem à primeira tentativa de se obter microesferas em que o material precursor foi separado na faixa de $38 \mu \mathrm{m}<\phi<63 \mu \mathrm{m}$ e a pressão de saída do combustível e do comburente da chama foi de $1,5 \mathrm{kgf} / \mathrm{cm}^{2}$ do gás GLP e $2,5 \mathrm{kgf} / \mathrm{cm}^{2}$ do gás $\mathrm{O}_{2}$. 


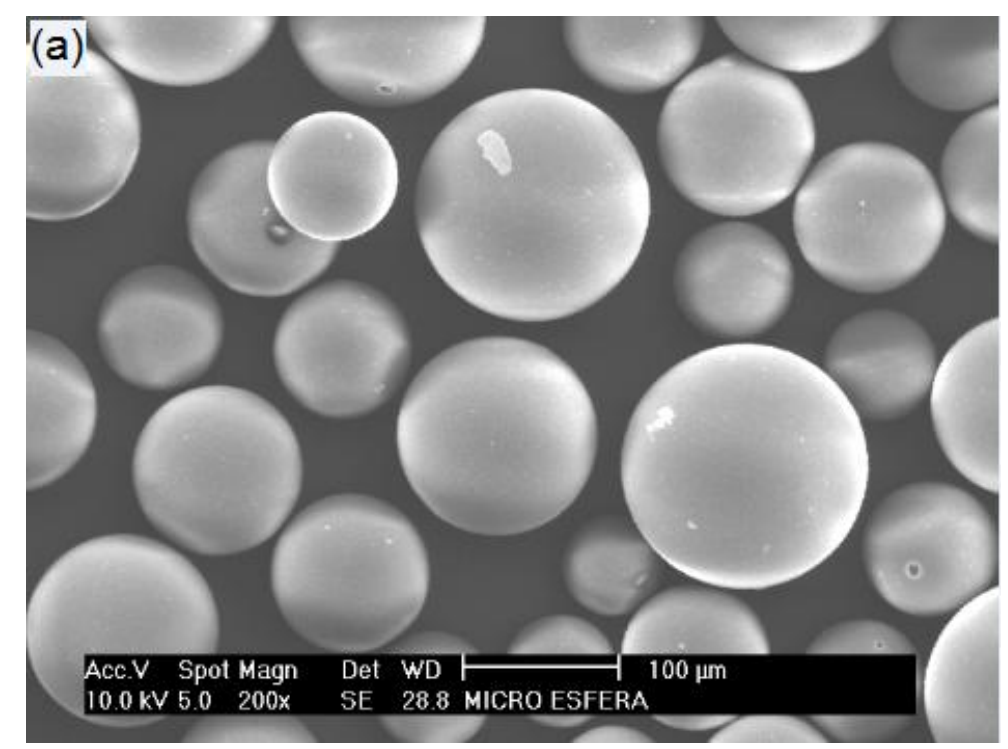

(b)

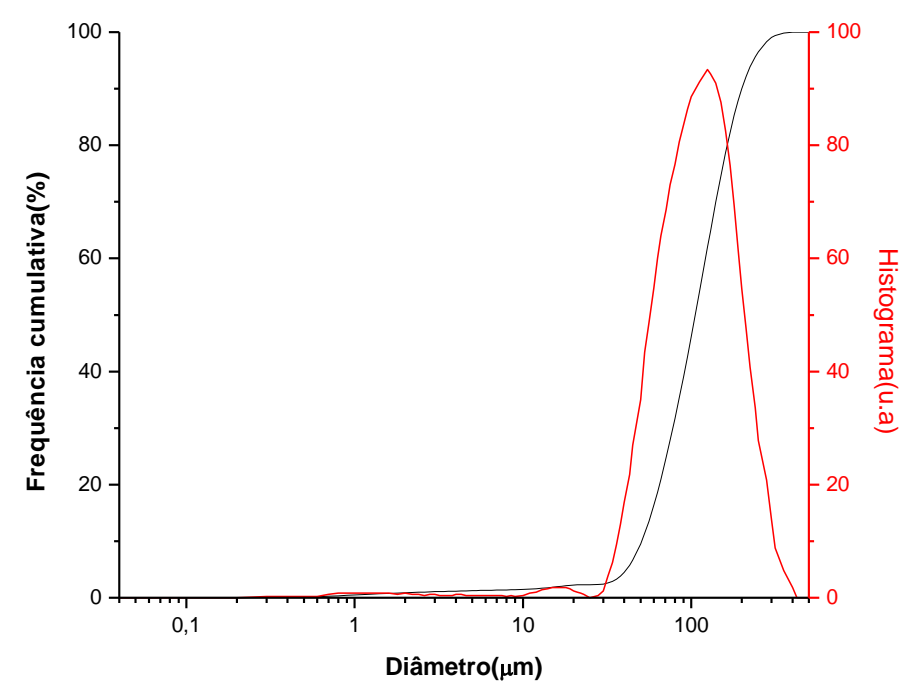

FIGURA 16 - Microesferas (a) MEV; (b) Distribuição granulométrica $\langle\Phi>=116 \mu \mathrm{m}$ 


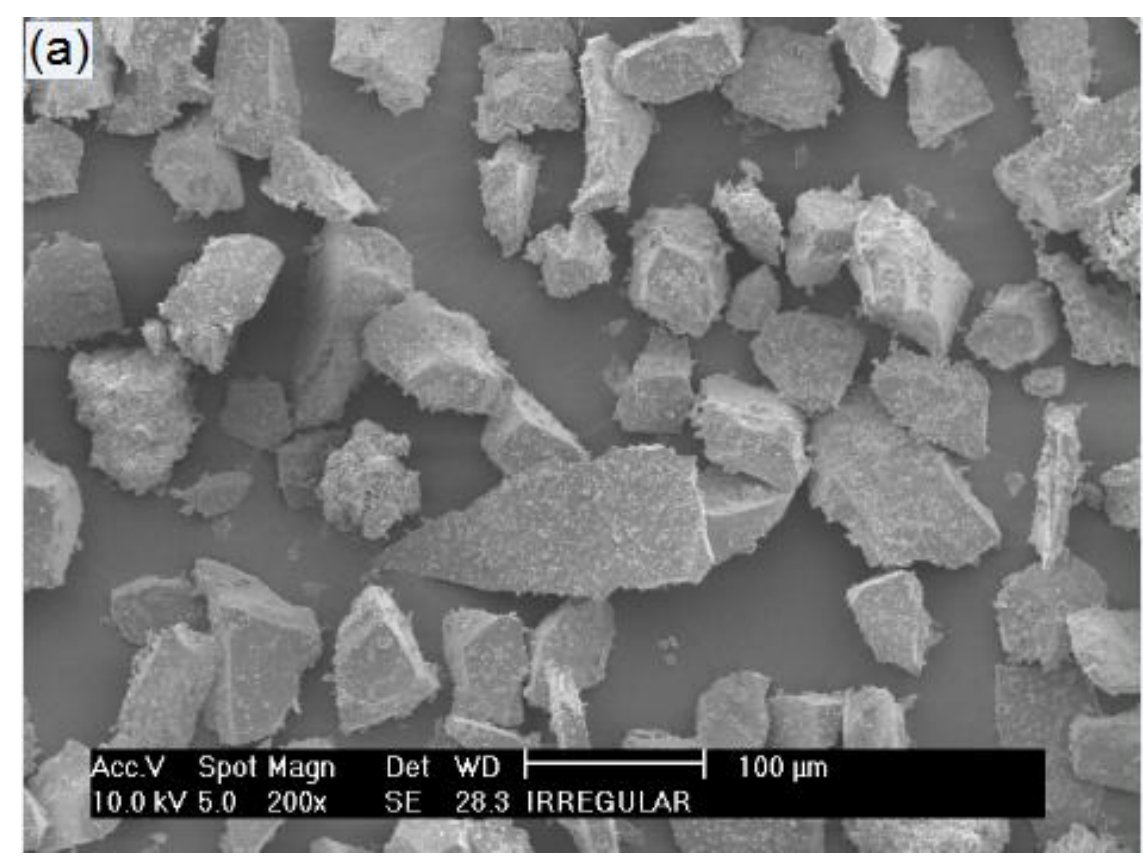

(b)

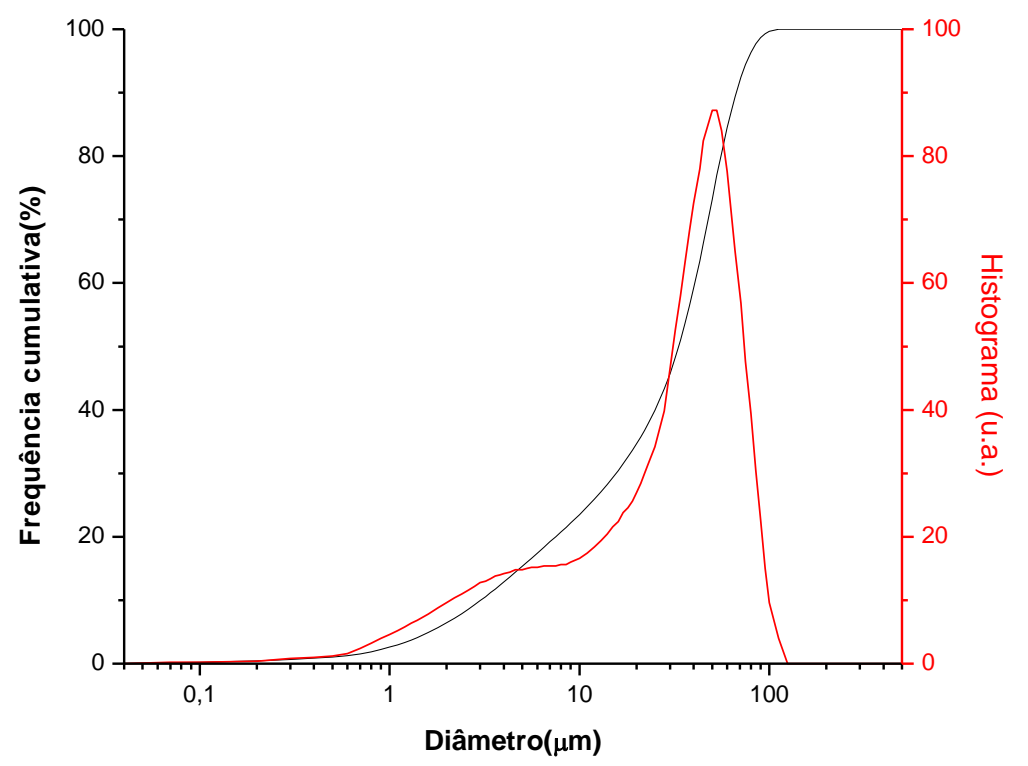

FIGURA 17 - Material Precursor (a) MEV; (b) Distribuição granulométrica $\langle\Phi\rangle=34 \mu \mathrm{m}$.

Nas imagens obtidas por MEV das microesferas observa-se que o processo de esferolização por chama é adequado para a obtenção deste material com uma morfologia esferoidal ainda que razoavelmente heterogênea. Contudo, nota-se que o diâmetro médio das microesferas é muito maior que o diâmetro equivalente encontrado para as partículas irregulares. As distribuições de tamanho de partículas para as 
microesferas e para o material precursor (FIG. 16(b) e 17(b)) são também distintas, tanto no tamanho quanto na forma da curva de distribuição. As microesferas de vidro apresentam uma distribuição aproximadamente unimodal centrada em $\langle\Phi\rangle=116 \mu \mathrm{m}$, enquanto que a distribuição do material formado por partículas irregulares apresenta dois máximos centrados em $\Phi=4 \mu \mathrm{m}$ e $\Phi=51 \mu \mathrm{m}$, respectivamente. A TAB. 4 lista os valores de diâmetro médio e aqueles obtidos a 10\% (D10), 50\% (D50) e 90\% (D90) da curva cumulativa, para os dois materiais.

TABELA 4 - Distribuição do tamanho de partículas por meio de difração a laser.

Distribuição do tamanho de partículas $(\mu \mathrm{m})$

\begin{tabular}{ccccc}
\hline & D10\% & D50\% & D90\% & diâmetro médio \\
Microesferas & 50,79 & 105,64 & 199,95 & 116,73 \\
Material precursor & 3,02 & 33,28 & 67,03 & 33,98 \\
\hline \hline
\end{tabular}

O fato do diâmetro médio das microesferas e do material precursor não serem compatíveis pode ser explicado devido à aglomeração de partículas irregulares durante o translado da espátula vibratória até a chama e consequente coalescência em microesferas ou devido à razão de aspecto das partículas irregulares, a qual deveria ser muito maior que 1 (formato acicular). Esta última hipótese é pouco provável como indicam os resultados de análise superficial específica e imagem por microscopia eletrônica de varredura da FIG. 17(a). Portanto, há fortes indícios que esteja ocorrendo coalescência das partículas irregulares vítreas durante o processo de esferolização devido a vários fatores como atuação de forças de Van der Waals, grande área de superfície específica que causa atrito elevado e provoca aglomerados que durante a queda tornam-se microesferas com diâmetro médio muito maior que o diâmetro equivalente das partículas irregulares. Também pode-se considerar a presença de partículas satélites (finos) na superfície das partículas maiores devido ao efeito de carregamento elétrico que provoca o aparecimento de aglomerados prejudicando a fluidez do pó. 


\subsubsection{Distribuição granulométrica do material precursor.}

Variou-se a distribuição granulométrica do material precursor nas faixas de $0<\Phi<38 \mu \mathrm{m} ; 40 \mu \mathrm{m}<\Phi<53 \mu \mathrm{m} ; 45 \mu \mathrm{m}<\Phi<56 \mu \mathrm{m} ; 45 \mu \mathrm{m}<\Phi<63 \mu \mathrm{m} ; 56 \mu \mathrm{m}<\Phi<63 \mu \mathrm{m} \mathrm{e}$ $63 \mu \mathrm{m}<\Phi<106 \mu \mathrm{m}$ por peneiramento para posterior obtenção das microesferas, mantendo-se as condições iniciais constantes e obtendo-se os resultados nas FIG. 18 a 29.

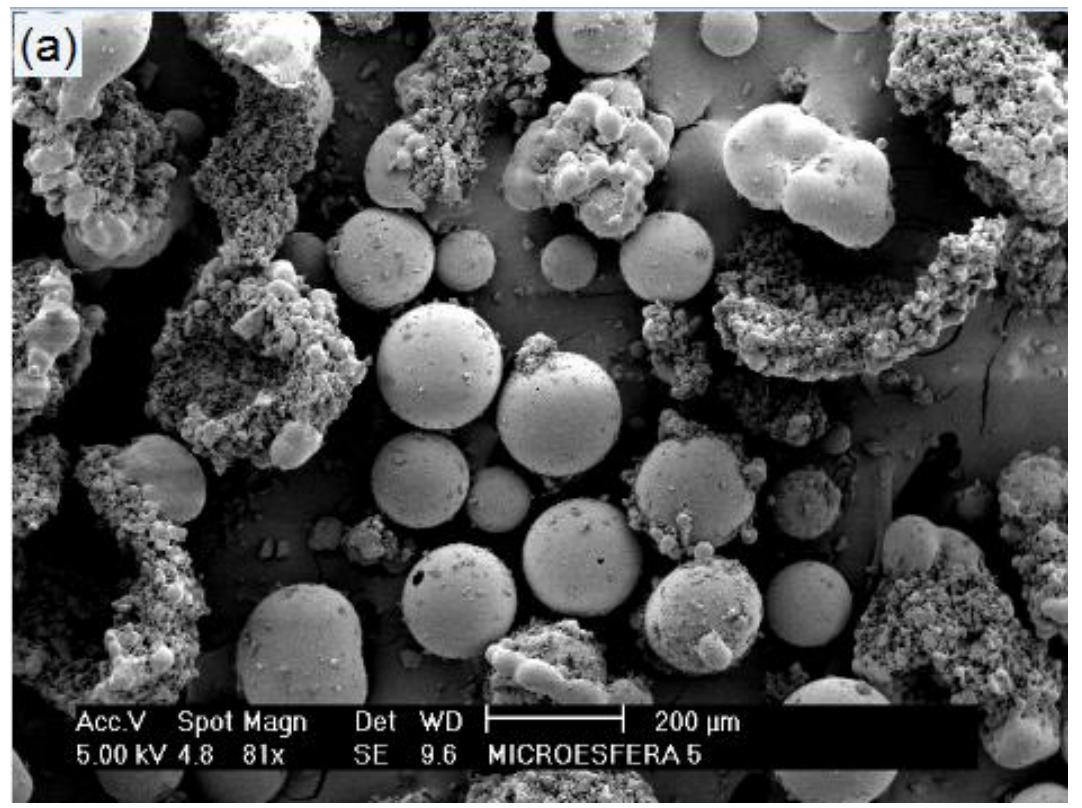

(b)

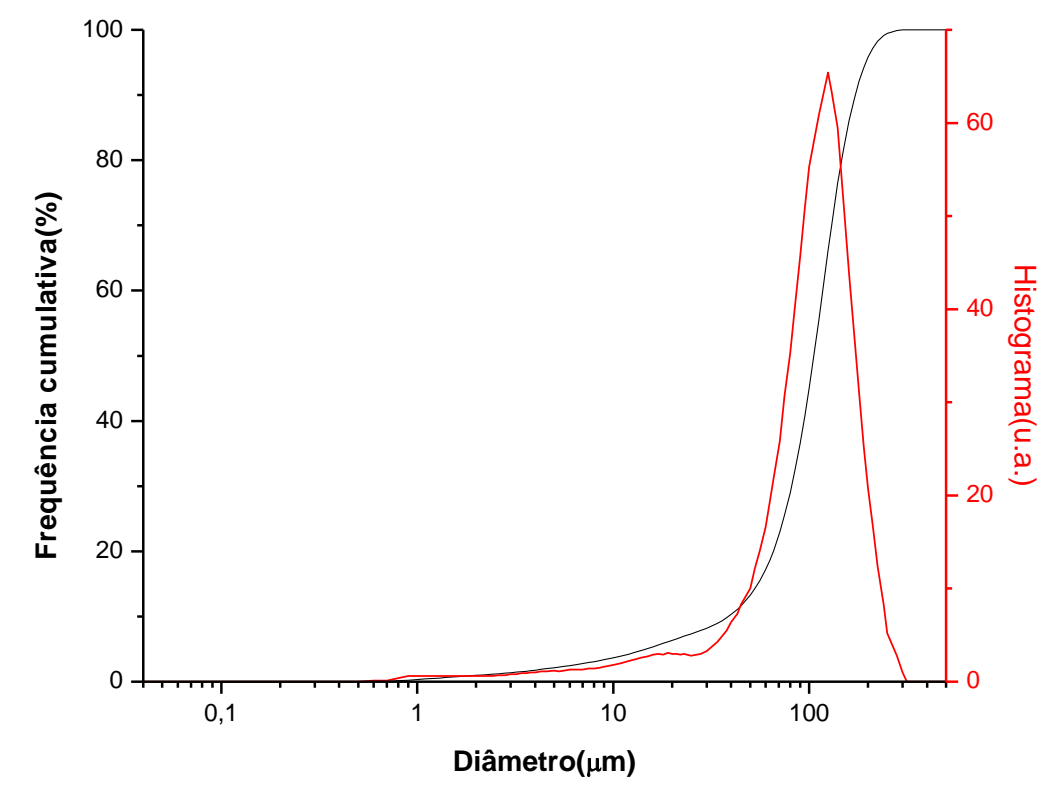

FIGURA 18 - Microesferas obtidas a partir de material precursor com granulometria entre $0<\Phi<38 \mu \mathrm{m}$ (a) MEV; (b) Distribuição granulométrica $<\Phi>=107 \mu \mathrm{m}$ 


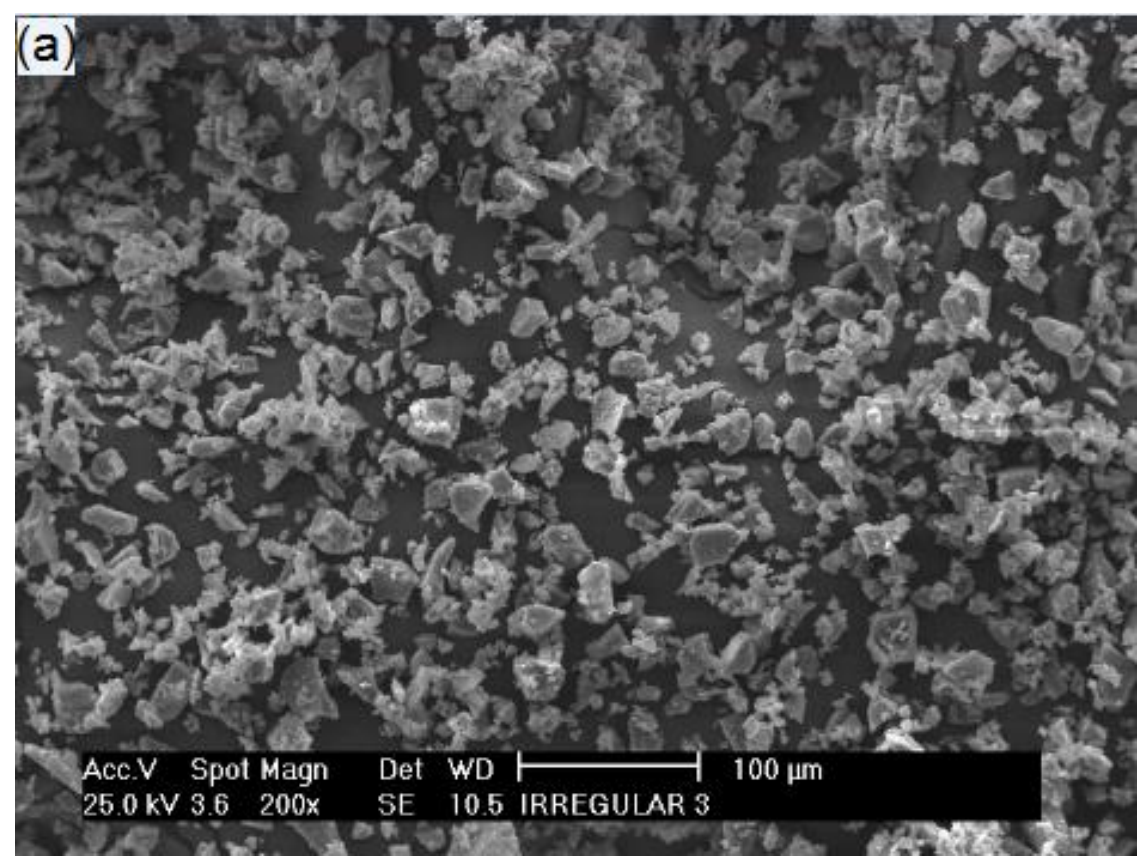

(b)

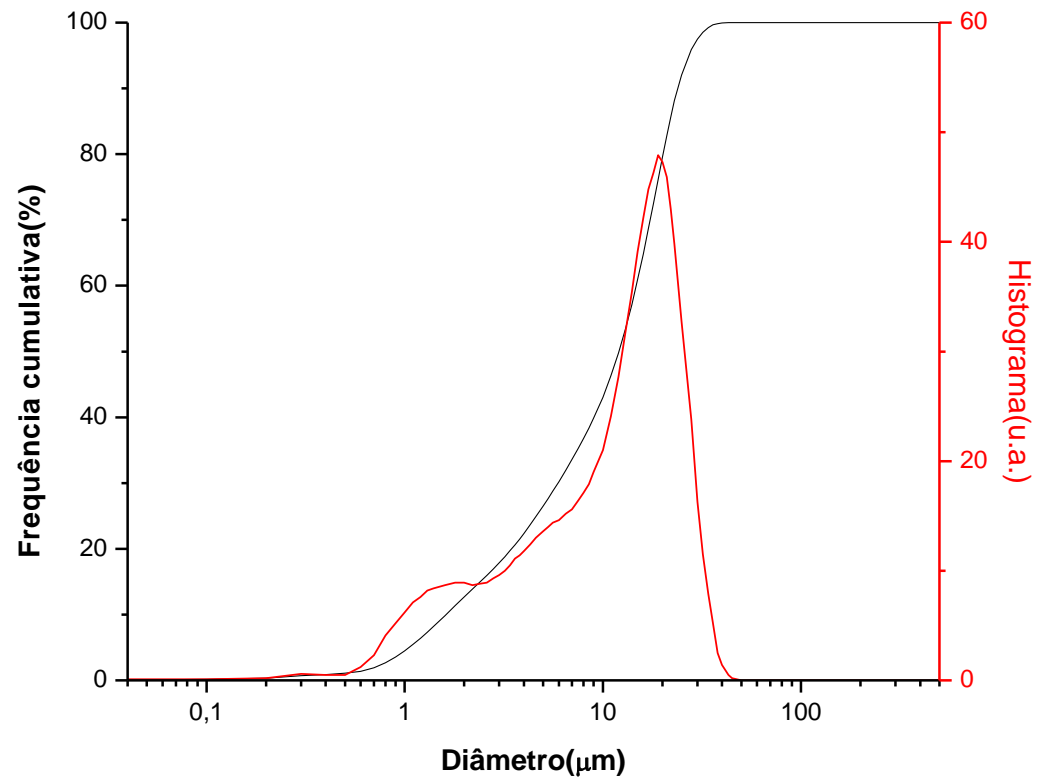

FIGURA 19 - Material precursor com granulometria entre $0<\Phi<38 \mu \mathrm{m}$ (a) MEV; (b) Distribuição granulométrica $\langle\Phi\rangle=12 \mu \mathrm{m}$. 

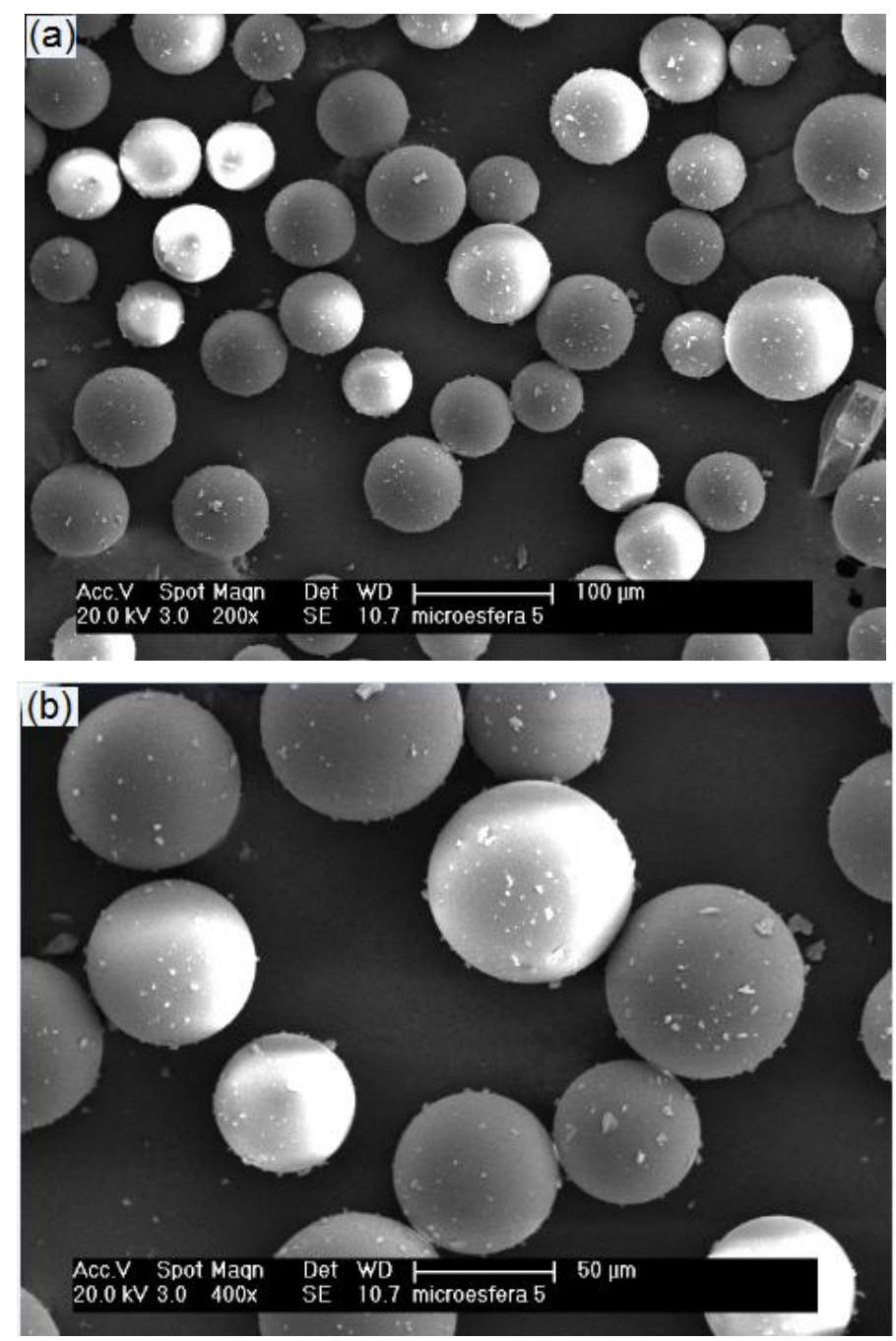

(c)

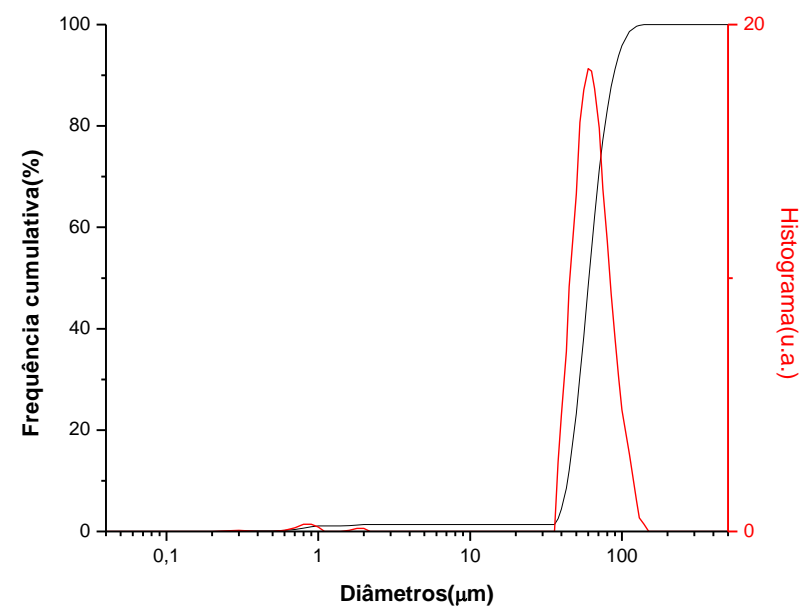

FIGURA 20 - Microesferas obtidas a partir de material precursor com granulometria entre $40 \mu \mathrm{m}<\Phi<53 \mu \mathrm{m}$ (a) e (b) MEV; (c) Distribuição granulométrica $<\Phi>=63 \mu \mathrm{m}$. 


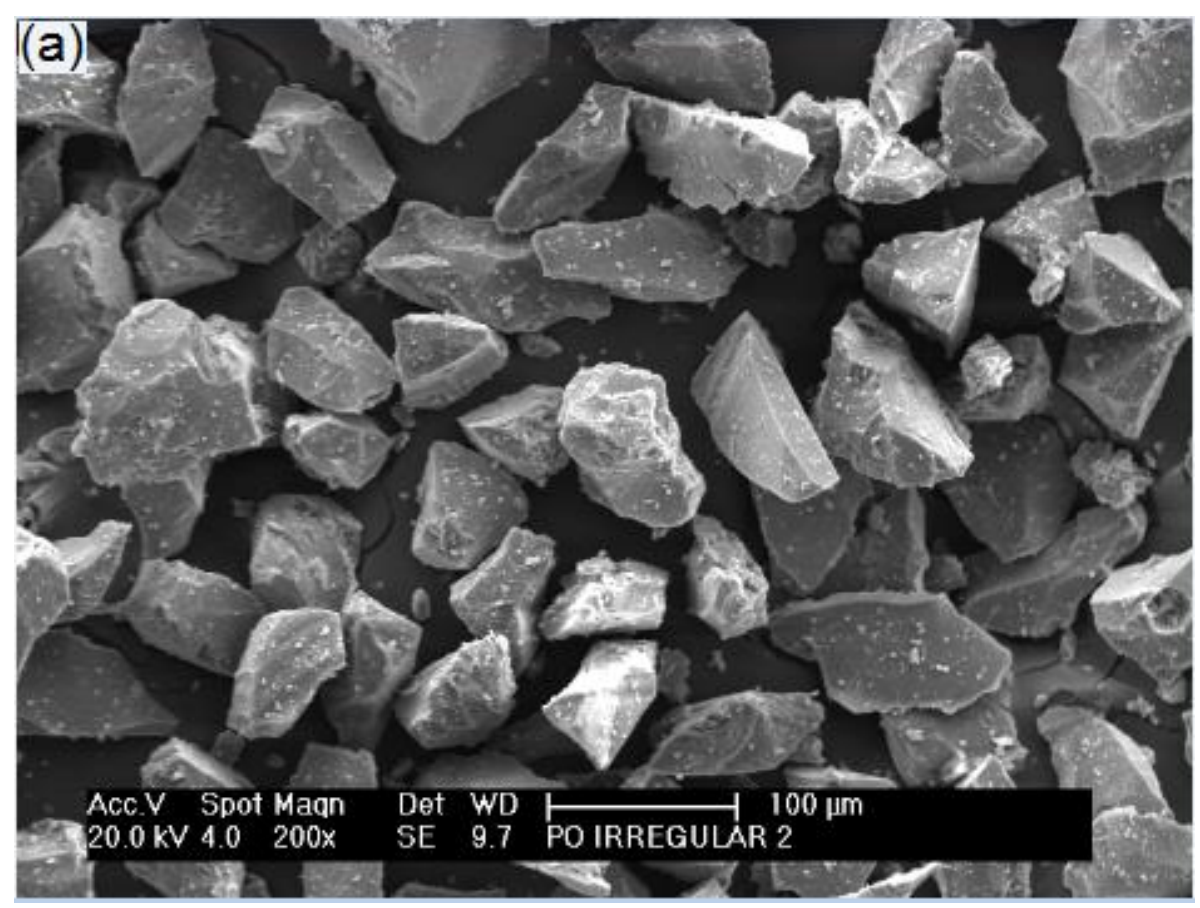

(b)

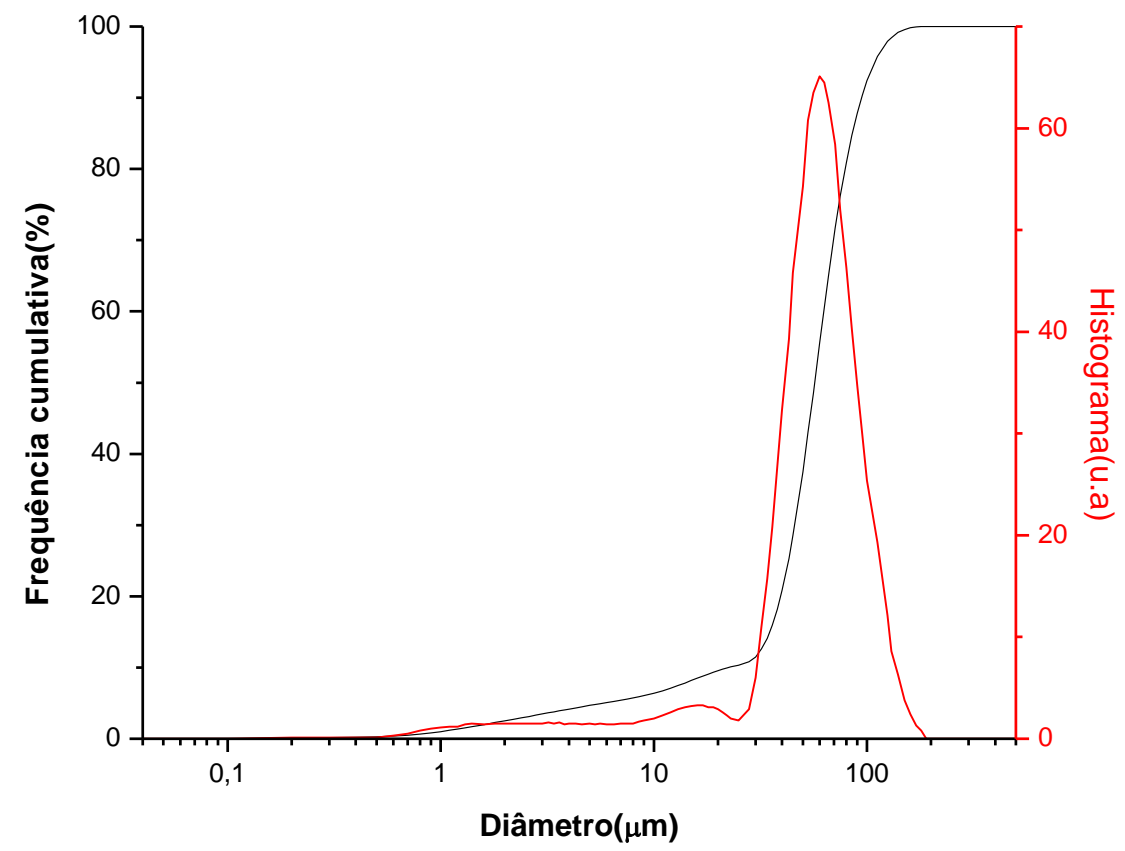

FIGURA 21 - Material precursor com granulometria entre $40 \mu \mathrm{m}<\Phi<53 \mu \mathrm{m}$ (a) MEV; (b) Distribuição granulométrica $\langle\Phi\rangle=59 \mu \mathrm{m}$. 

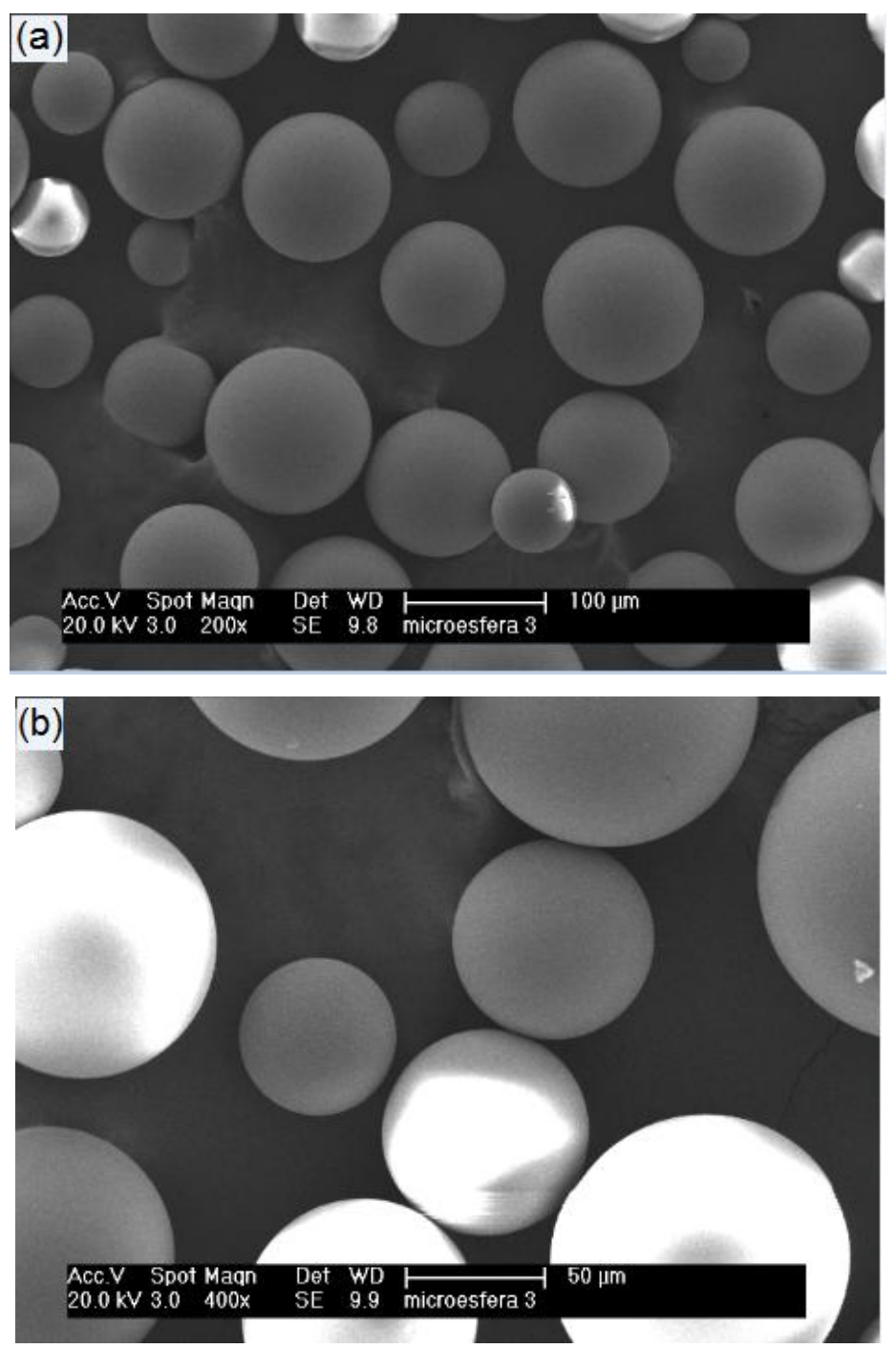

(c)

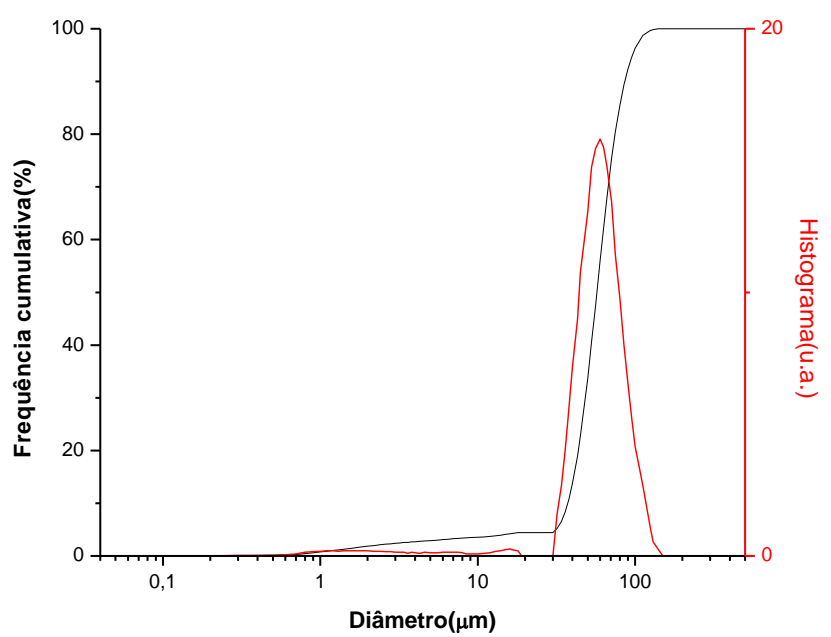

FIGURA 22 - Microesferas obtidas a partir de material precursor com granulometria entre $45 \mu \mathrm{m}<\Phi<56 \mu \mathrm{m}$ (a) e (b) MEV; (c) Distribuição granulométrica $<\Phi>=67 \mu \mathrm{m}$. 


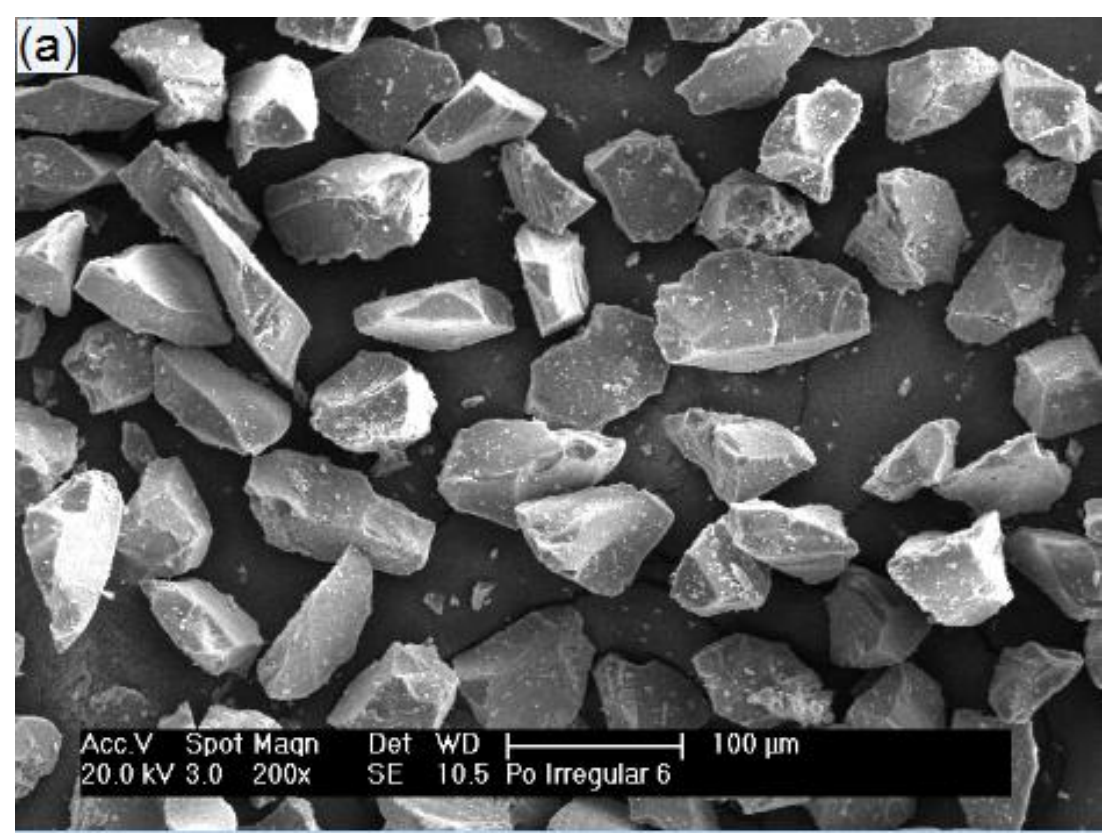

(b)

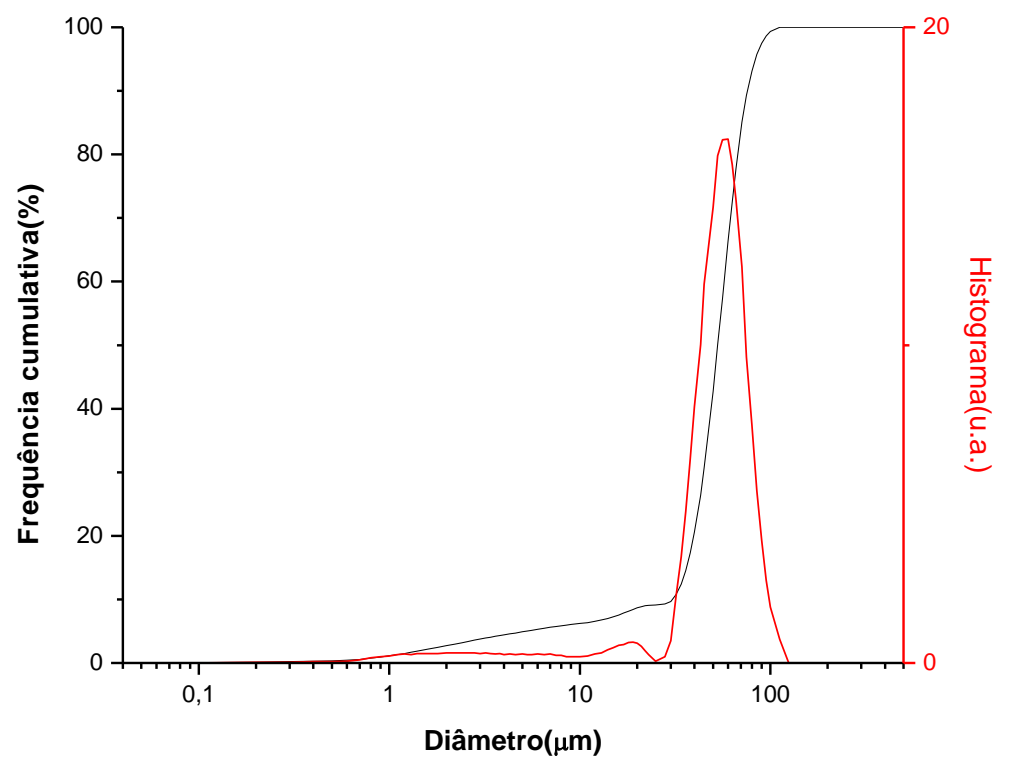

FIGURA 23 - Material precursor com granulometria entre $45 \mu \mathrm{m}<\Phi<56 \mu \mathrm{m}$ (a) MEV; (b) Distribuição granulométrica $\langle\Phi\rangle=52 \mu \mathrm{m}$. 

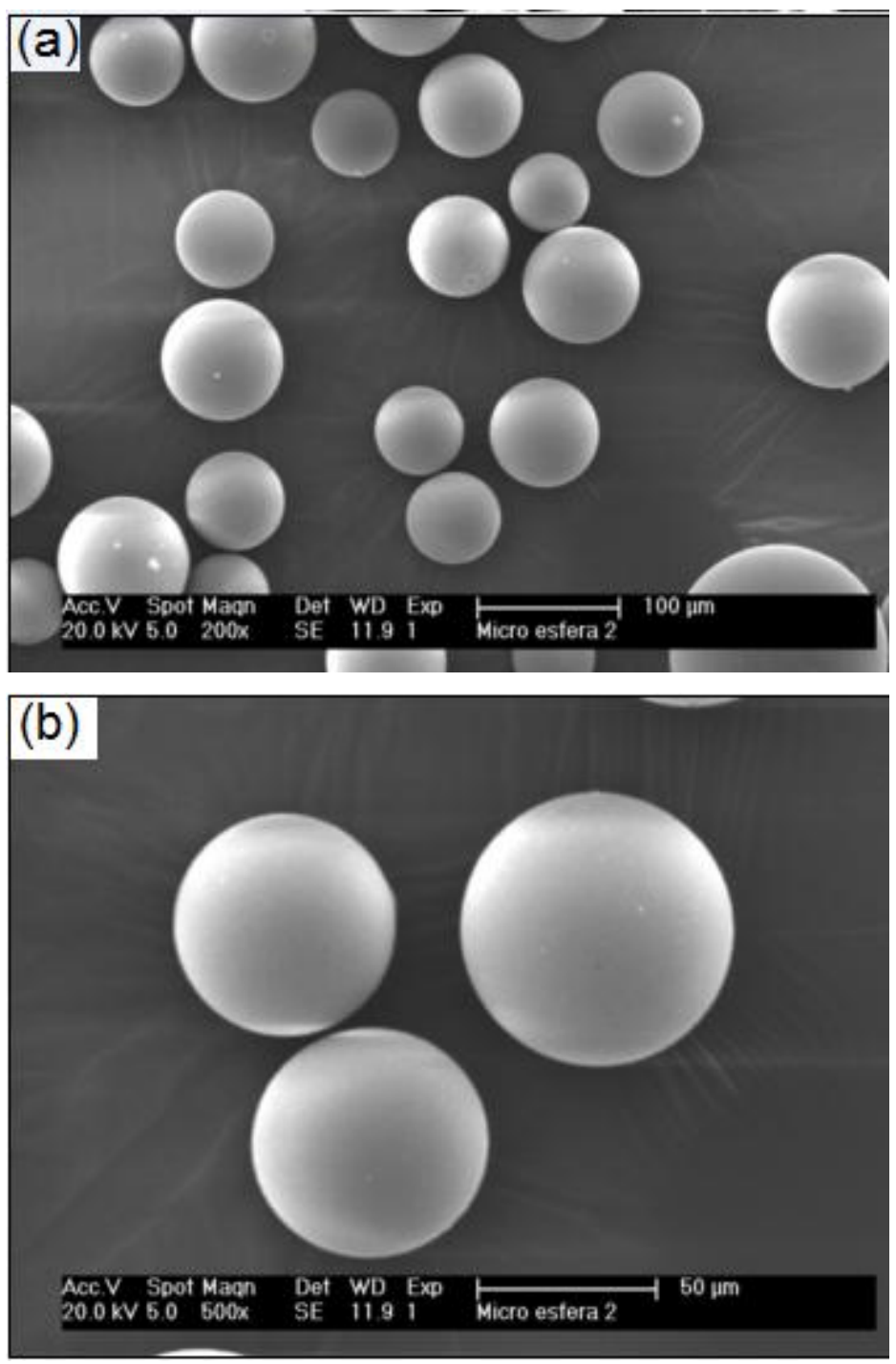

(c)

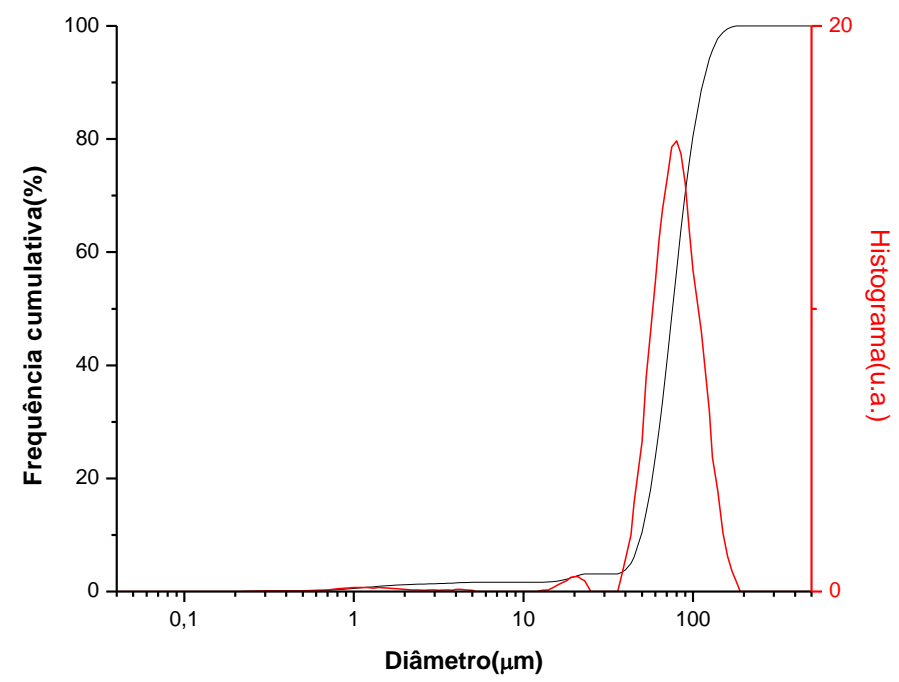

FIGURA 24 - Microesferas obtidas a partir de material precursor com granulometria entre $45 \mu \mathrm{m}<\Phi<63 \mu \mathrm{m}$ (a) e (b) MEV; (c) Distribuição granulométrica $<\Phi>=78 \mu \mathrm{m}$. 

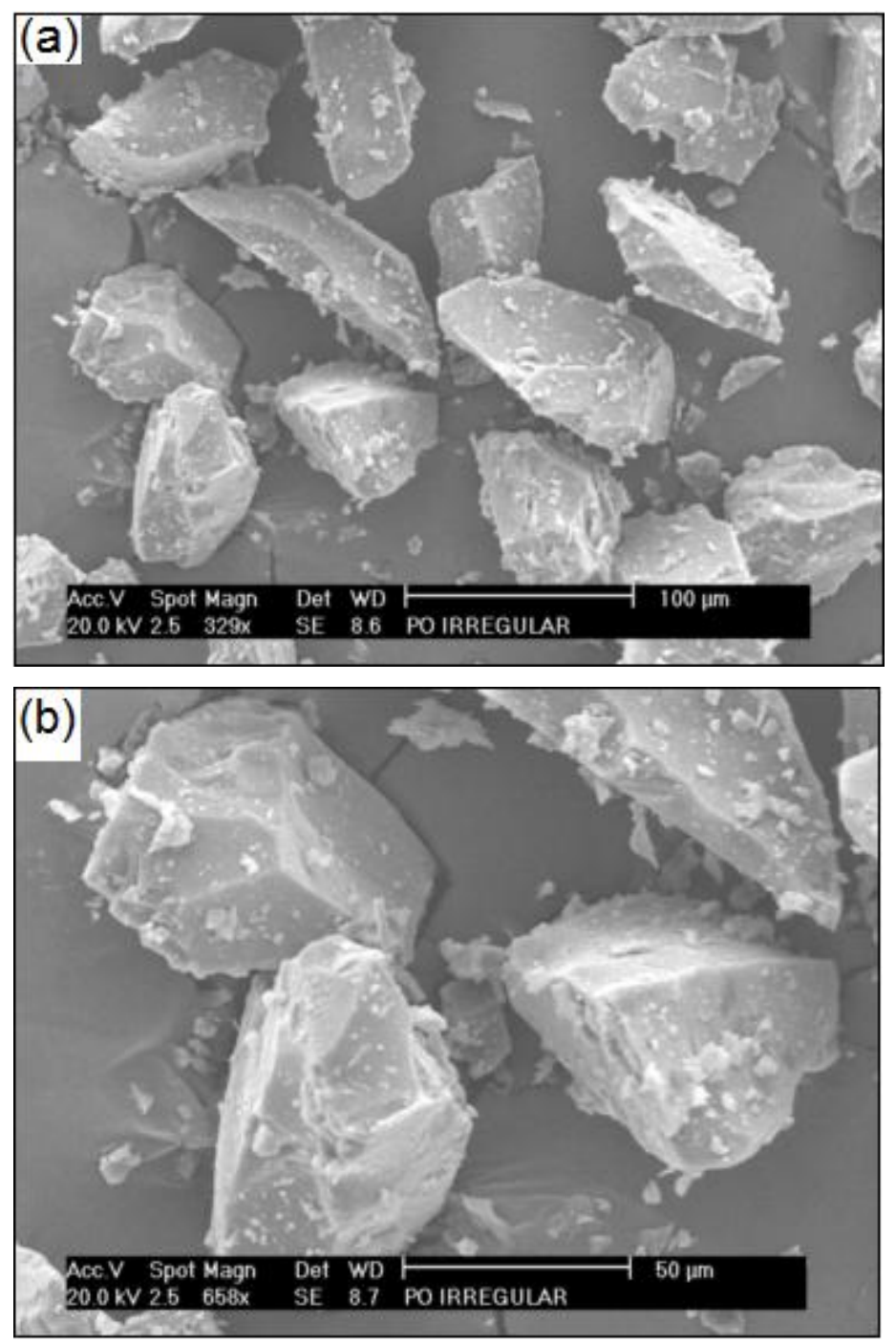

(c)

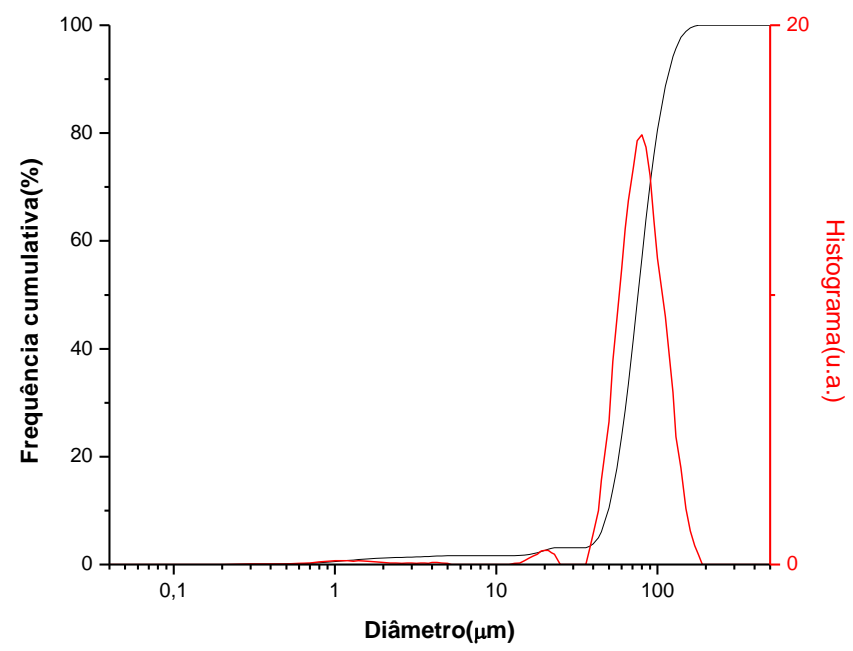

FIGURA 25 - Material precursor com granulometria entre $45 \mu \mathrm{m}<\Phi<63 \mu \mathrm{m}$ (a) e (b) MEV; (c) Distribuição granulométrica $\langle\Phi\rangle=62 \mu \mathrm{m}$. 

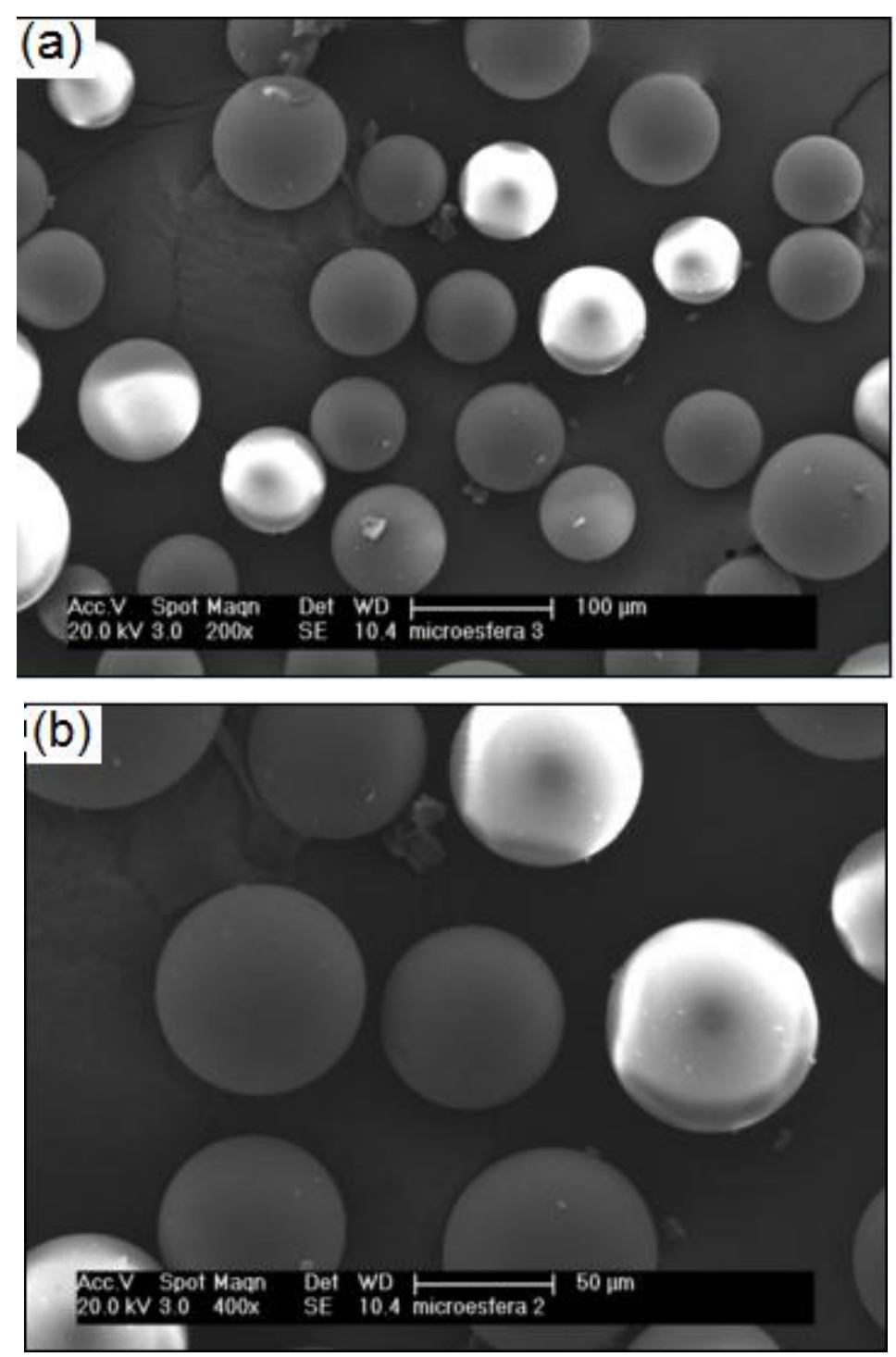

(c)

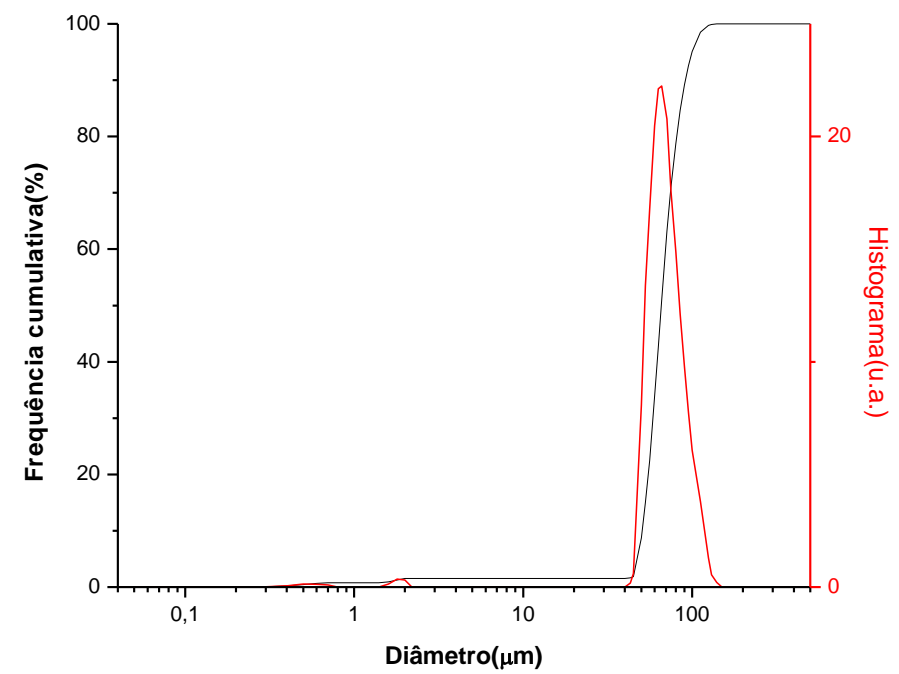

FIGURA 26 - Microesferas obtidas a partir de material precursor com granulometria entre $56 \mu \mathrm{m}<\phi<63 \mu \mathrm{m}$ (a) e (b) MEV; (c) Distribuição granulométrica $\langle\Phi>=68 \mu \mathrm{m}$. 


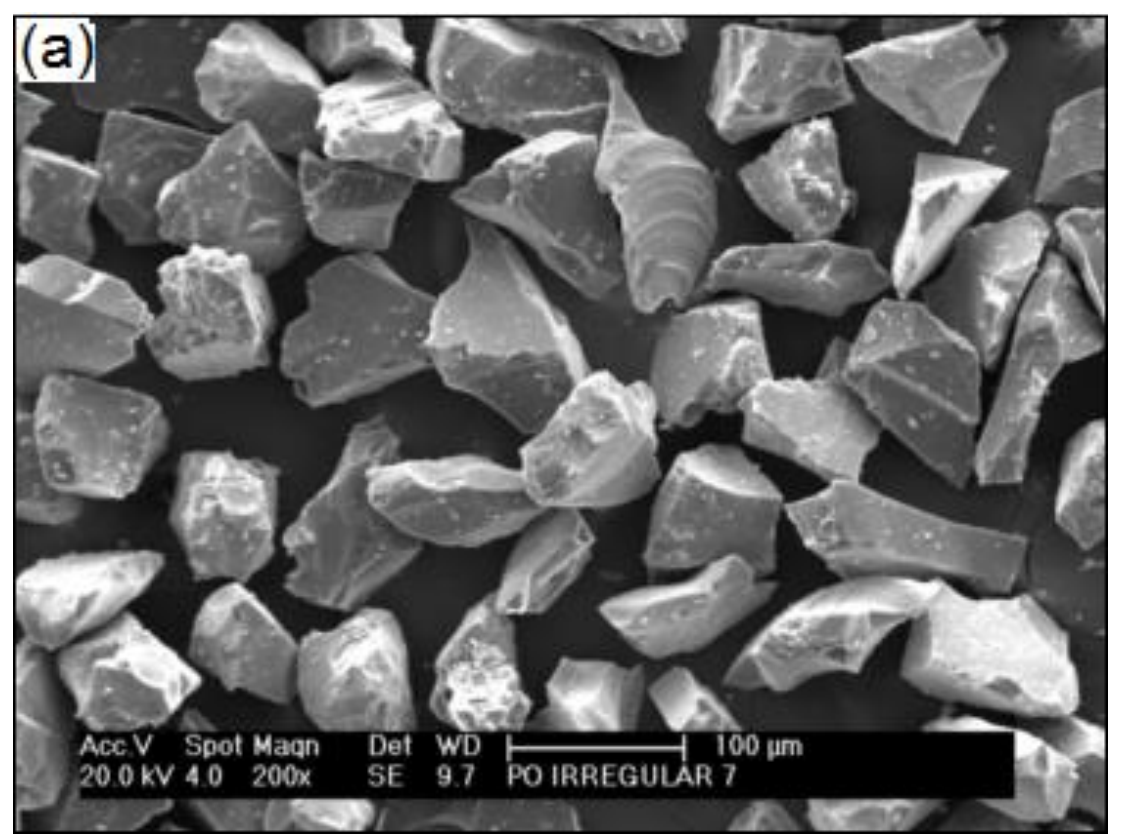

(b)

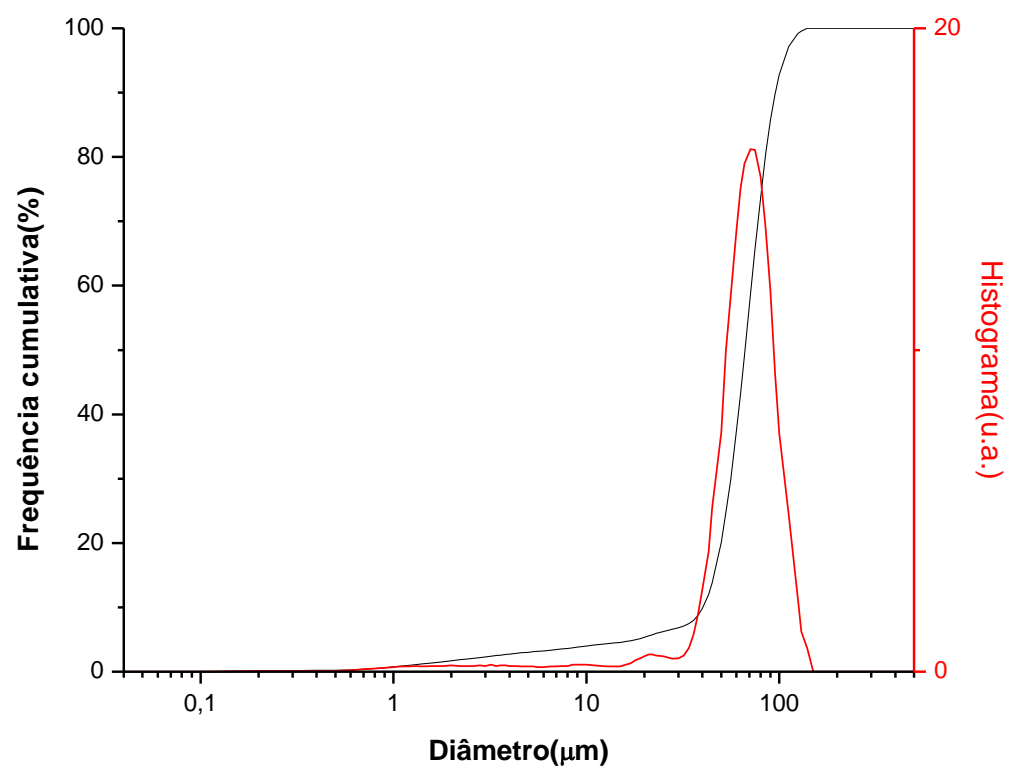

FIGURA 27 - Material precursor com granulometria entre $56 \mu \mathrm{m}<\Phi<63 \mu \mathrm{m}$ (a) MEV;

(b) Distribuição granulométrica $\langle\Phi\rangle=66 \mu \mathrm{m}$. 


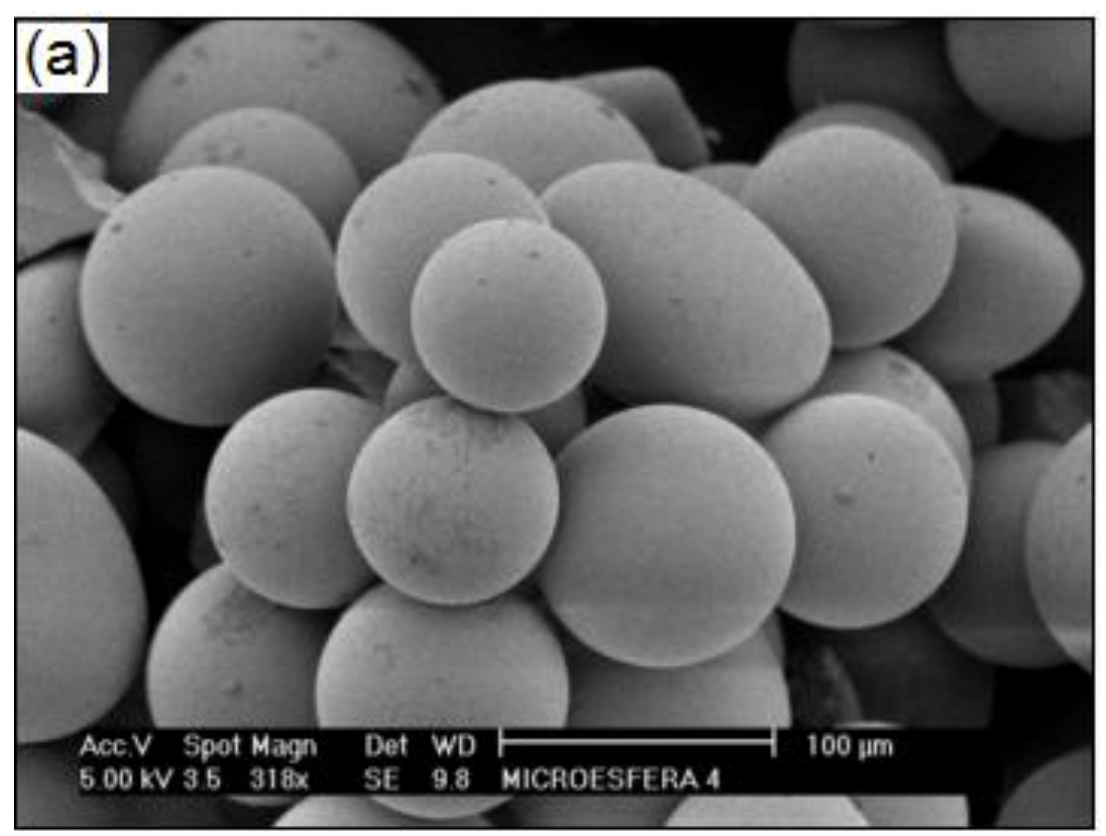

(b)

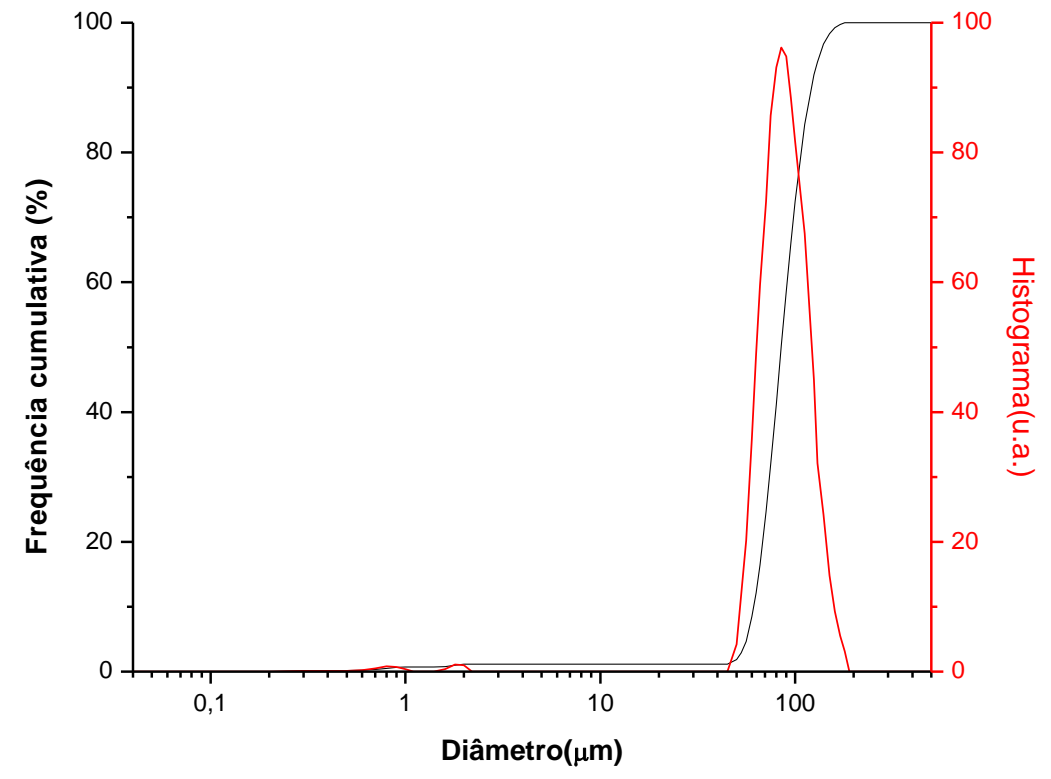

FIGURA 28 - Microesferas obtidas a partir de material precursor com granulometria entre $63 \mu \mathrm{m}<\Phi<106 \mu \mathrm{m}$ (a) MEV; (b) Distribuição granulométrica $<\Phi>=88 \mu \mathrm{m}$. 


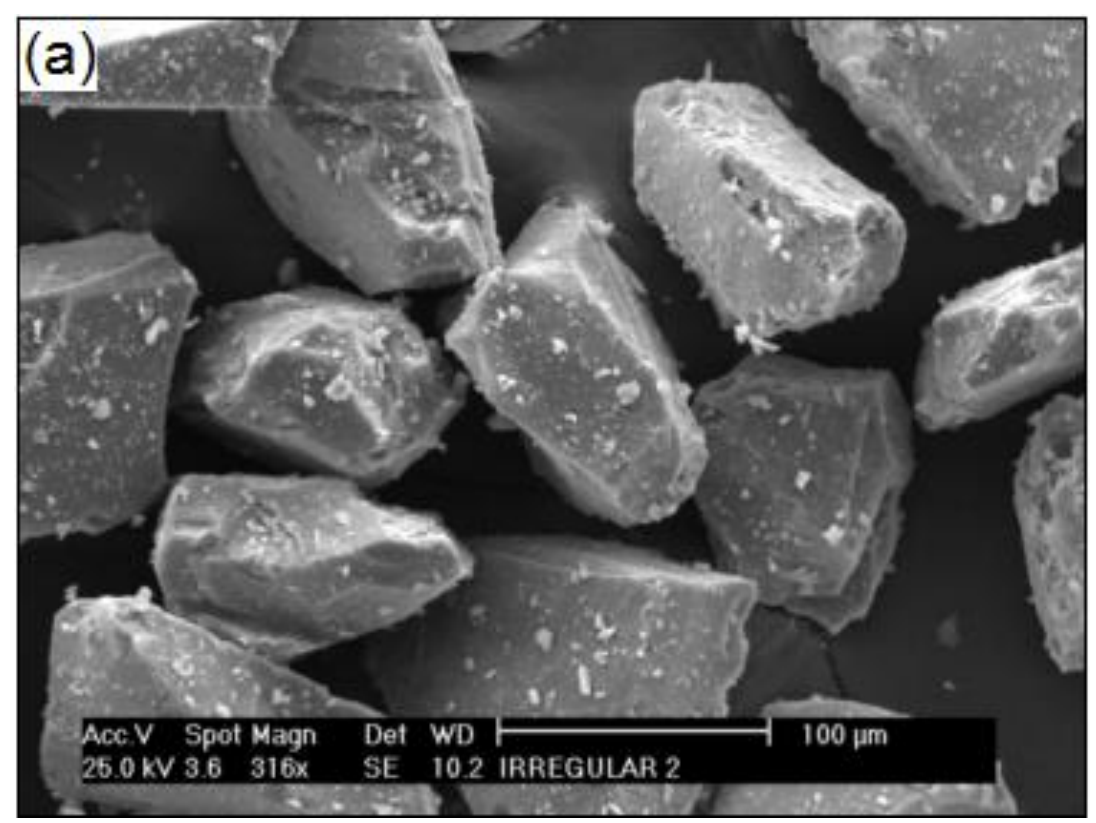

(b)

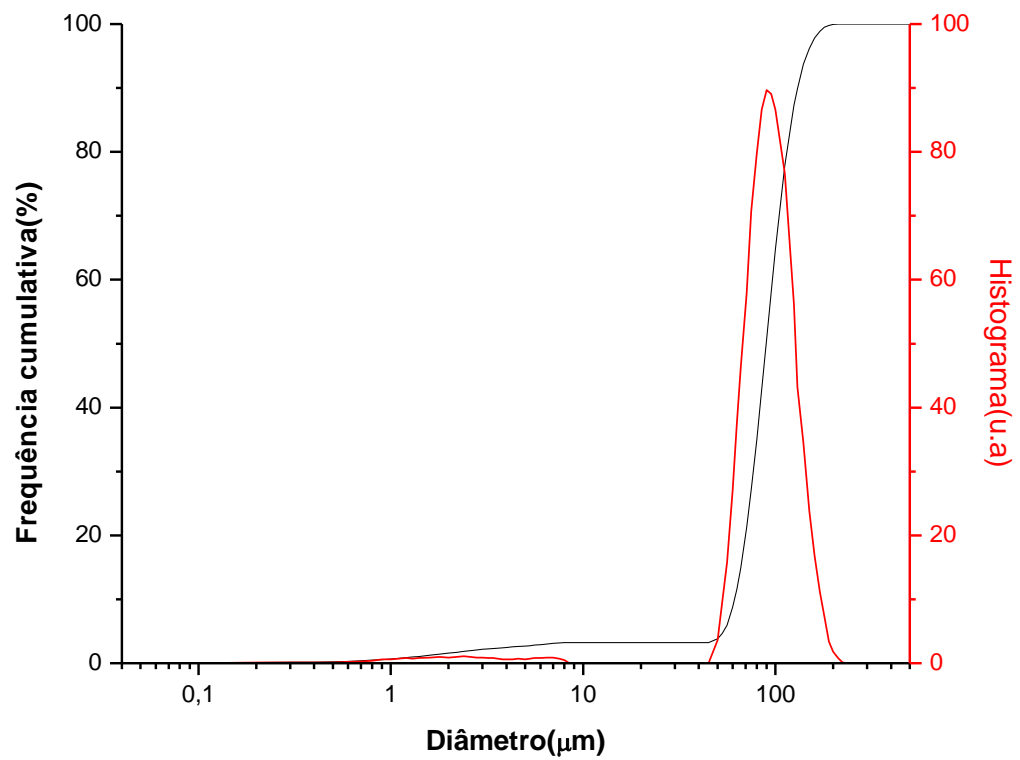

FIGURA 29 - Material precursor com granulometria entre $63 \mu \mathrm{m}<\Phi<106 \mu \mathrm{m}$ (a) MEV; (b) Distribuição granulométrica $\langle\Phi\rangle=92 \mu \mathrm{m}$. 
Não foi possível obter microesferas com morfologia adequada a partir do material precursor com granulometria entre $0<\phi<38 \mu \mathrm{m}$. O pó apresentou alta aglomeração e pouca fluidez e o resultado do processo de esferolização foram partículas disformes. Tentou-se lançar novamente essas partículas na chama supondo-se que os aglomerados formados poder-se-iam tornar microesferas com diâmetro adequado desde que eles não fossem suficientemente grandes e possuíssem baixo atrito, o que foi notado pela melhor fluidez do pó na espátula vibratória; no entanto, a micrografia apresentada na FIG.18(a) mostra que as microesferas resultantes são inadequadas morfologicamente para o objetivo deste trabalho. Como mostrado na Fig.19(a) o material precursor é muito fino possuindo diâmetro máximo da ordem de $30 \mu \mathrm{m}$, implicando em alta superfície específica do pó e consequente aumento do atrito entre as partículas, o que gerou a presença de aglomerados. A grande maioria destas partículas não foi capaz de adquirir o formato esférico após o processo de esferolização.

Nos demais casos em que o material precursor foi peneirado em diversas granulometrias, foi possível obter microesferas morfologicamente satisfatórias. As curvas de distribuição granulométrica das microesferas podem ser consideradas aproximadamente como unimodais ao passo que as relativas ao material precursor mostraram-se, em muitos casos, características de uma distribuição bimodal. O diâmetro médio das microesferas e o diâmetro equivalente do material precursor são apresentados nas TAB. 5 e 6 , respectivamente.

TABELA 5 - Distribuição do tamanho de microesferas Distribuição do tamanho de microesferas $(\mu \mathrm{m})$

\begin{tabular}{cccccc}
\hline & & & & & diâmetro \\
granulometria do material precursor $(\mu \mathrm{m})$ & $D 10 \%$ & $D 50 \%$ & $D 90 \%$ & médio \\
$0<\Phi<38$ & 38,76 & 105,63 & 172,05 & 106,55 \\
$38<\Phi<63$ & 50,79 & 105,64 & 199,95 & 116,73 \\
$\mathbf{4 0}<\boldsymbol{\Phi}<\mathbf{5 3}$ & $\mathbf{4 3 , 8 3}$ & $\mathbf{6 0 , 6 2}$ & $\mathbf{8 8 , 2 0}$ & $\mathbf{6 3 , 2 6}$ \\
$45<\Phi<56$ & 45,86 & 64,45 & 93,76 & 67,14 \\
$45<\Phi<63$ & 48,99 & 75,63 & 115,74 & 78,49 \\
$56<\Phi<63$ & 50,59 & 65,65 & 91,20 & 68,02 \\
$63<\Phi<106$ & 61,24 & 84,87 & 121,49 & 88,06 \\
\hline \hline
\end{tabular}


TABELA 6 - Distribuição do tamanho de partículas

Distribuição do tamanho de partículas irregulares $(\mu \mathrm{m})$

diâmetro

$\begin{array}{ccccc}\text { granulometria do material precursor }(\mu \mathrm{m}) & D 10 \% & D 50 \% & D 90 \% & \text { médio } \\ 0<\Phi<38 & 1,62 & 12,07 & 23,93 & 12,44 \\ 38<\Phi<63 & 3,02 & 33,28 & 67,03 & 33,98 \\ 40<\Phi<53 & 22,35 & 56,82 & 94,29 & 58,69 \\ 45<\Phi<56 & 30,56 & 52,96 & 75,92 & 52,12 \\ 45<\Phi<63 & 19,07 & 63,30 & 95,87 & 62,41 \\ 56<\Phi<63 & 40,23 & 66,43 & 95,43 & 66,27 \\ 63<\Phi<106 & 61,28 & 89,55 & 130,42 & 91,89\end{array}$

Estes resultados aliados àqueles obtidos inicialmente sugerem que quando o limite inferior da granulometria do material precursor obtido por peneiramento é menor que $40 \mu \mathrm{m}$ observa-se a presença de partículas satélites (finos) que geram grande atrito e provocam aglomeração entre um grupo de partículas pequenas e grandes durante o translado da espátula vibratória até a queda na chama. As microesferas obtidas apresentam um diâmetro médio muito maior do que o diâmetro equivalente do material precursor (vide microesferas obtidas pelo material precursor separado na faixa de $38 \mu \mathrm{m}<\phi<63 \mu \mathrm{m})$. Quando o limite inferior da faixa granulométrica do material precursor é aumentado, eliminam-se muitas partículas pequenas que se aglomerariam em partículas maiores e, portanto, ocorre a diminuição do atrito entre as partículas e consequente diminuição da ocorrência de aglomerados, obtendo-se microesferas com morfologia adequada e diâmetro médio menor. Entretanto, o diâmetro médio das microesferas volta a aumentar se o limite inferior do material precursor aumentar para valores maiores que $63 \mu \mathrm{m}$. Notou-se que esta variável é uma das mais importantes para o controle do diâmetro das microesferas e que nas condições que o experimento foi realizado, a granulometria do material precursor mais adequado foi entre $40 \mu \mathrm{m}<\Phi<53 \mu \mathrm{m}$ em que as microesferas resultantes apresentaram diâmetro médio próximo de $\langle\Phi\rangle=63 \mu \mathrm{m}$. O histograma mostrado na FIG. 30 apresenta a dependência do diâmetro médio das microesferas com a granulometria do material precursor utilizado: 


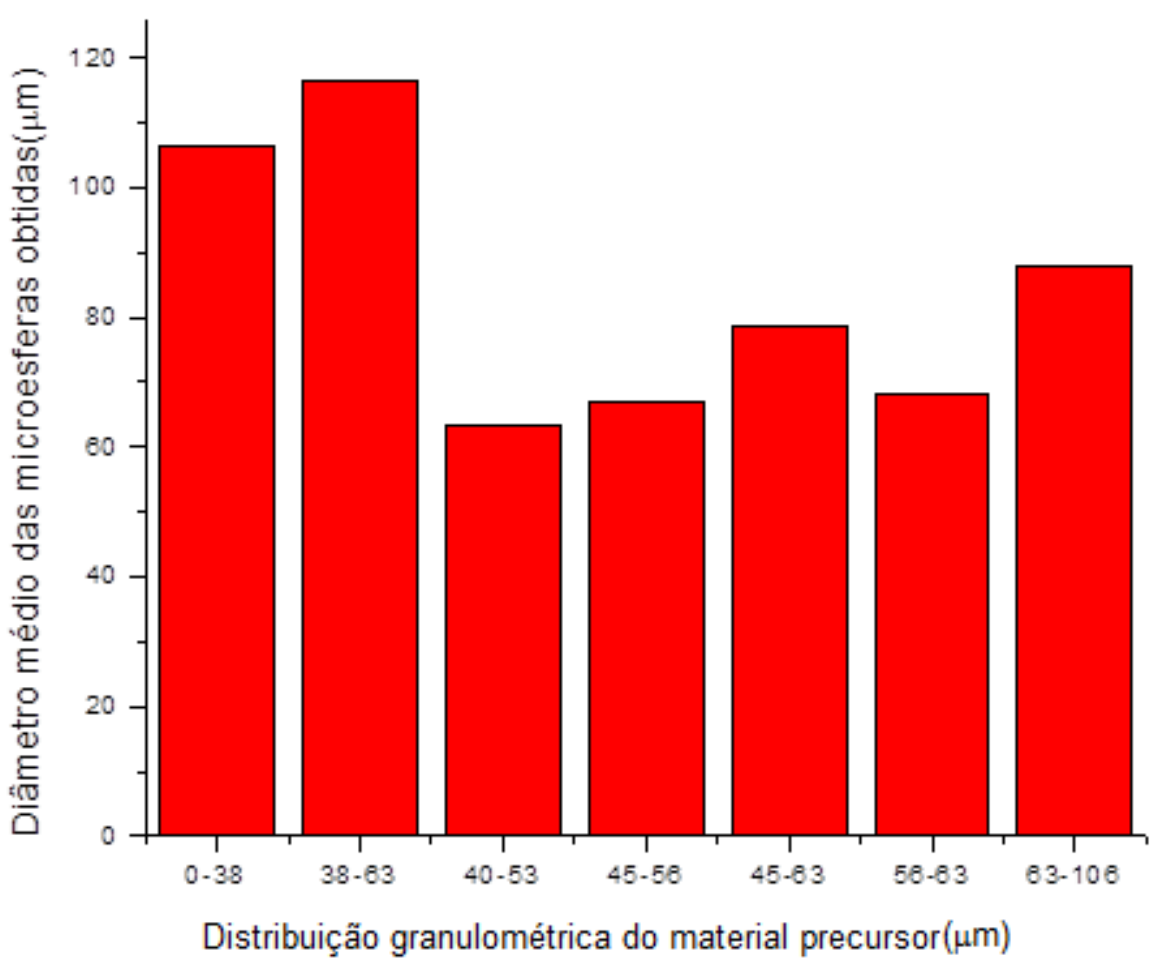

FIGURA 30 - Dependência do diâmetro médio das microesferas com a granulometria do material precursor. 


\subsubsection{Temperatura da chama}

No processo de esferolização por chama, variou-se a temperatura da chama controlando-se a pressão de saída do combustível (gás GLP) e do comburente $\left(\mathrm{O}_{2}\right)$. As imagens obtidas por MEV e distribuição granulométrica das partículas sintetizadas são mostradas nas FIG. 31 a 34.

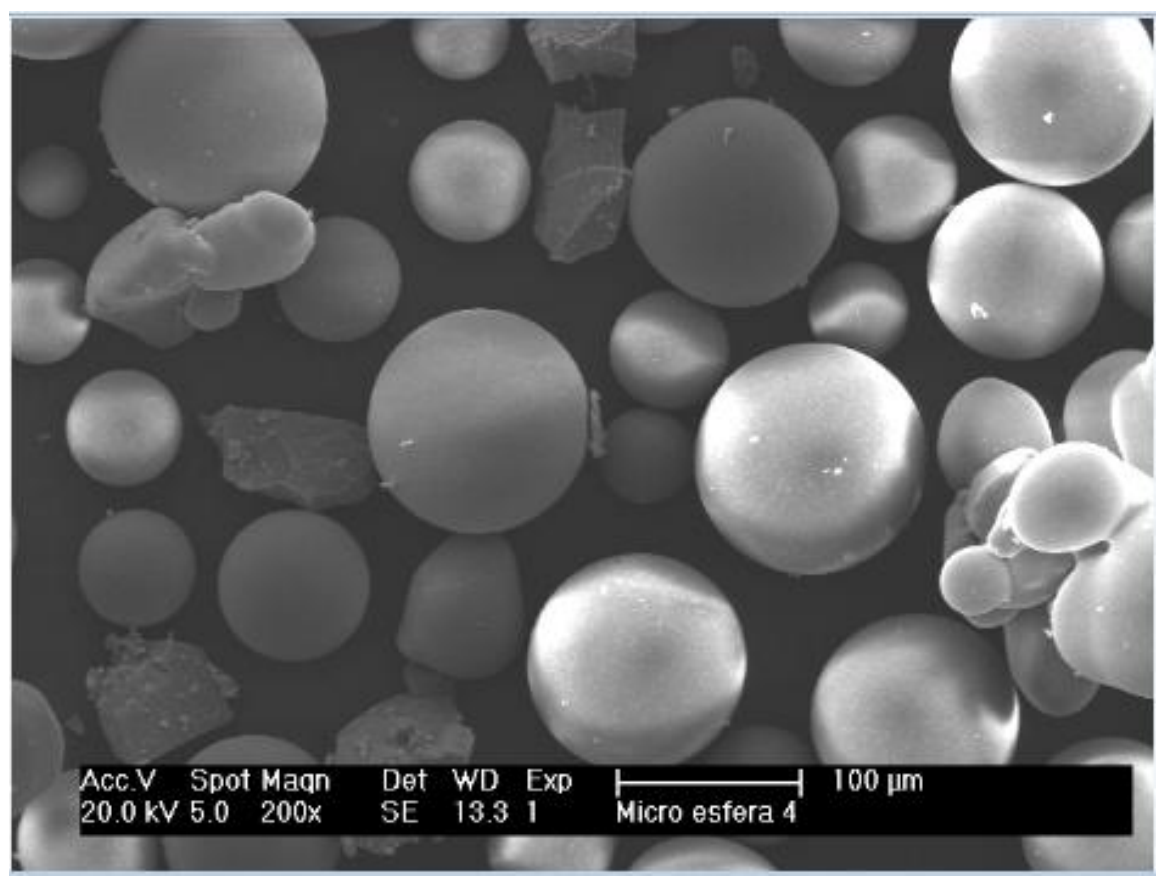

FIGURA 31 - Micrografias (MEV) das microesferas produzidas em chama "fria" com pressão de saída de $1,5 \mathrm{kgf} / \mathrm{cm}^{2}$ do gás GLP e $1,0 \mathrm{kgf} / \mathrm{cm}^{2}$ do comburente $\left(\mathrm{O}_{2}\right)$.

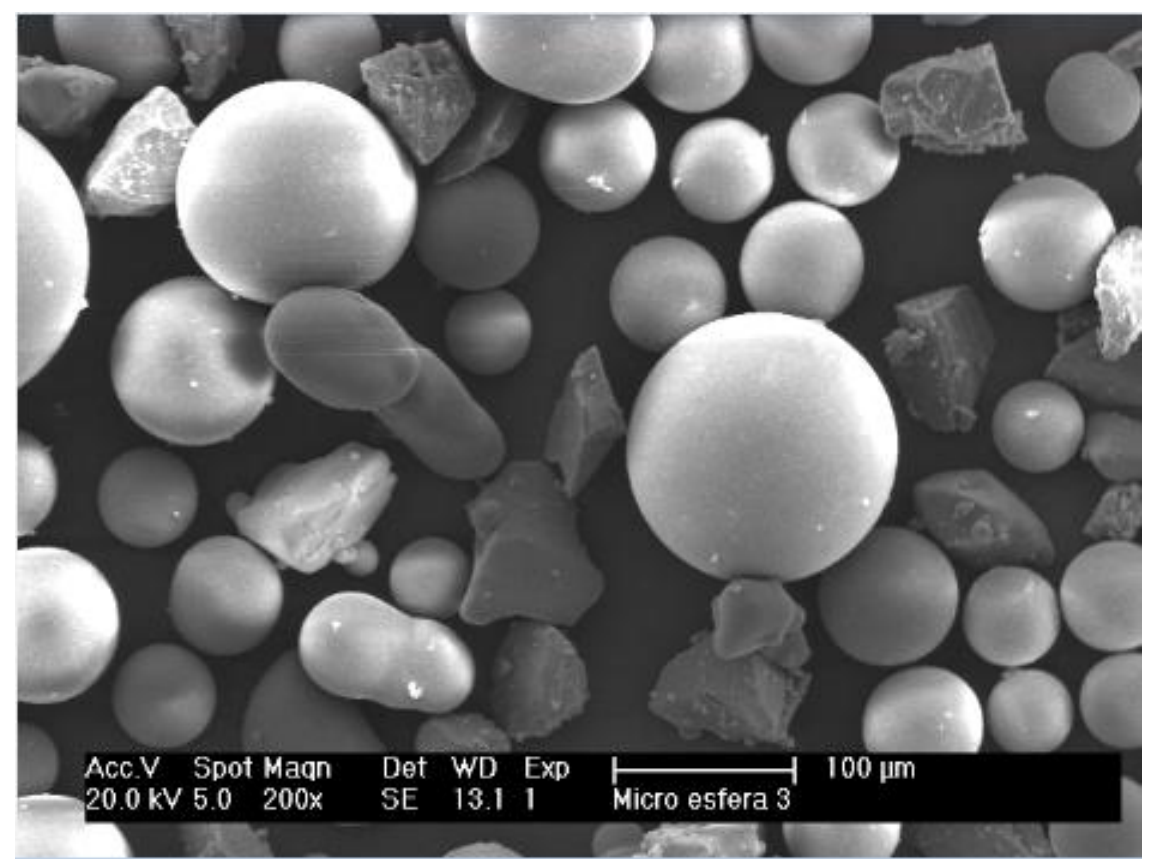

FIGURA 32 - Micrografias (MEV) de microesferas produzidas em chama "fria" com pressão de saída de $2,4 \mathrm{kgf} / \mathrm{cm}^{2}$ do gás GLP e de $1,5 \mathrm{kgf} / \mathrm{cm}^{2}$ do comburente $\left(\mathrm{O}_{2}\right)$. 


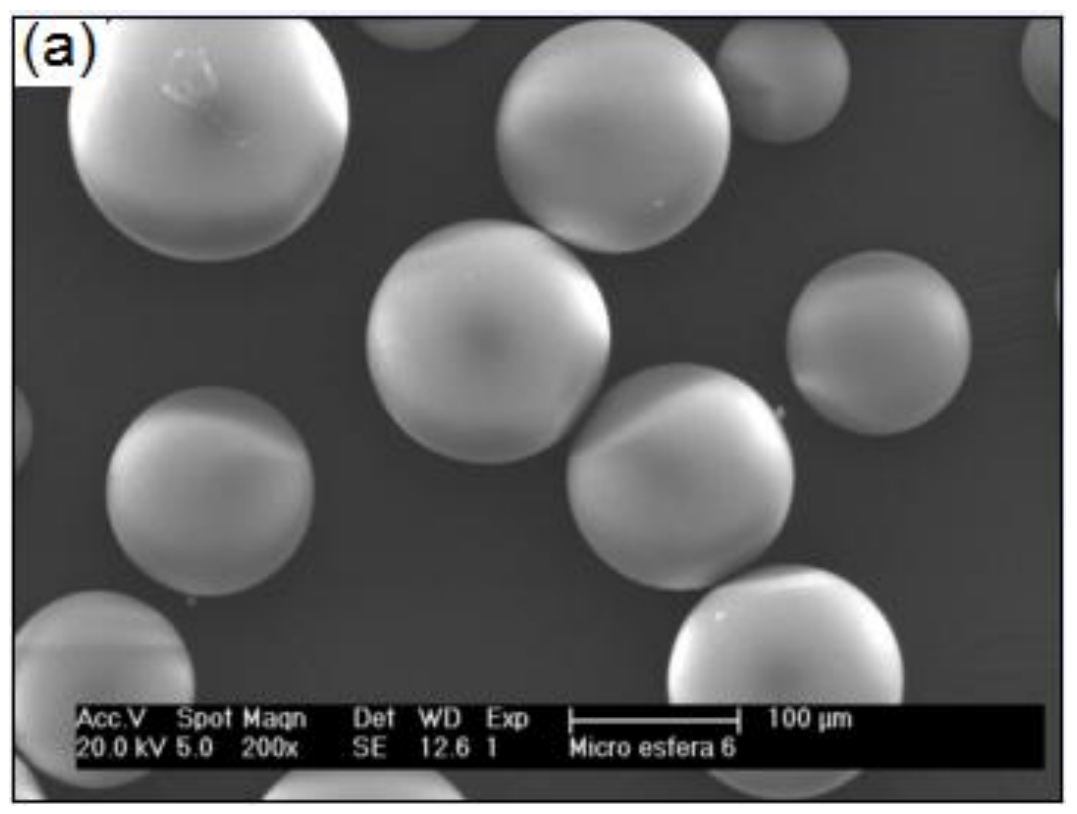

(b)

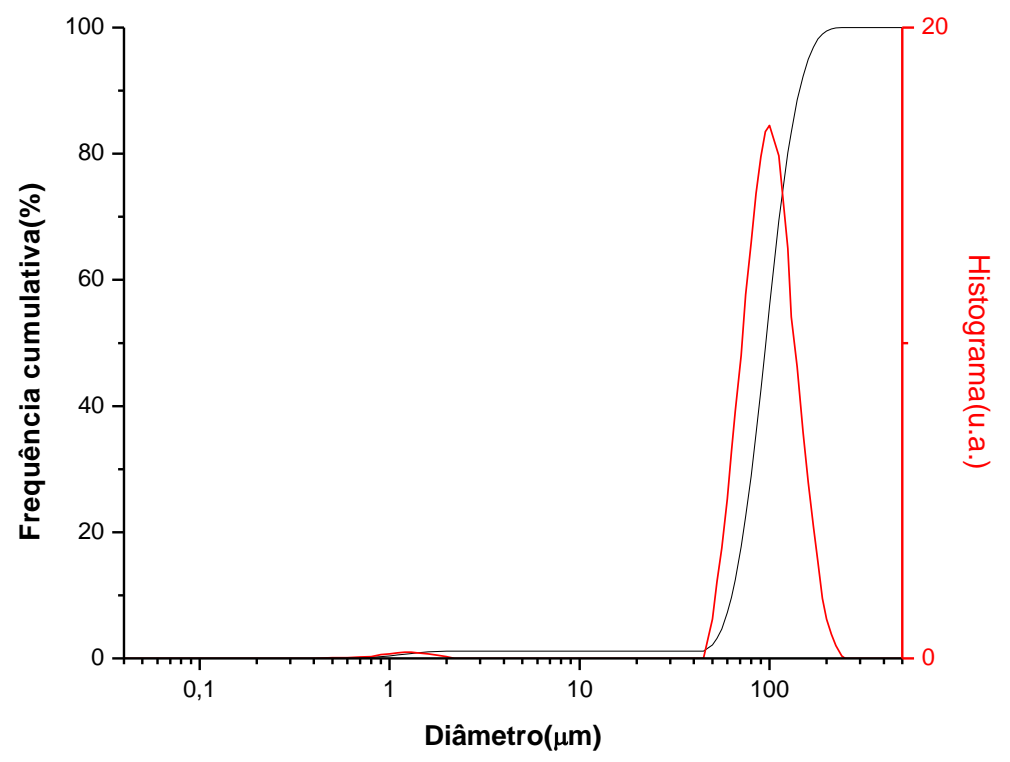

FIGURA 33 - Microesferas produzidas em chama "quente" com pressão de saída de $1,35 \mathrm{kgf} / \mathrm{cm}^{2}$ do gás GLP e de $2,5 \mathrm{kgf} / \mathrm{cm}^{2}$ do comburente $\left(\mathrm{O}_{2}\right)$. (a) MEV (b) Distribuição granulométrica $<\Phi>=92 \mu \mathrm{m}$. 


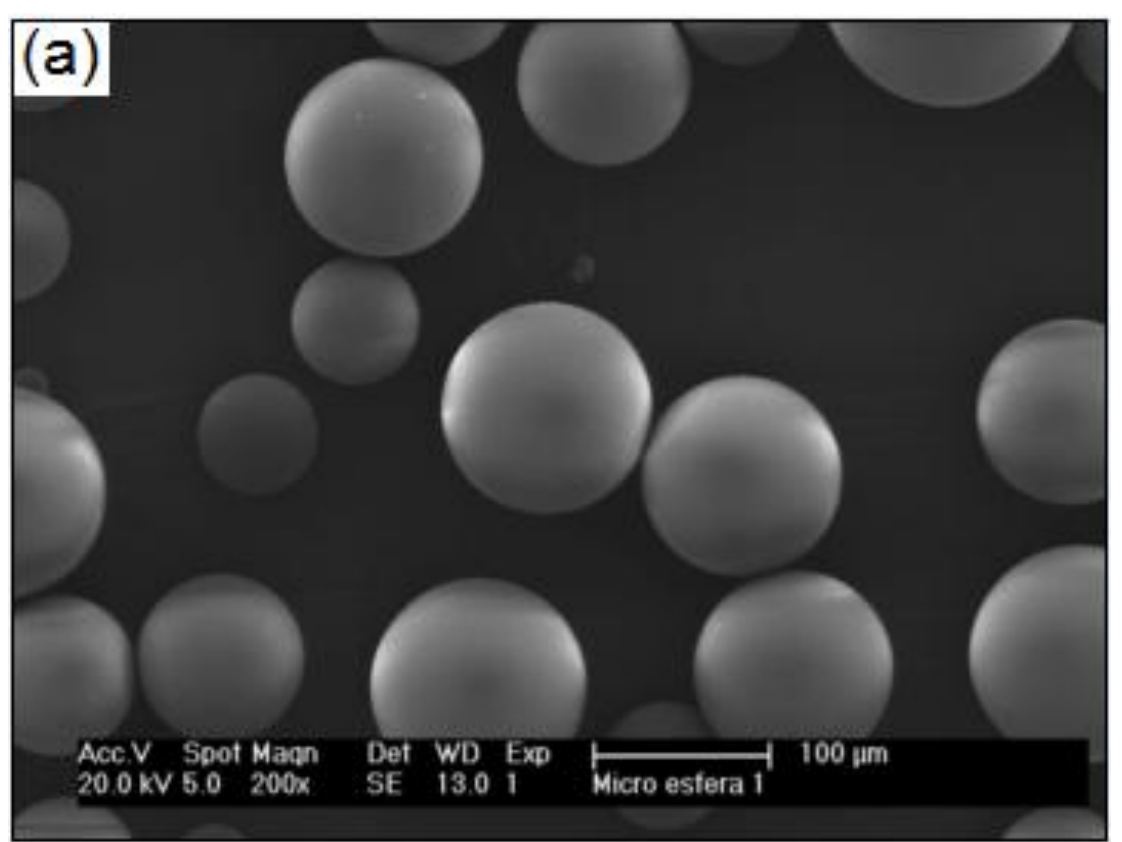

(b)

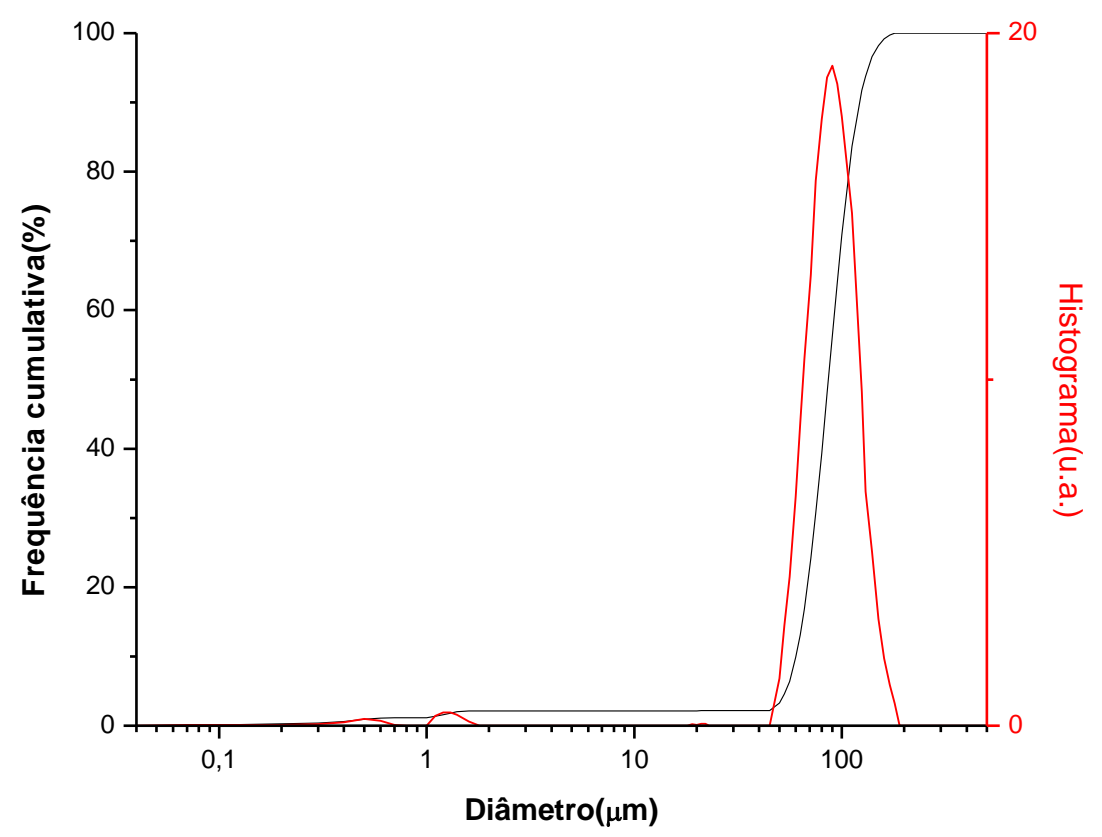

FIGURA 34 - Microesferas produzidas em chama "quente" com pressão de saída de 1,5 $\mathrm{kgf} / \mathrm{cm}^{2}$ e de $3,0 \mathrm{kgf} / \mathrm{cm}^{2}$ do comburente $\left(\mathrm{O}_{2}\right)$ (a) $\mathrm{MEV}$ (b) Distribuição granulométrica $<\Phi>=88 \mu \mathrm{m}$. 
Estes resultados indicam que as temperaturas da chama utilizadas quando as pressões de saída do combustível e comburente foram aquelas usadas nos casos das FIG. 31 e 32(chamas "frias") não foram adequadas para obtenção de microesferas morfologicamente satisfatórias para o objetivo deste trabalho, pois muitas partículas irregulares não tornaram-se esféricas. Este fato pode estar relacionado com a temperatura da chama que não foi alta o suficiente para diminuir a viscosidade do vidro de modo adequado a este comportar-se homogeneamente como um líquido. Nos processos onde foi possível obter microesferas com formato adequado (chamas "quentes"), notou-se um pequeno aumento no diâmetro médio das microesferas produzidas nas condições da FIG. 33 em relação àquelas produzidas nas condições da FIG. 34. As distribuições do tamanho de microesferas apresentadas nas curvas das FIG. 33(b) e 34(b) são unimodais e centradas em $\langle\phi\rangle=92 \mu \mathrm{m}$ e $\langle\phi\rangle=88 \mu \mathrm{m}$, respectivamente. Estes resultados indicam que a temperatura da chama influencia a forma das microesferas, mas muito pouco o diâmetro médio. 


\subsubsection{Tempo de voo}

Os efeitos causados pelo tempo de voo das partículas durante o processo de esferolização por chama foram avaliados dividindo-se o percurso das microesferas em duas partes, sendo que aquelas coletadas na primeira parte (próximo à chama) possuíam um tempo de voo "curto" e aquelas coletadas na segunda parte (mais afastadas da chama) possuíam um tempo de voo "longo". Os resultados são mostrados nas FIG. 35 e 36:

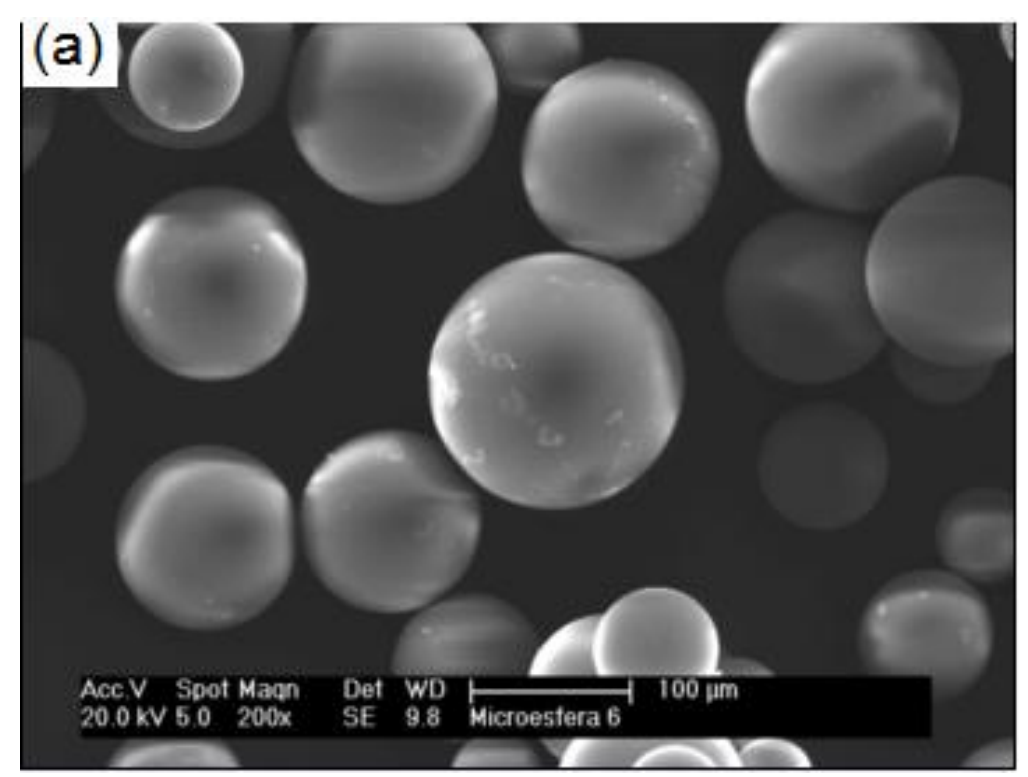

(b)

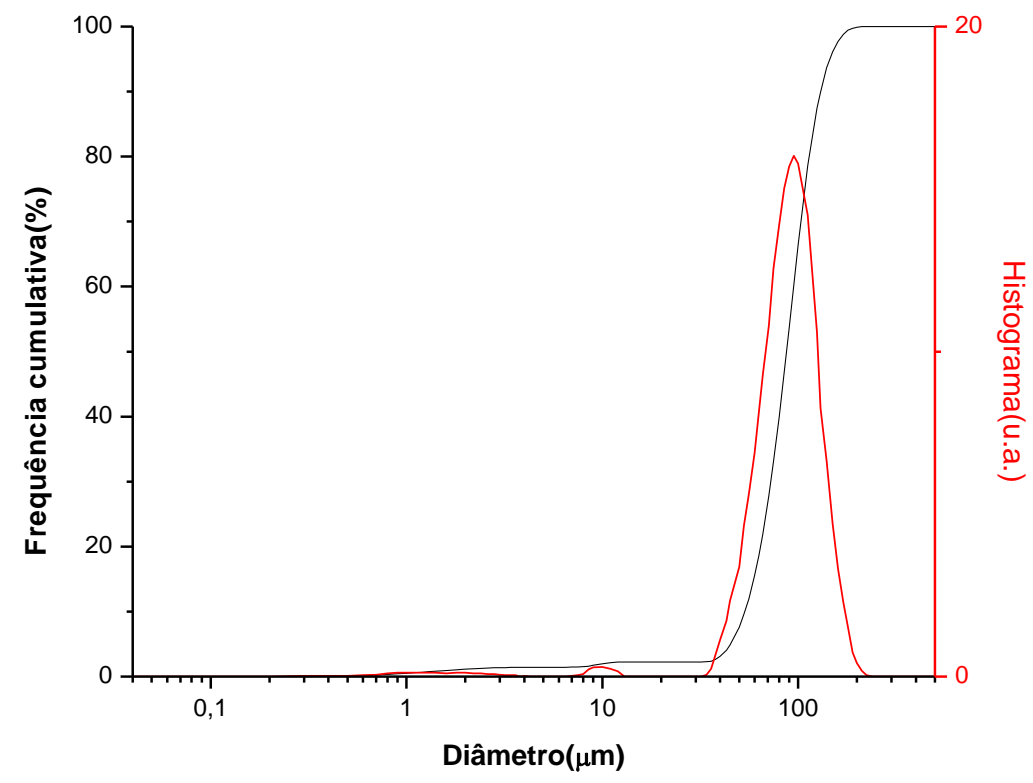

FIGURA 35 - Microesferas coletadas na primeira metade do percurso total (tempo de voo "curto") (a) MEV (b) Distribuição granulométrica $<\Phi>=89 \mu \mathrm{m}$. 


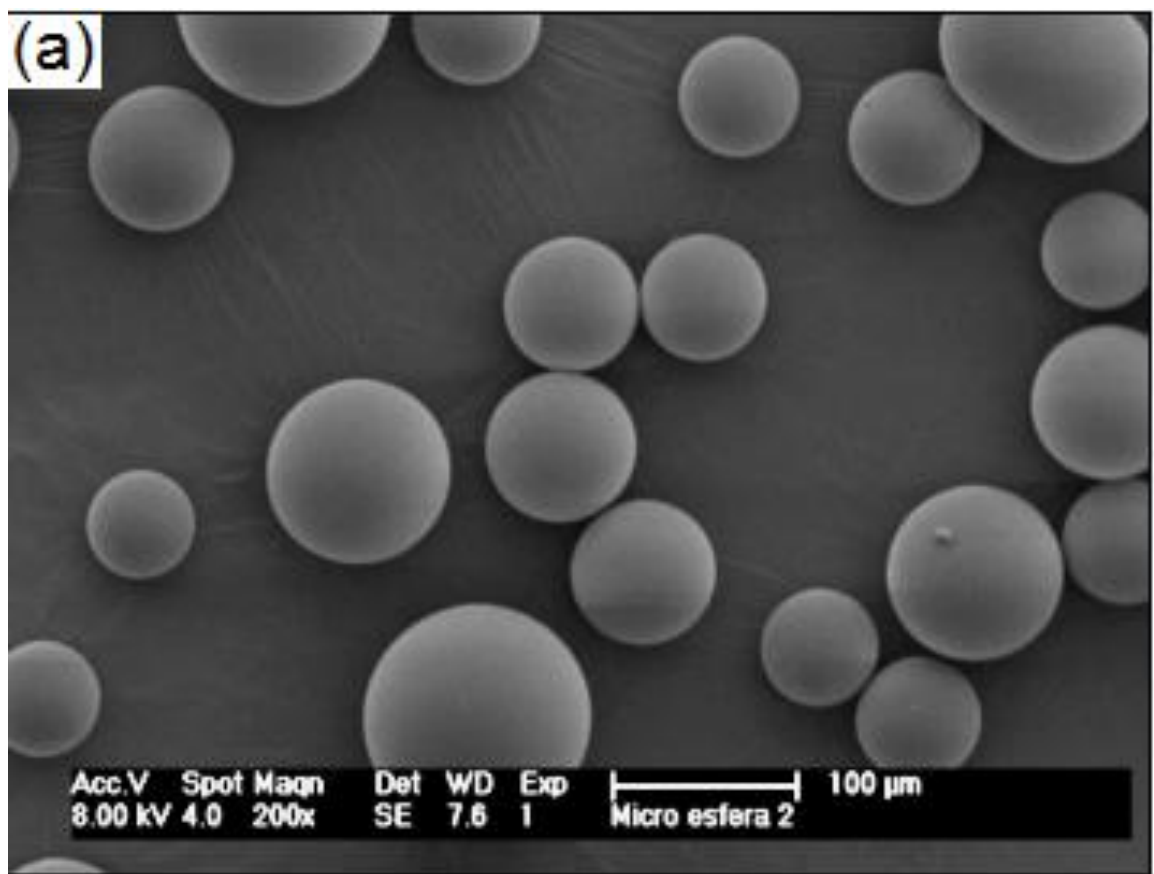

(b)

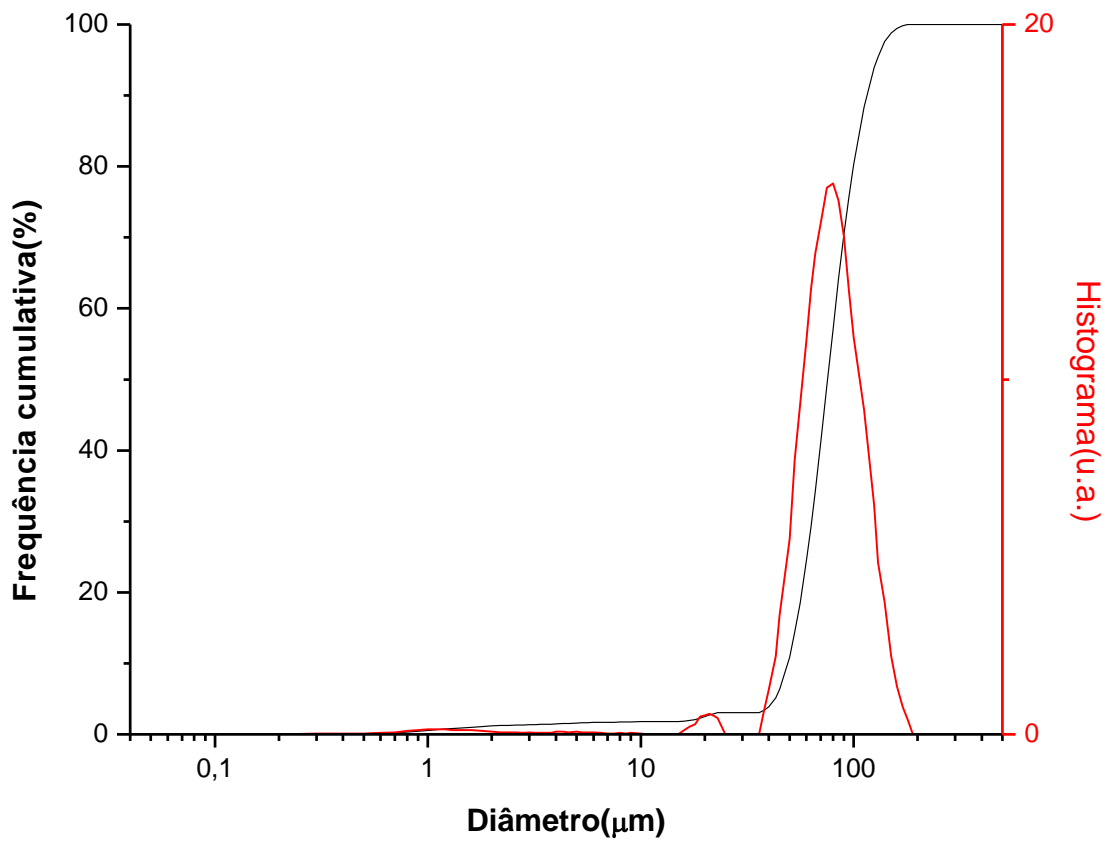

FIGURA 36 - Microesferas coletadas na segunda metade do percurso total (tempo de voo "longo") (a) MEV (b) Distribuição granulométrica $<\Phi>=78 \mu \mathrm{m}$. 
Pelos resultados obtidos, notou-se que as microesferas produzidas na primeira metade do percurso e, portanto, que possuíam um tempo de voo "curto", apresentaram um aumento no diâmetro médio $(\langle\phi\rangle=89 \mu \mathrm{m})$ em comparação com as microesferas encontradas na segunda metade do percurso e que possuíam um tempo de voo "longo" ( $\langle\phi\rangle=78 \mu \mathrm{m})$. Nos dois casos, nota-se que a morfologia das microesferas mostrou-se adequada para finalidade do presente trabalho.

\subsubsection{Esferolização por queda gravitacional}

\subsubsection{Fluxo de ar ascendente}

Foram avaliados os efeitos da variação do parâmetro de processo "fluxo de ar ascendente" nas características das microesferas produzidas pelo processo de esferolização por queda gravitacional nas condições iniciais descritas na seção 4.2.4.2 . As micrografias de MEV correspondentes são mostradas nas FIG. 37 a 39:

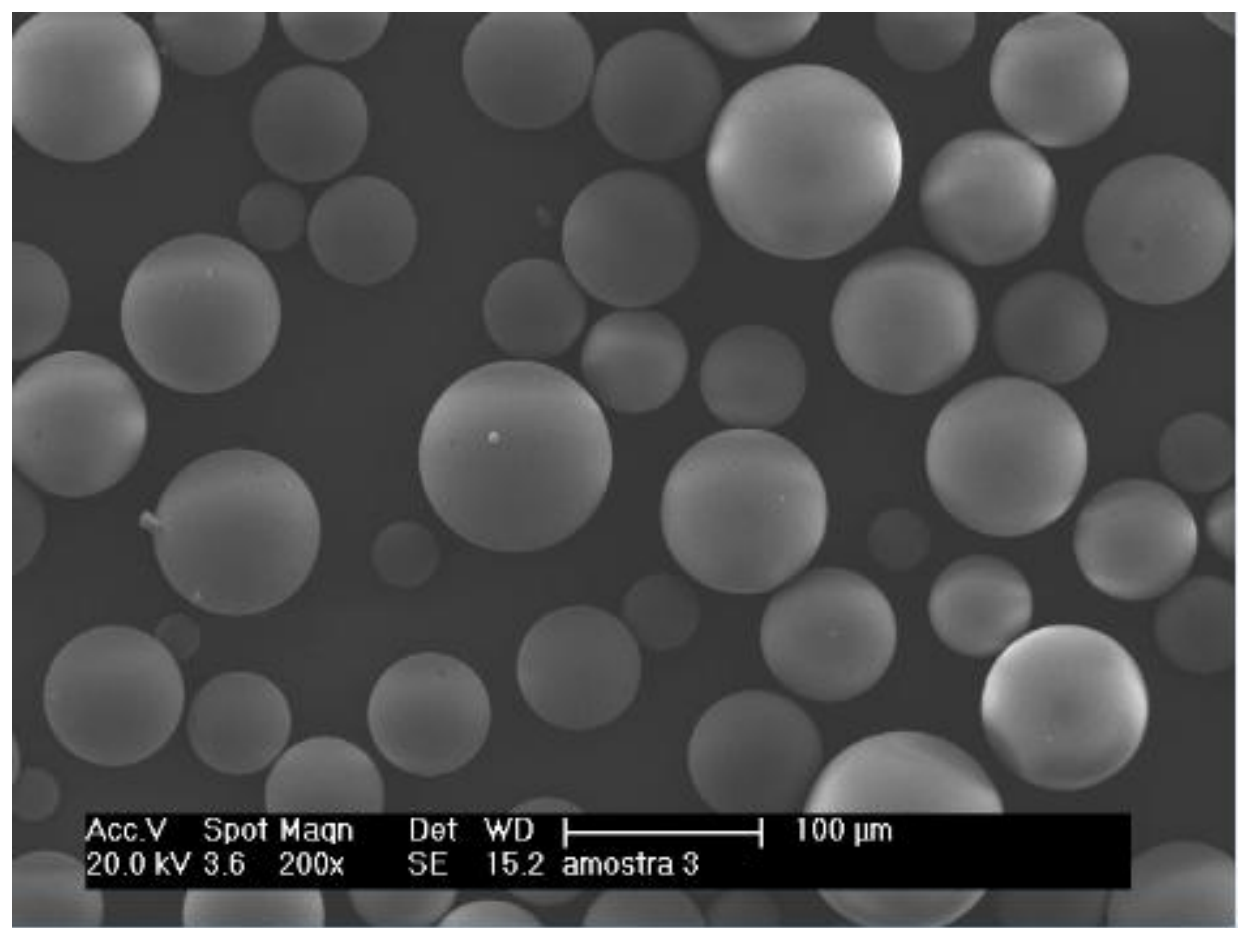

FIGURA 37 - Micrografias (MEV) das microesferas produzidas sob fluxo de ar ascendente "fraco". 


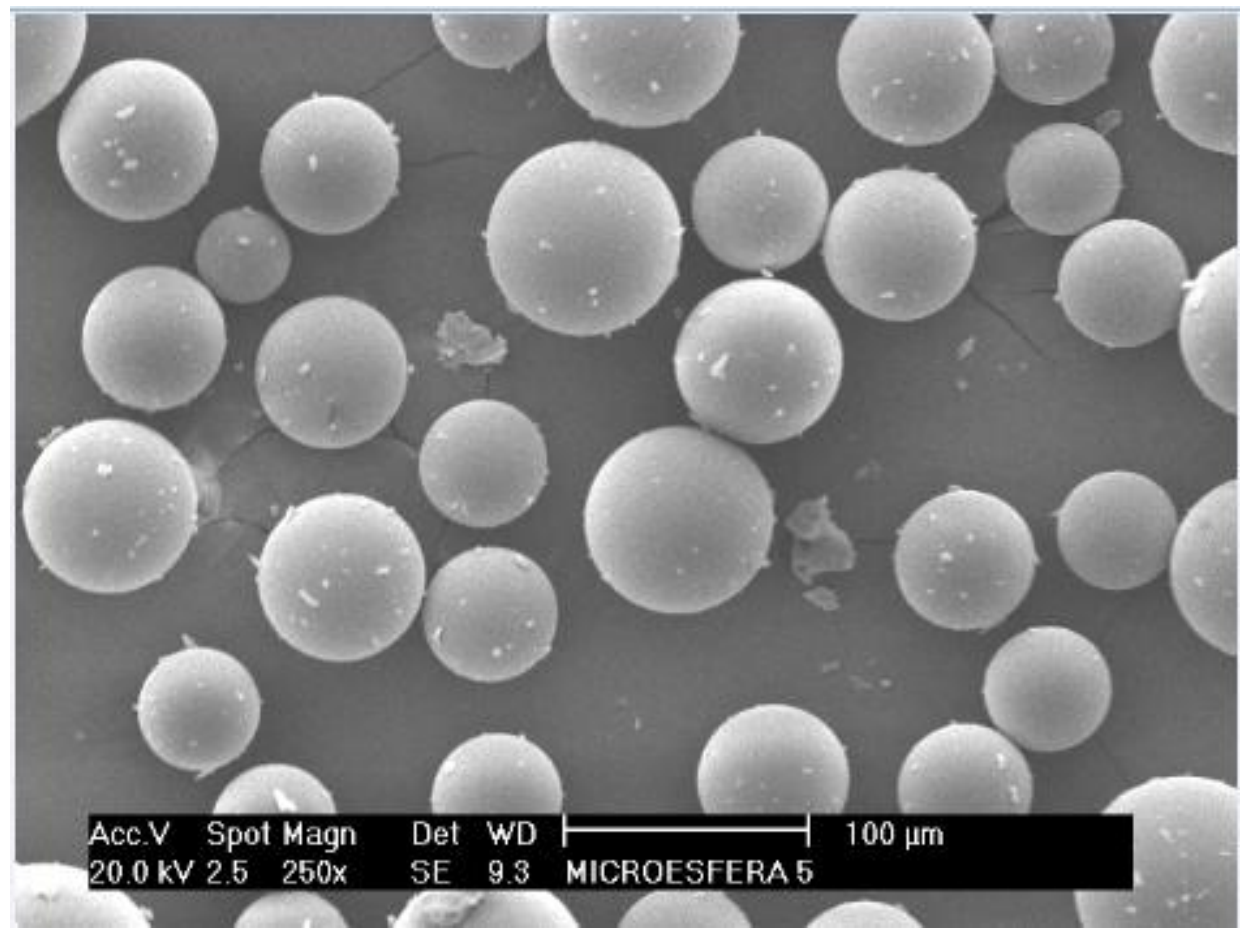

FIGURA 38 - Micrografias das microesferas produzidas sob fluxo de ar ascendente "médio".

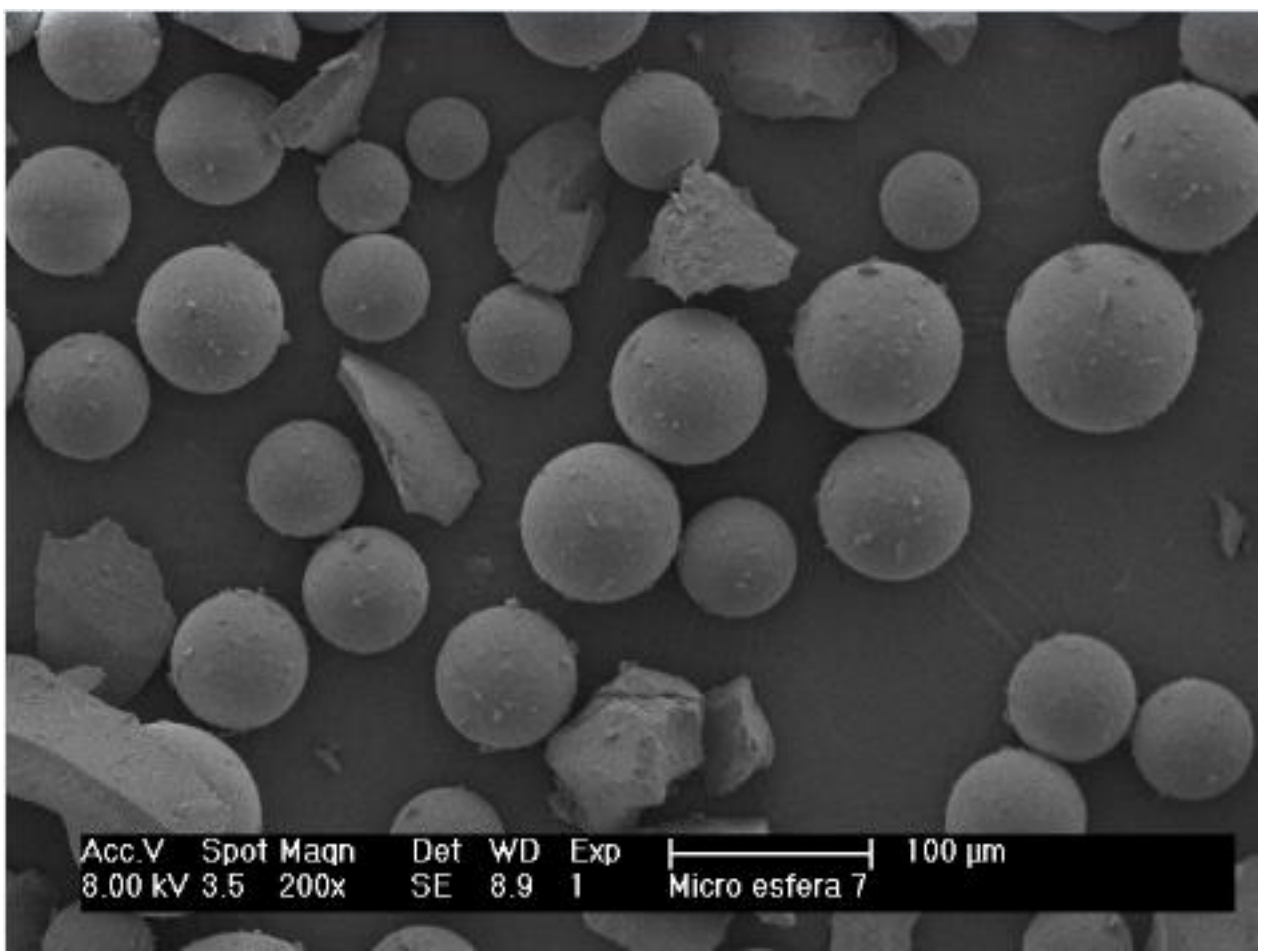

FIGURA 39 - Micrografias das microesferas produzidas sob fluxo de ar ascendente "forte".

Estas micrografias mostram que fluxos de ar ascendente "médios" e "fortes" tendem a prejudicar a morfologia das microesferas e mostram a presença de partículas 
satélites na superfície das microesferas . Notou-se que na presença desses fluxos há a aglomeração de muitas partículas na saída do tubo de alumina para o forno. Quando o fluxo é reduzido para "fraco", a aglomeração das partículas no tubo de alumina cessa de ocorrer e nota-se um grau superior de esferolização das partículas como mostrado na FIG 37.

\subsubsection{Temperatura da zona aquecida do forno.}

Foram avaliados os efeitos da variação da temperatura da zona aquecida nas características das microesferas produzidas pelo processo de esferolização por queda gravitacional. As temperaturas analisadas foram $1200^{\circ} \mathrm{C}, 1380^{\circ} \mathrm{C}, 1460^{\circ} \mathrm{C}$ e $1490^{\circ} \mathrm{C}$. As micrografias de MEV correspondentes são mostradas nas FIG. 40 a 43.
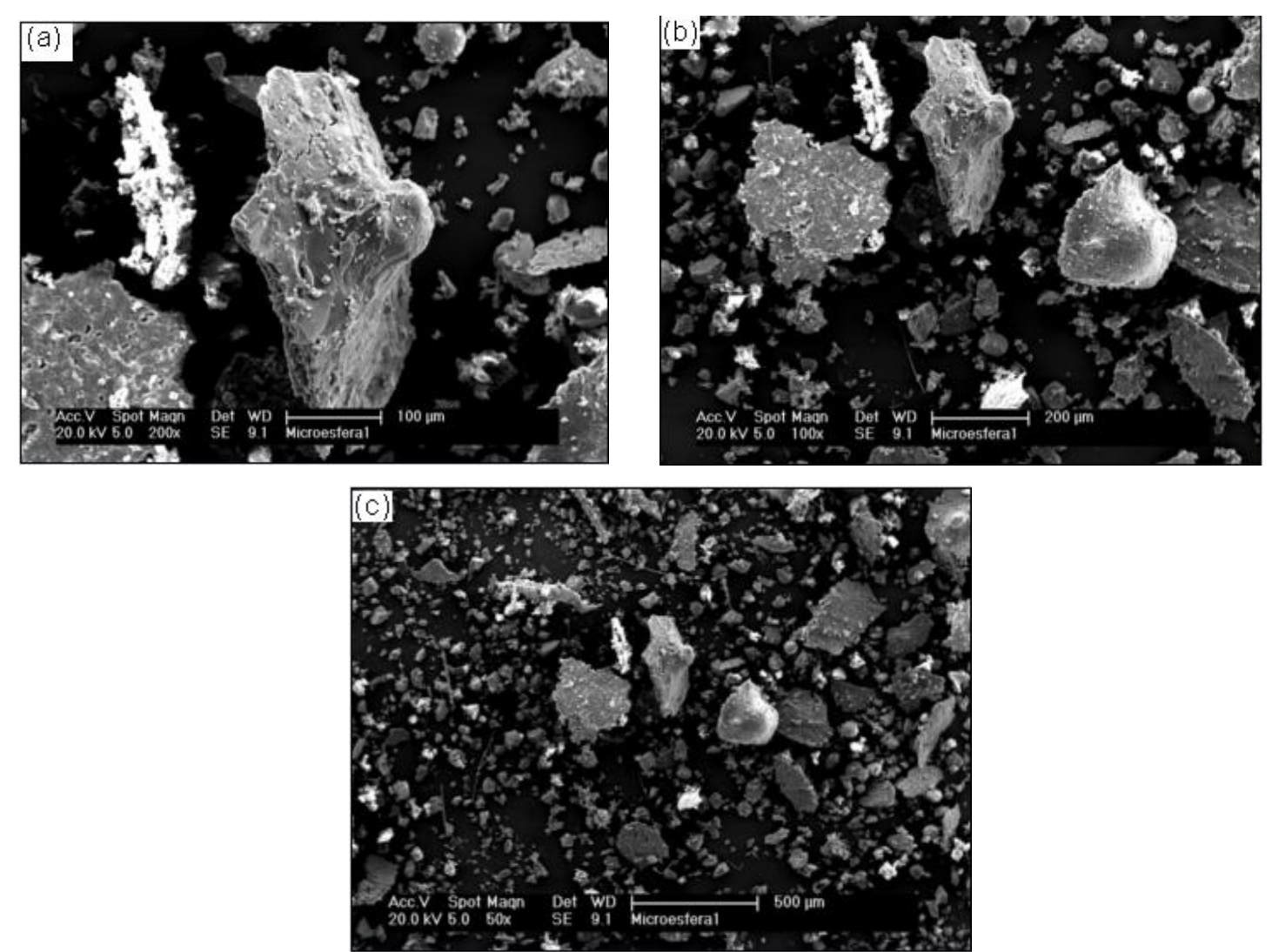

FIGURA 40 - Micrografias das "partículas" produzidas à temperatura de $1200^{\circ} \mathrm{C}$. 

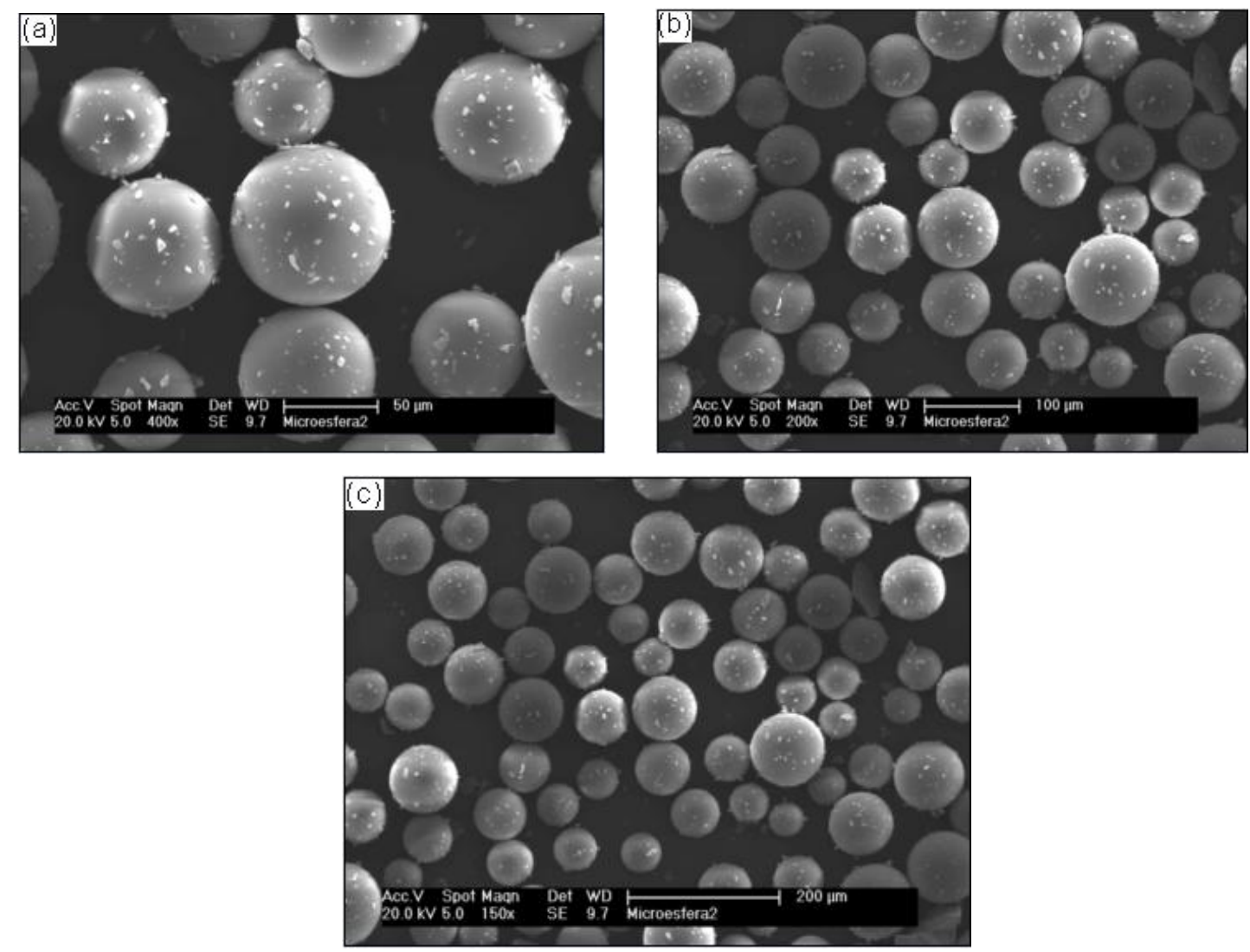

FIGURA 41 - Micrografias das microesferas produzidas à temperatura de $1380^{\circ} \mathrm{C}$.
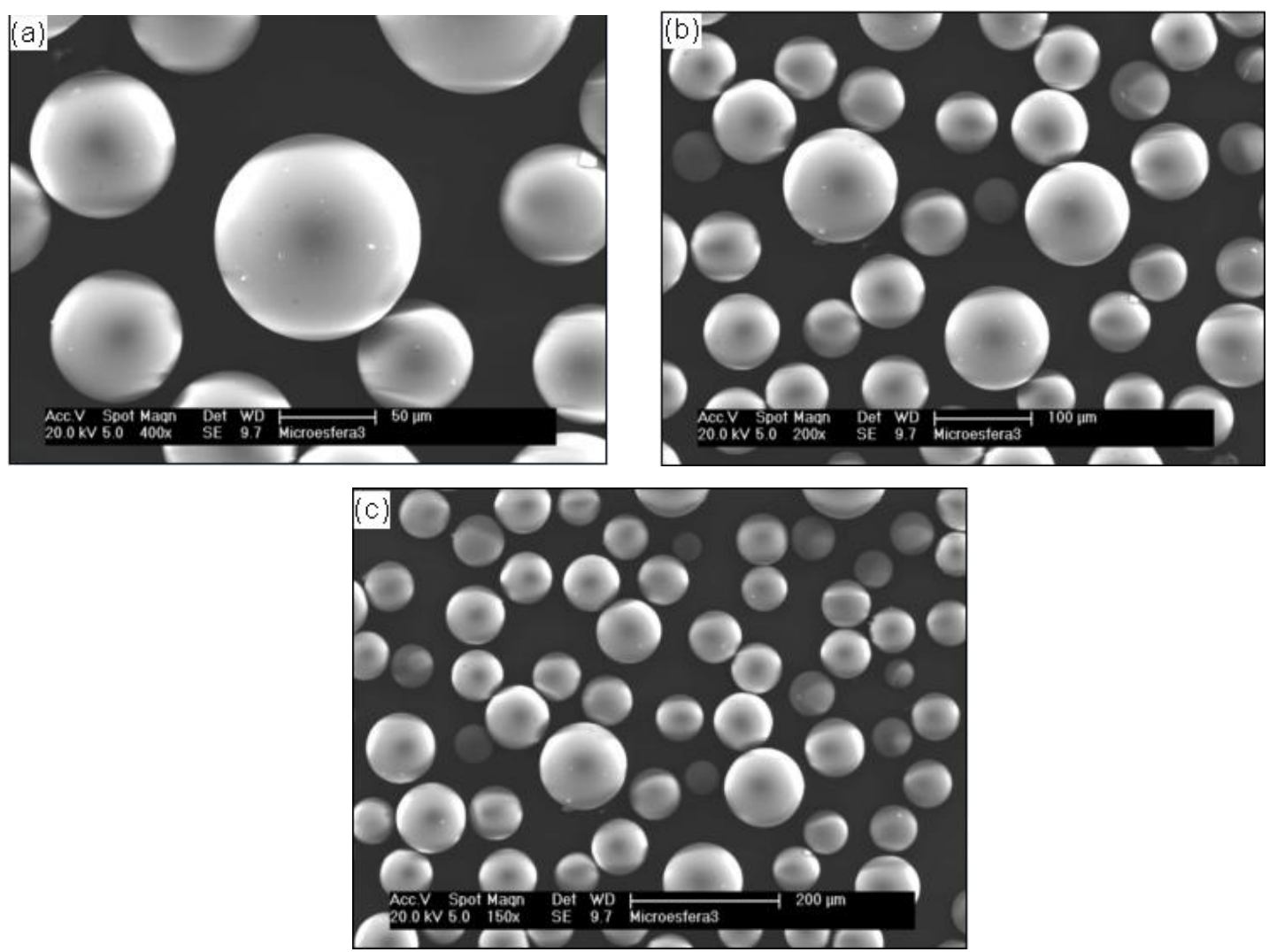

FIGURA 42 - Micrografias das microesferas produzidas à temperatura $1460^{\circ} \mathrm{C}$. 

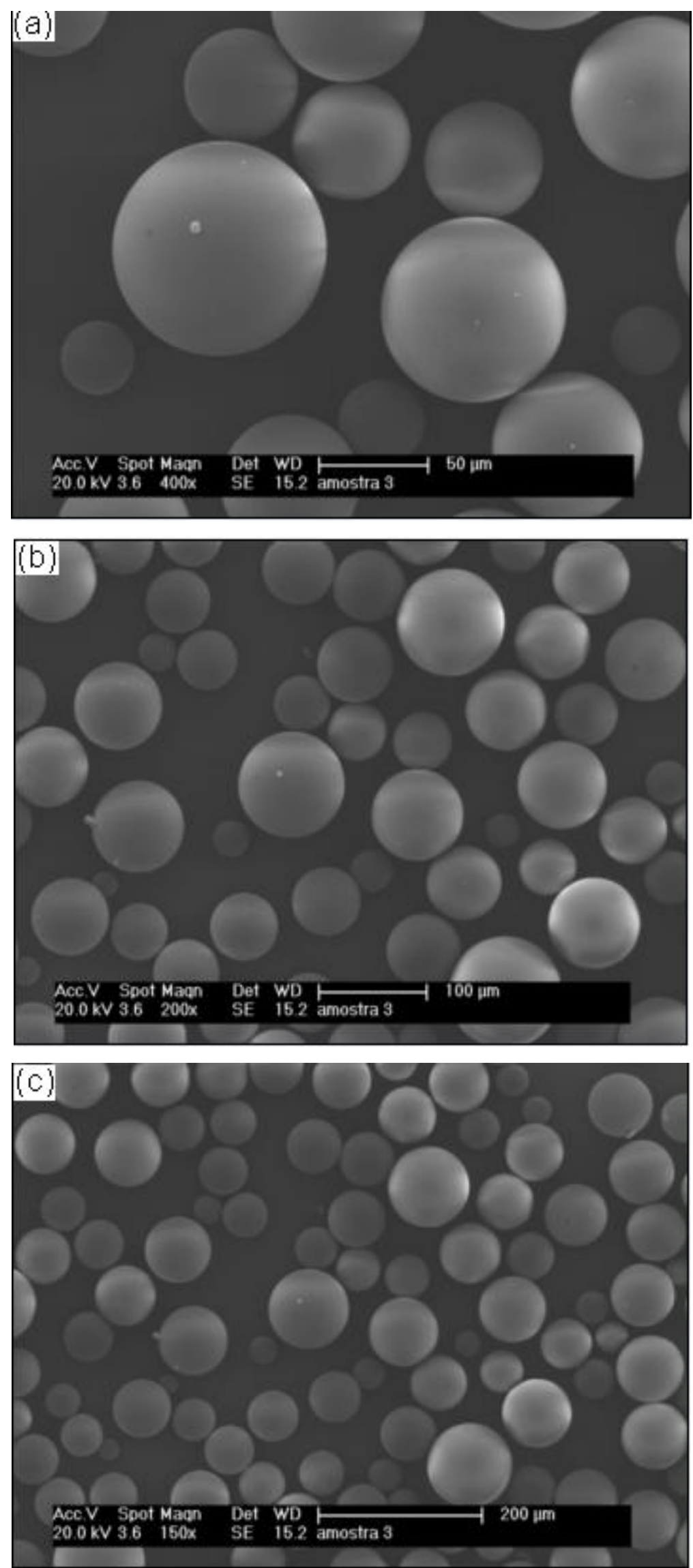

FIGURA 43 - Micrografias das microesferas produzidas à temperatura de $1490^{\circ} \mathrm{C}$. 
Por meio da observação das micrografias nota-se que as temperaturas mais adequadas para obtenção de microesferas morfologicamente aceitáveis são $1460^{\circ} \mathrm{C} \mathrm{e}$ $1490^{\circ} \mathrm{C}$. A partir das análises das micrografias anteriores, nota-se que a temperatura de $1420^{\circ} \mathrm{C}$ mostrou-se também satisfatória. Tal fato deve-se a temperatura da zona quente ser suficientemente alta para a diminuição adequada da viscosidade e também suficientemente baixa para que o fluxo de ar ascendente "fraco" seja o menos intenso em comparação com temperaturas mais altas. A temperatura de $1200^{\circ} \mathrm{C}$ não foi considerada adequada, pois a viscosidade permaneceu muito alta impedindo a formação de microesferas. Na temperatura de $1380^{\circ} \mathrm{C}$ as microesferas possuíam muitas partículas satélites ligadas a sua superfície que poderiam prejudicar a aplicação na terapia pretendida. Isto ocorreu, pois a temperatura da zona quente do forno não foi suficientemente alta para que a viscosidade do vidro fosse adequada para a conformação de todas as partículas vítreas em microesferas. Aparentemente este parâmetro influencia apenas a morfologia das microesferas, não interferindo no diâmetro médio das mesmas conforme sugere as micrografias.

\subsubsection{Tipo de moagem}

Variou-se o tipo de moagem para obtenção do material precursor anteriormente peneirado entre $45 \mu \mathrm{m}<\Phi<63 \mu \mathrm{m}$, tentando verificar se a morfologia do pó irregular é uma variável dominante do processo de esferolização. As micrografias e as distribuições dos tamanhos de partículas correspondentes são mostradas nas FIG. 44 a 47: 

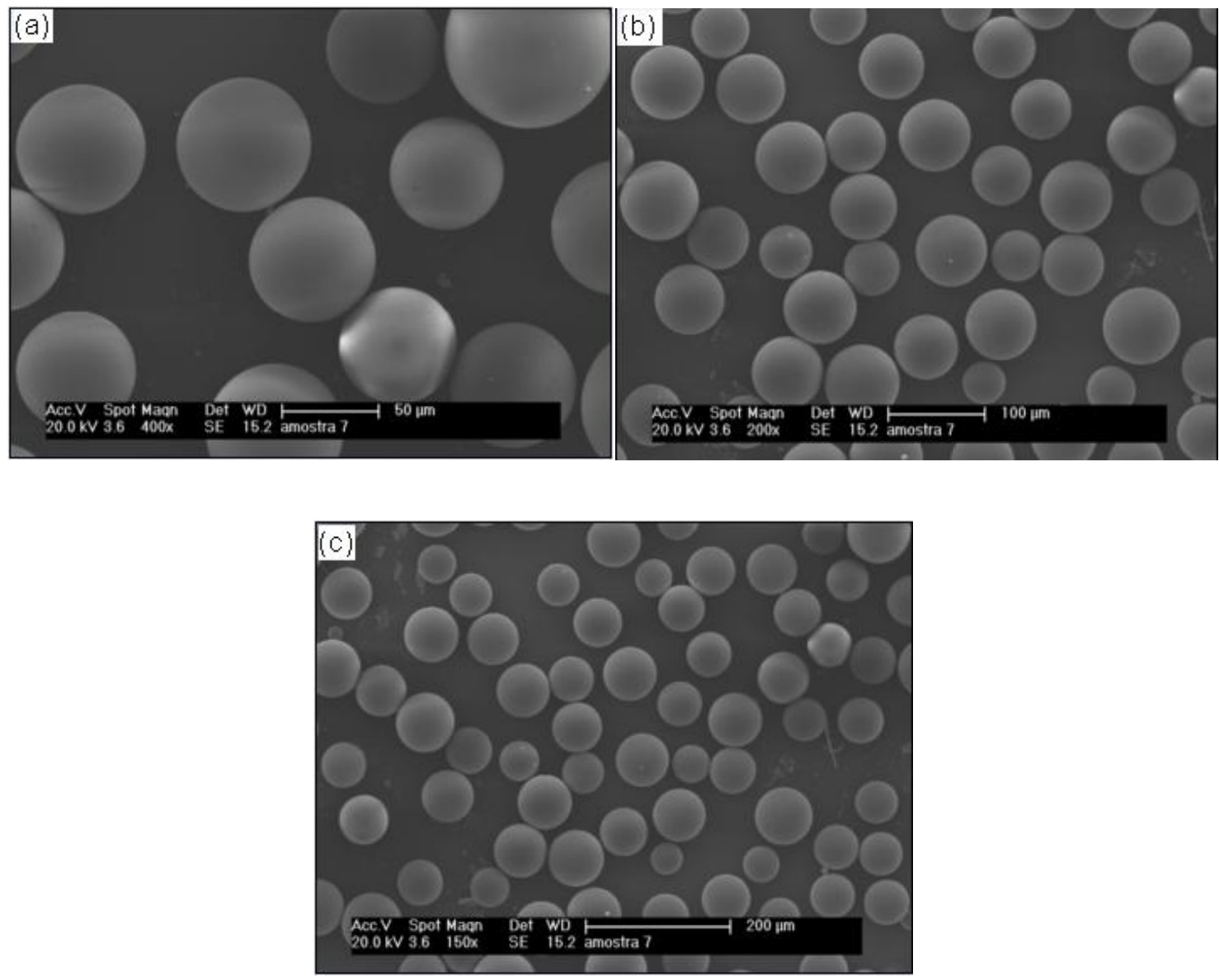

(d)

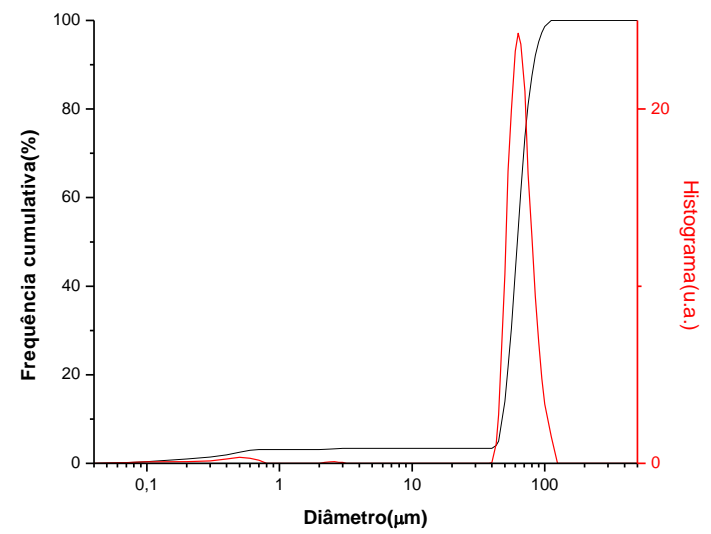

FIGURA 44 - Microesferas produzidas a partir de material precursor moído em moinho planetário de bola de tungstênio. (a) (b) e (c) MEV (d) Distribuição granulométrica $<\Phi>=63 \mu \mathrm{m}$. 

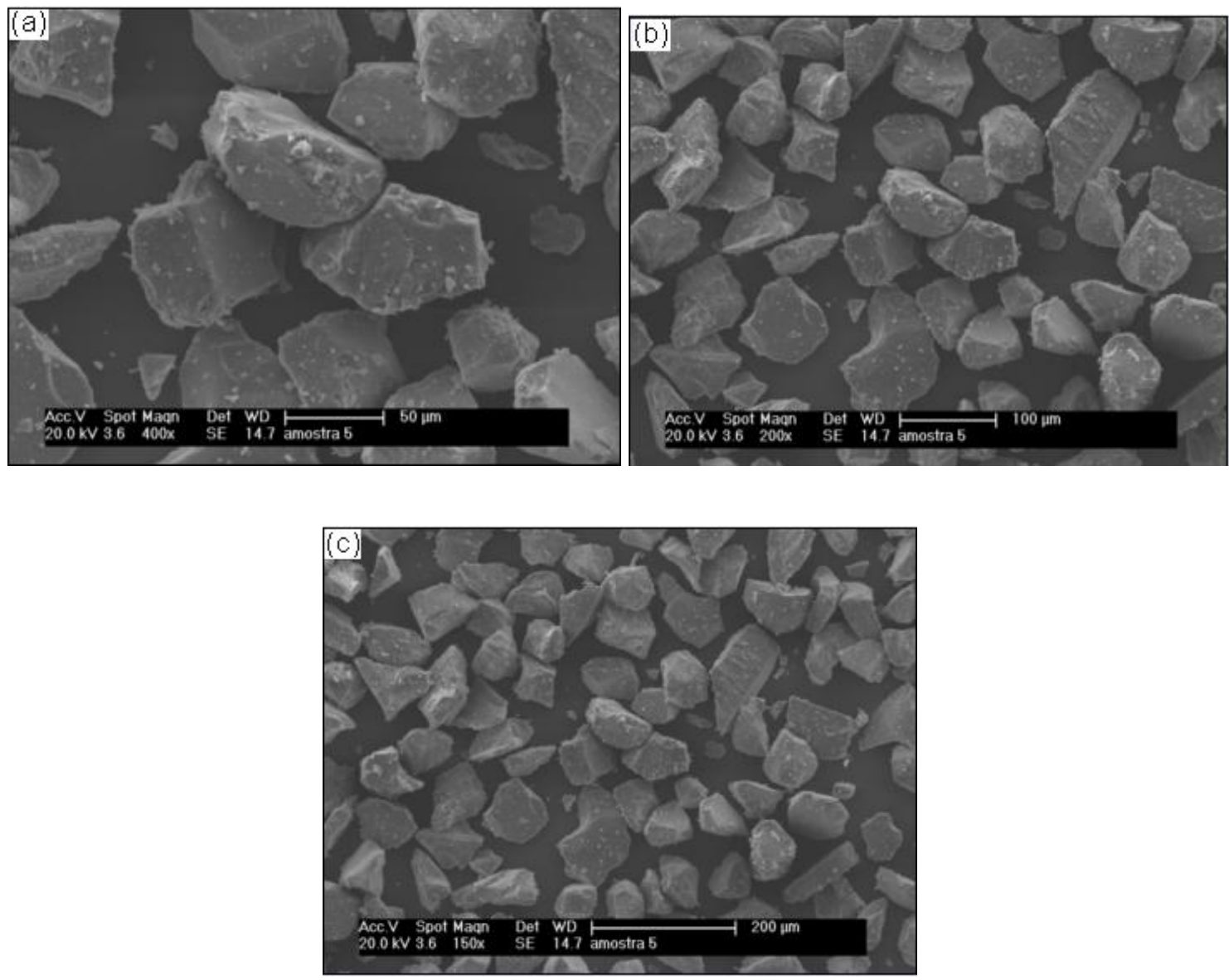

(d)

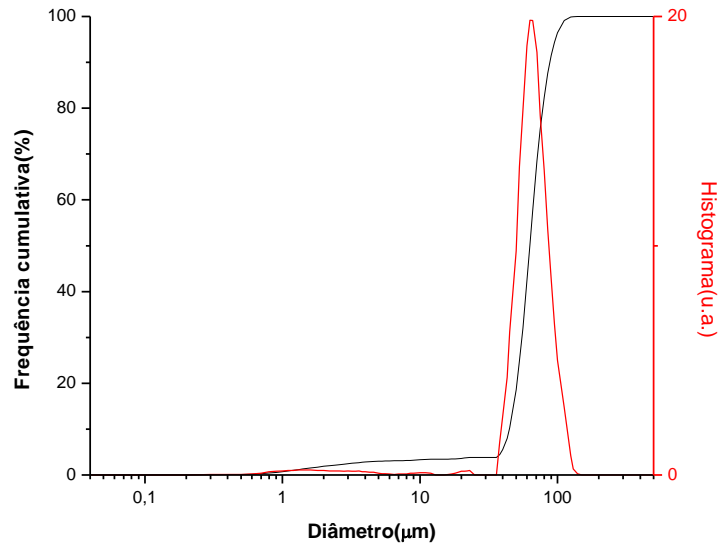

FIGURA 45 - Material precursor moído em moinho planetário de bola de Tungstênio (a) (b) e (c) MEV (d) Distribuição granulométrica $<\Phi>=64 \mu \mathrm{m}$. 

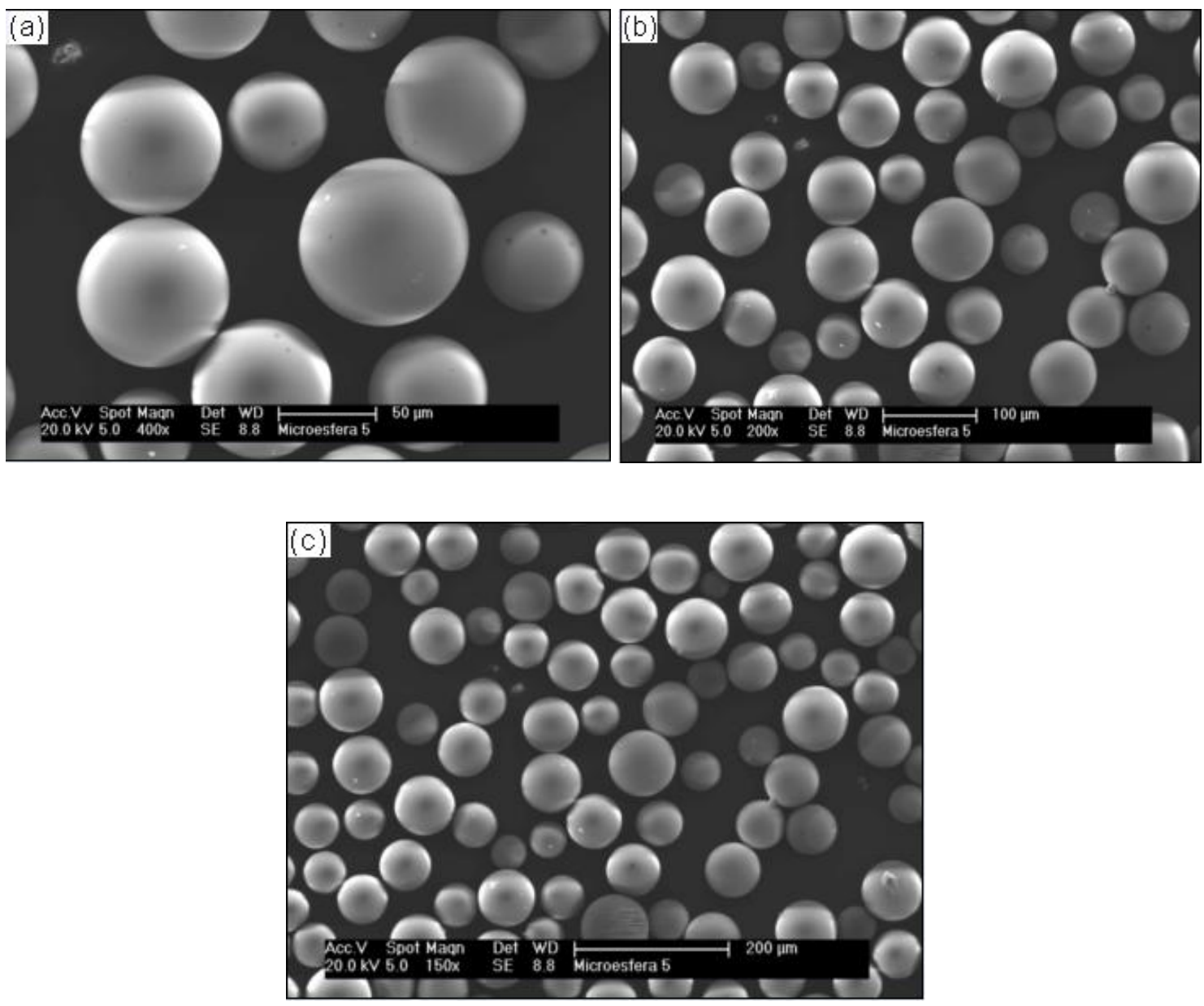

(d)

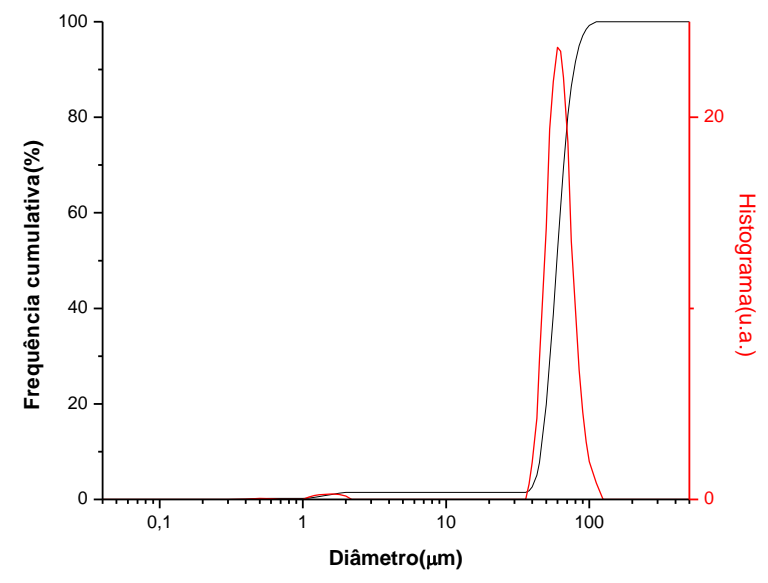

FIGURA 46 - Microesferas produzidas a partir de material precursor moído em moinho de facas (a) (b) e (c) MEV (d) Distribuição granulométrica $\langle\Phi>=60 \mu \mathrm{m}$. 

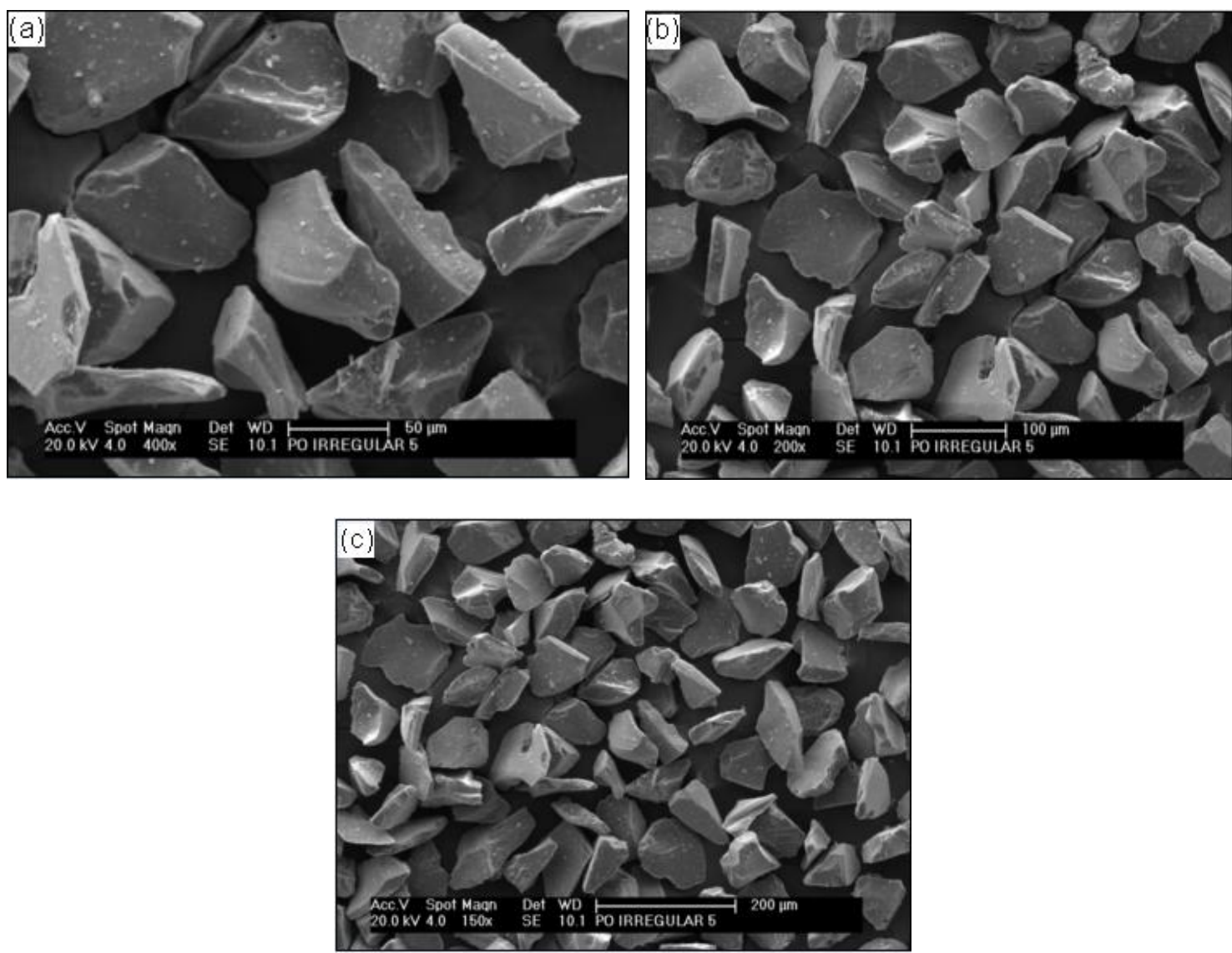

(d)

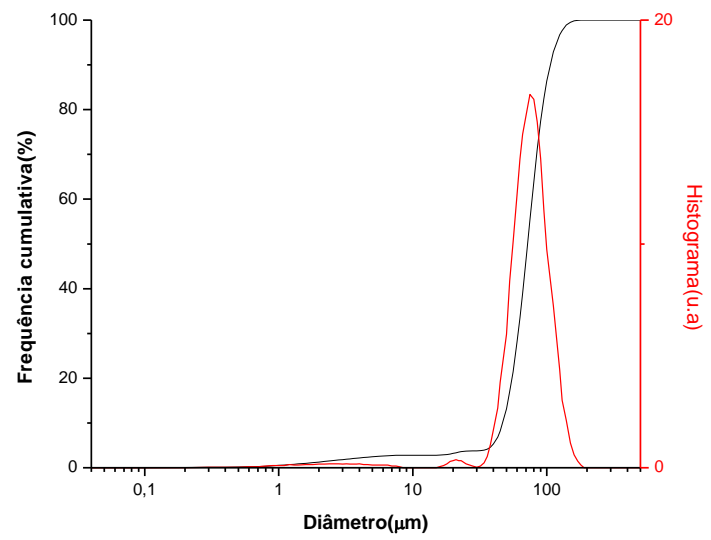

FIGURA 47 - Material precursor moído em moinho de facas (a) (b) e (c) MEV (d) Distribuição granulométrica $<\Phi>=74 \mu \mathrm{m}$.

Nos resultados obtidos verifica-se uma melhora significativa tanto da morfologia quanto da diminuição do diâmetro médio das microesferas obtidas a partir do material precursor moído em moinho planetário de bola de tungstênio e moinho de facas. Os resultados mostrando o diâmetro médio e equivalente das microesferas e do 
material de partida obtidos por análise granulométrica por difração a laser são apresentados nas TAB. 7 e 8:

TABELA 7: Distribuição do tamanho de microesferas obtidas a partir de material precursor submetido a diferentes tipos de moagem.

Distribuição do tamanho de microesferas $(\mu \mathrm{m})$

\begin{tabular}{lcccc}
\hline Tipo de moagem & $\mathrm{D} 10 \%$ & $\mathrm{D} 50 \%$ & $\mathrm{D} 90 \%$ & diâmetro médio \\
Moinho de bola de tungstênio & 47,71 & 62,12 & 82,69 & 62,56 \\
Moinho de facas & 45,88 & 59,40 & 78,37 & 60,48 \\
\hline \hline
\end{tabular}

TABELA 8: Distribuição do tamanho de partícula submetidas a diferentes tipos de moagem.

\begin{tabular}{lrccc}
\hline \hline \multicolumn{4}{c}{ Distribuição do tamanho de partículas irregulares $(\mu \mathrm{m})$} \\
\hline Tipo de moagem & $\mathrm{D} 10 \%$ & $\mathrm{D} 50 \%$ & $\mathrm{D} 90 \%$ & diâmetro médio \\
Moinho de bola de tungstênio & 44,76 & 62,91 & 88,01 & 63,70 \\
Moinho de facas & 46,75 & 72,01 & 106,48 & 73,64 \\
\hline \hline
\end{tabular}

Nota-se a partir das micrografias uma homogeneização do tamanho das microesferas que pode estar relacionada à morfologia do material precursor. Conforme resultados expostos nas FIG. 45 e 47, o material precursor possui formato homogêneo com reduzida razão de aspecto, o que pode estar contribuindo para a diminuição do atrito entre as partículas e consequente diminuição de ocorrência de aglomerados implicando na diminuição do diâmetro médio das microesferas. O material precursor obtido após moagem em moinho de facas apresentou diâmetro equivalente superior ao do material precursor obtido após moagem em moinho de bola de tungstênio. No entanto, as microesferas resultantes dos dois materiais precursores apresentaram diâmetros médios praticamente equivalentes. Isto pode ter acontecido devido às partículas satélites ligadas à superfície das partículas maiores no material precursor da FIG. 45 terem aumentado o atrito causando ocorrência de aglomerados e provocando o aumento do diâmetro médio das microesferas. Como no material precursor da FIG. 47 não há a presença de partículas satélites incrustadas às partículas maiores, o atrito foi menor, gerando microesferas com o diâmetro menor comparado ao material precursor.

Os resultados são promissores, pois se obtiveram microesferas abaixo do limite superior da granulometria indicada para a terapia pretendida. 


\subsubsection{Eliminação de finos por decantação simples.}

$\mathrm{Na}$ tentativa de eliminar as partículas satélites que podem causar aumento do atrito durante o escoamento do material precursor até a zona quente e que provocam a indesejável aglomeração do pó vítreo, foi realizado um método de decantação simples a fim de separar os finos (partículas satélites) das partículas maiores. As micrografias e distribuição granulométrica correspondentes são mostradas nas FIGs. 48 e 49: 

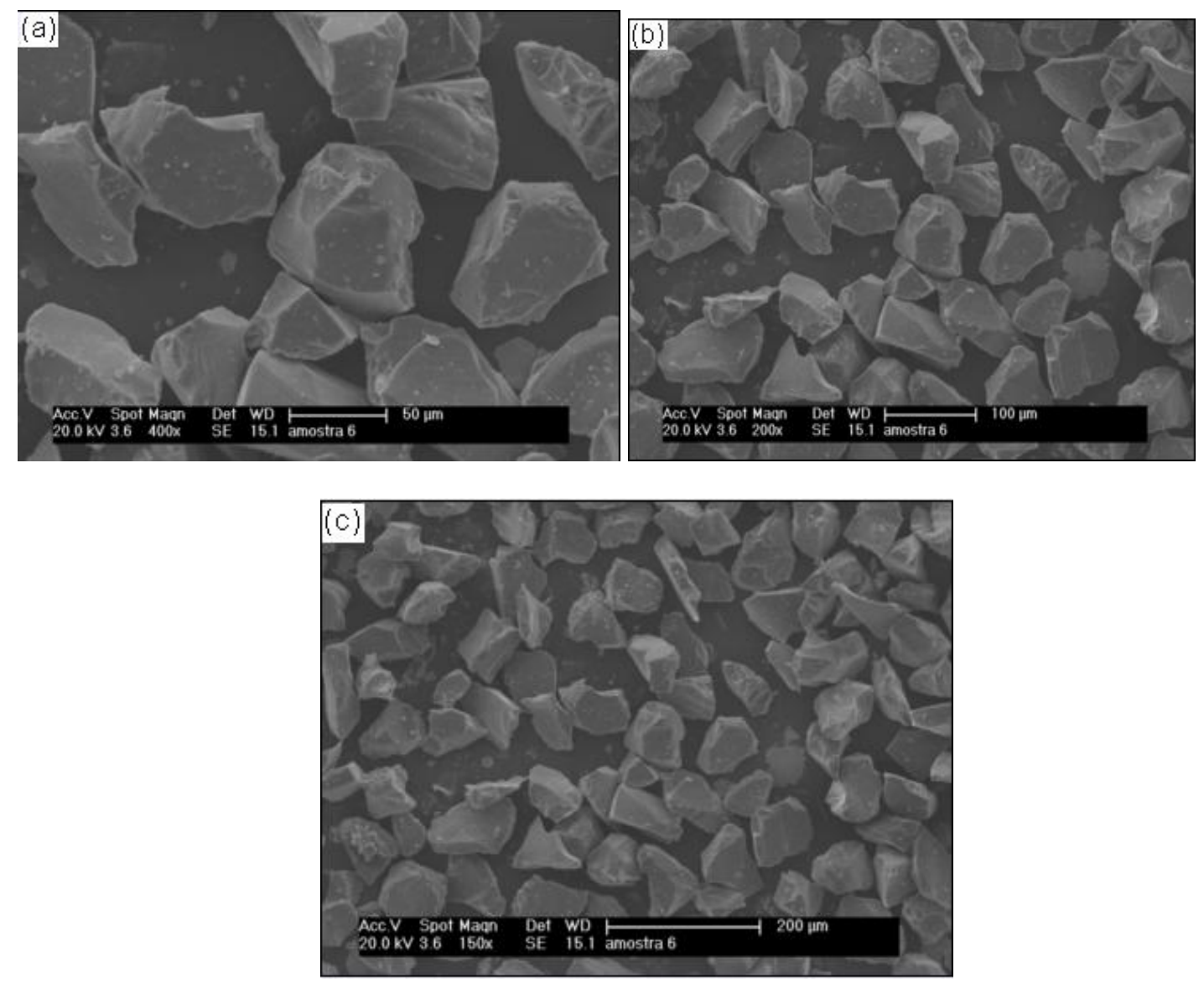

(d)

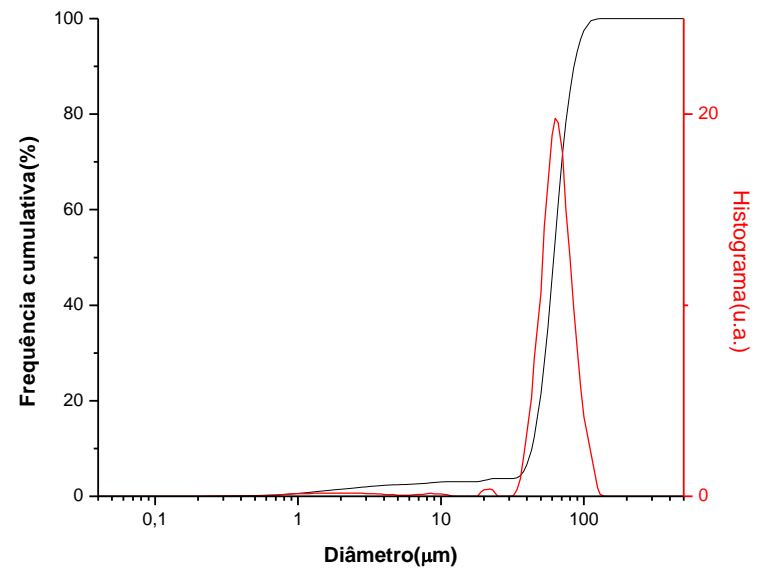

FIGURA 48 - Material precursor obtido após processo de decantação simples (a) (b) e (c) MEV (d) Distribuição granulométrica $<\Phi>=61 \mu \mathrm{m}$. 

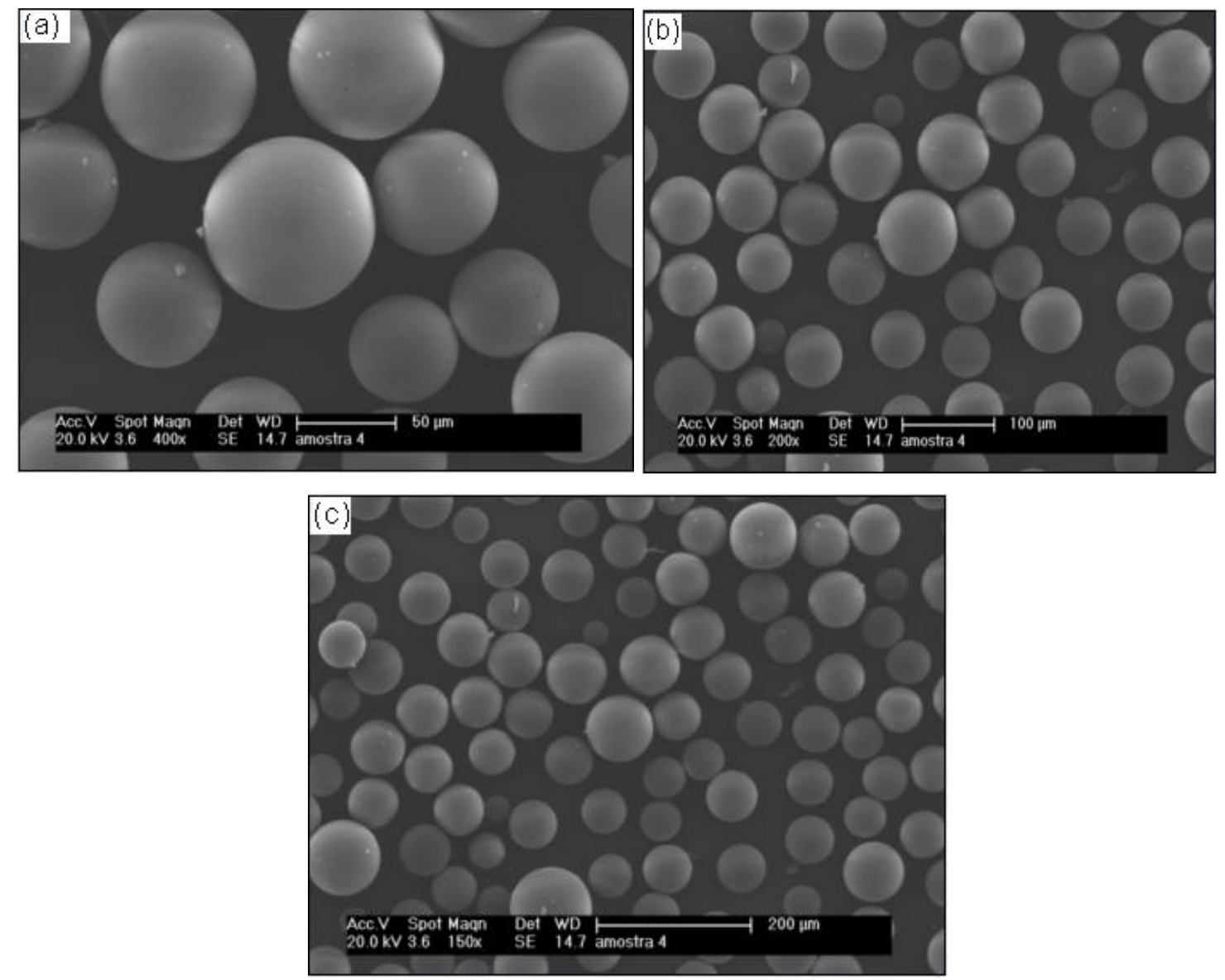

(d)

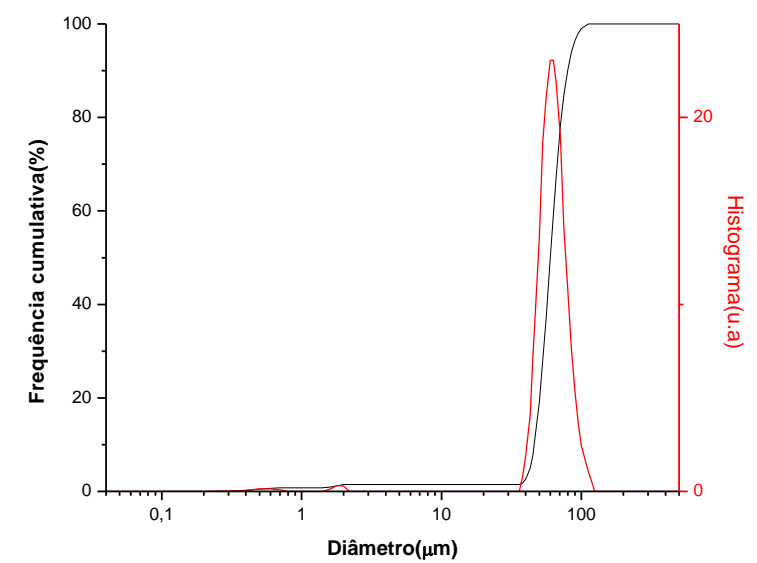

FIGURA 49 - Microesferas obtidas após processo de decantação simples. (a) (b) e (c) MEV (d) Distribuição granulométrica $<\Phi>=61 \mu \mathrm{m}$.

Esses resultados mostram uma diminuição do diâmetro médio de $\langle\Phi\rangle=$ $78 \mu \mathrm{m}$ para $\langle\Phi>=61 \mu \mathrm{m}$ das microesferas obtidas a partir do material precursor peneirado entre $45 \mu \mathrm{m}<\Phi<63 \mu \mathrm{m}$ que passou pelo processo de decantação. Como mostrado na FIG. 48, as partículas irregulares praticamente não contêm partículas satélites agregadas em suas superfícies após serem submetidas ao processo de 
desaglomeração em solução de tetrapirosfosfato de sódio. Consequentemente, houve a diminuição do diâmetro médio das microesferas correspondentes.

\subsubsection{Eliminação de finos por agitação mecânica/ultrassom/decantação.}

Visando a um aperfeiçoamento do processo anterior, a solução de tetrapirofosfato de sódio e o pó irregular imerso foram submetidos a ondas de ultrassom e agitação mecânica. Os resultados são mostrados nas FIG. 50 e 51: 

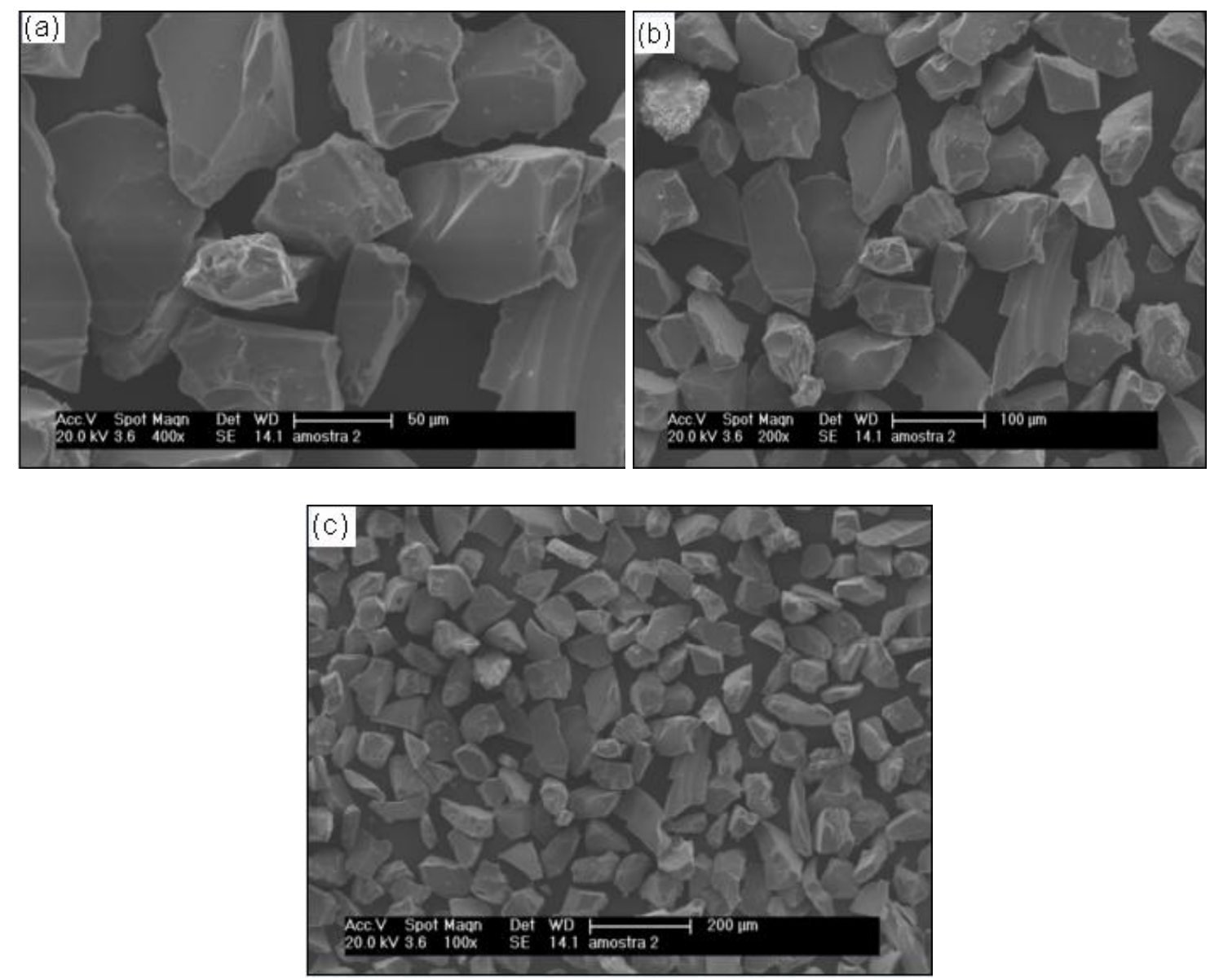

(d)

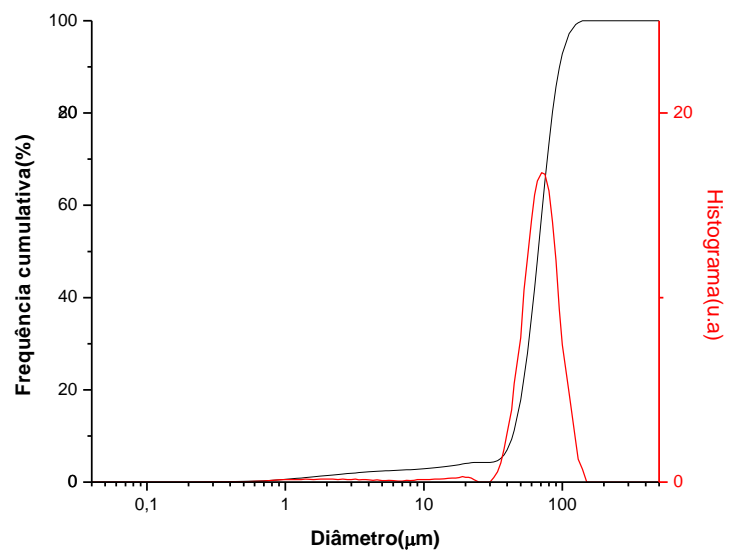

FIGURA 50 - Material precursor obtido após processo de decantação/agitação/ ultrassom (a) (b) e (c) MEV (d) Distribuição granulométrica. 

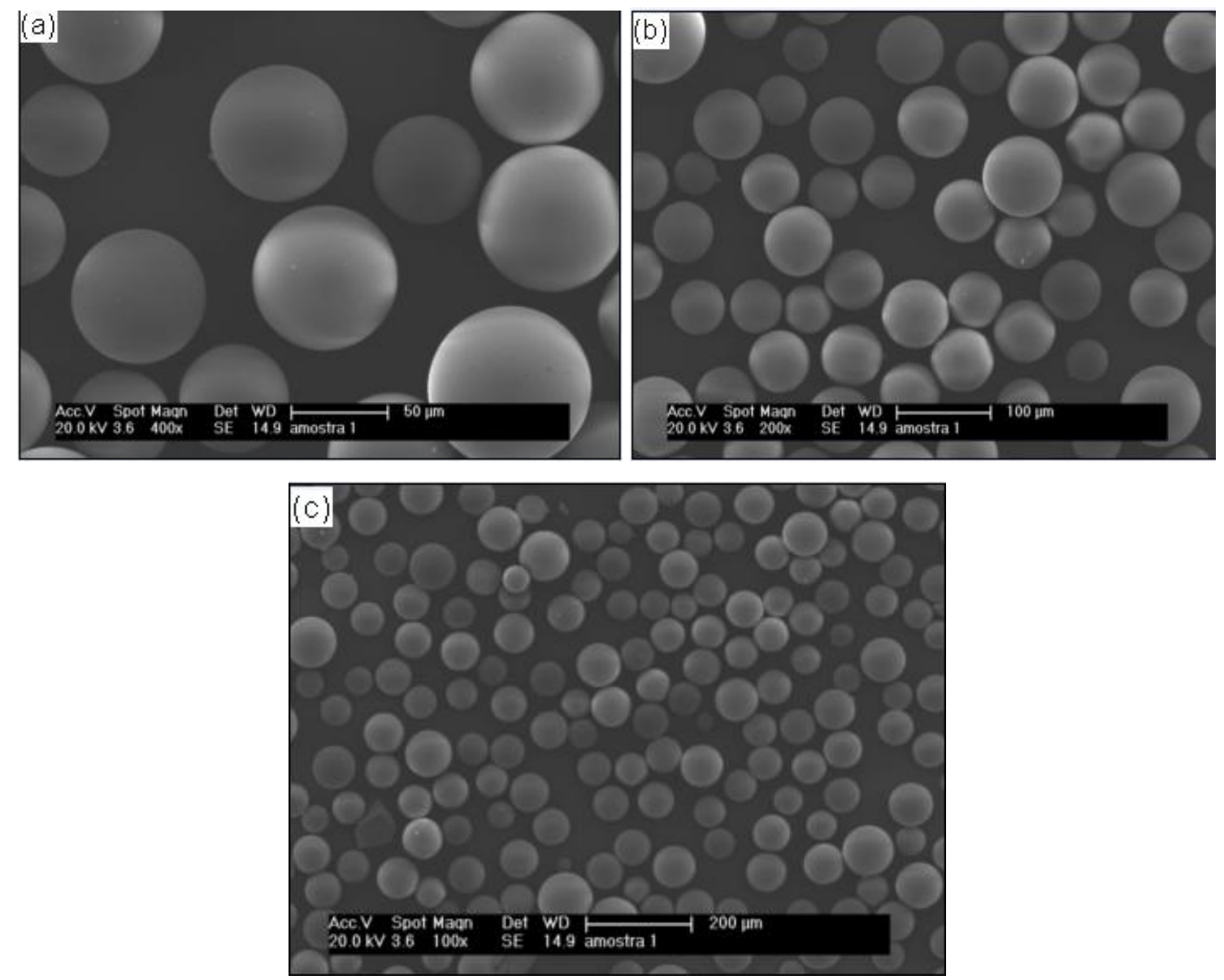

(d)

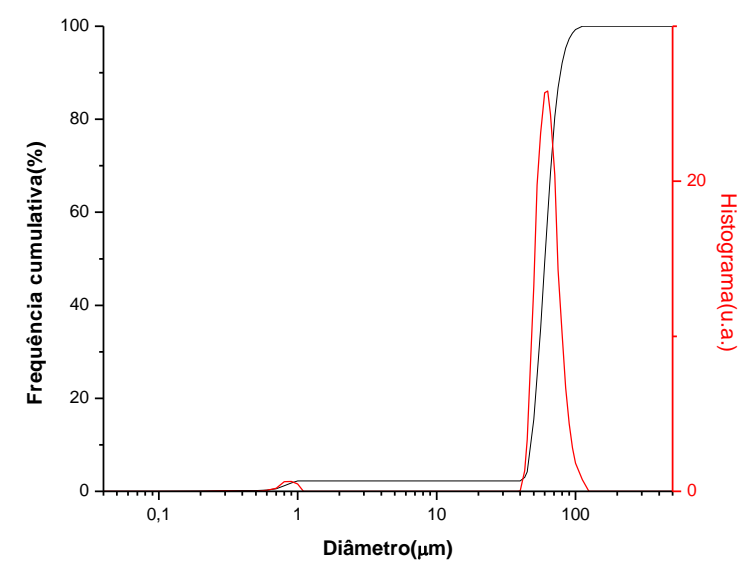

FIGURA 51 - Microesferas obtidas após processo de decantação/agitaçao/ultrassom (a) (b) e (c) MEV (d) Distribuição granulométrica $\langle\Phi>=60 \mu \mathrm{m}$.

Notou-se uma diminuição no diâmetro médio das microesferas obtidas para $<\Phi>=60 \mu \mathrm{m}$ quando o material precursor passa pelo processo de desaglomeração. Também nota-se uma homogeneização das microesferas obtidas. Na FIG. 50, é mostrado o material precursor praticamente sem a presença de partículas satélites que 
causariam o aumento do diâmetro médio das microesferas devido à coalescência durante o processo de esferolização.

\subsection{Avaliação dos danos superficiais após irradiação por nêutrons}

Foram obtidas micrografias por MEV das microesferas pretendendo constatar sua integridade física após o processo de ativação neutrônica. A avalição foi realizada após um período de mais de 10 meias-vidas do ${ }^{166} \mathrm{Ho}$ e quando sua atividade era menor que 35,6(1,7) Bq. Essa atividade remanescente deve-se a presença do ${ }^{166 \mathrm{~m}} \mathrm{Ho}$. Este radioisótopo metaestável resulta da absorção de nêutrons pelo ${ }^{165} \mathrm{Ho}$, que neste caso possui uma baixa seção de choque. Embora o ${ }^{166 m}$ Ho possua uma meia vida longa $\left(\mathrm{t}_{1 / 2}=1200 \mathrm{a}\right)$, essa atividade não inviabiliza a utilização das microesferas para radioterapia interna seletiva. As micrografias destas microesferas são mostradas na FIG. 52.
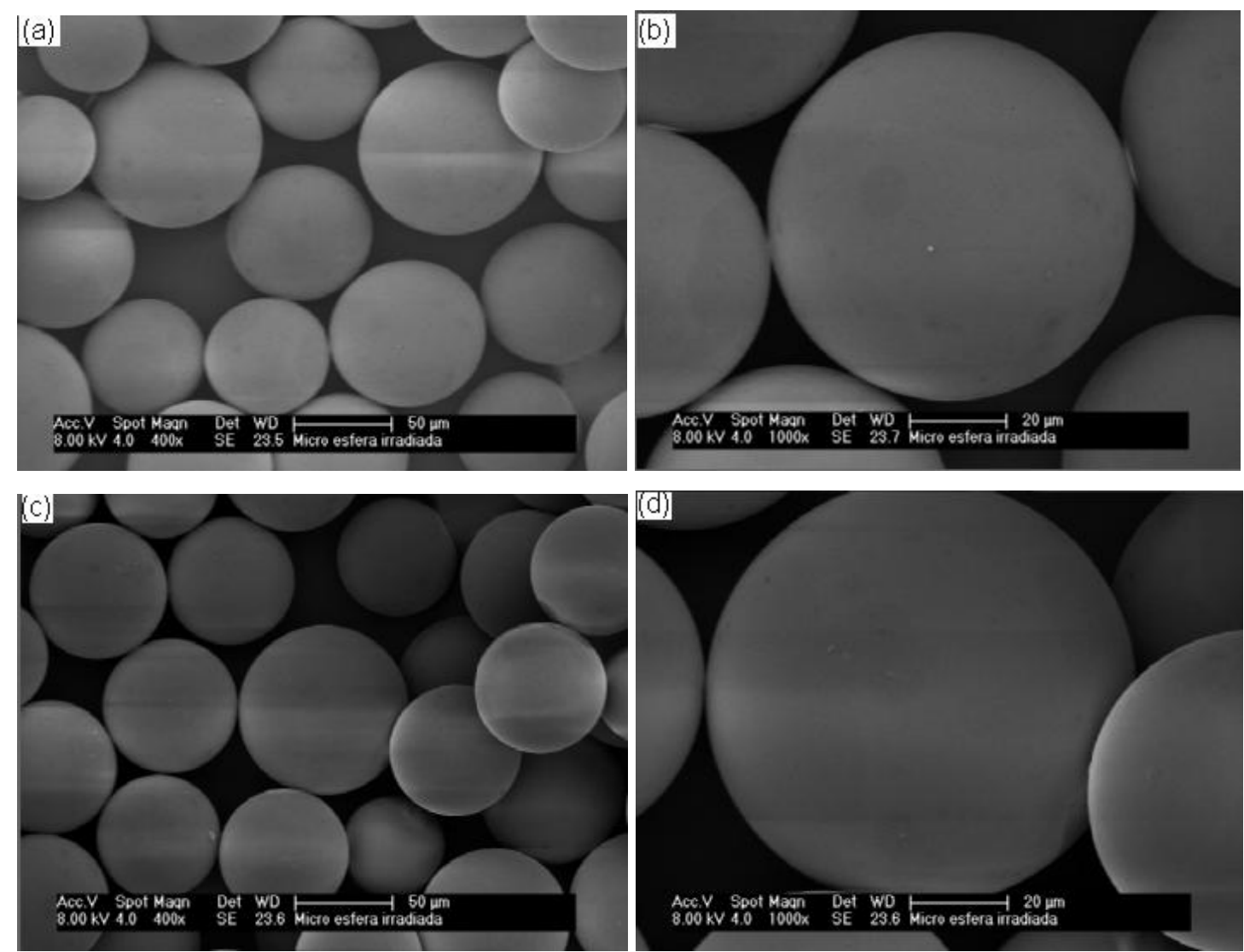

FIGURA 52 - Micrografias de microesferas após ativação neutrônica.

Percebe-se que não houve danos à superfície das microesferas mesmo após o processo de ativação neutrônica. Diferentemente das microesferas poliméricas, as microesferas de vidros são muito mais resistentes à radiação e por isso os vidros são comumente usados como imobilizadores de rejeitos radioativos [35]. 


\subsection{Aumento do teor de Hólmio}

Foi aumentado o teor de óxido de hólmio na composição nominal de vidros aluminossilicatos de $5 \%$ para $25 \%$ e $37 \%$ em peso e, consequentemente, produzidas microesferas com estas novas composições. As composições reais foram determinadas por EDX e estão apresentadas nas TAB. 9 e 10:

TABELA 9: Composição real de vidros contendo 25\% (nominal) em peso de $\mathrm{Ho}_{2} \mathrm{O}_{3}$.

\section{Composição química obtida por EDX (\% massa)}

\begin{tabular}{ccc}
\hline Componente & Microesferas & Material precursor \\
\hline $\mathrm{SiO}_{2}$ & $42,1(7)$ & $41,5(9)$ \\
$\mathrm{Al}_{2} \mathrm{O}_{3}$ & $16,9(7)$ & $17,2(9)$ \\
$\mathrm{MgO}$ & $17,21(10)$ & $17,18(26)$ \\
$\mathrm{Ho}_{2} \mathrm{O}_{3}$ & $20,53(27)$ & $19,8(4)$ \\
$\mathrm{Lu}_{2} \mathrm{O}_{3}$ & $1,63(16)$ & $1,2(3)$ \\
$\mathrm{CaO}$ & $0,25(12)$ & $0,57(14)$ \\
$\mathrm{Na}_{2} \mathrm{O}$ & $1,3(5)$ & $2,4(7)$ \\
\hline \hline
\end{tabular}

TABELA 10: Composição real de vidros contendo $37 \%$ (nominal) em peso de $\mathrm{Ho}_{2} \mathrm{O}_{3}$

Composição química obtida por EDX (\% massa)

\begin{tabular}{ccc}
\hline Componente & Microesferas & Material precursor \\
\hline $\mathrm{SiO}_{2}$ & $33,4(5)$ & $33,3(7)$ \\
$\mathrm{Al}_{2} \mathrm{O}_{3}$ & $14,5(5)$ & $14,5(8)$ \\
$\mathrm{MgO}$ & $14,22(10)$ & $14,20(11)$ \\
$\mathrm{Ho}_{2} \mathrm{O}_{3}$ & $32,8(6)$ & $32,8(7)$ \\
$\mathrm{Lu}_{2} \mathrm{O}_{3}$ & $2,04(6)$ & $2,03(9)$ \\
$\mathrm{CaO}$ & - & $0,183(16)$ \\
$\mathrm{Na}_{2} \mathrm{O}$ & $2,99(8)$ & $2,99(14)$ \\
\hline \hline
\end{tabular}

Não foram observadas mudanças significativas nas composições reais das microesferas e do material precursor para ambos os vidros; no entanto, nota-se uma mudança entre a composição real e nominal. Houve uma diminuição da quantidade de óxido de hólmio da composição real em relação à composição nominal. Isto ocorreu 
após o processo de fusão e pode estar relacionado à vaporização dos reagentes e interação destes com o cadinho ou devido a presença de impurezas.

Nota-se uma contaminação próxima de $1,5 \%$ e $3 \%$ de óxido de sódio nas composições reais dos vidros com $25 \%$ e $37 \%$ de óxido de hólmio em peso respectivamente que pode estar relacionada ao teor de pureza do óxido de magnésio utilizado na composição. Essa contaminação pode ter influenciado na formação do vidro, reduzindo a viscosidade do líquido durante a fusão. O sódio possui baixa seção de choque para absorção de nêutrons e, desse modo, não interferirá nos objetivos deste trabalho.

As micrografias e análises granulométricas são mostradas nas FIG. 53 e 54:
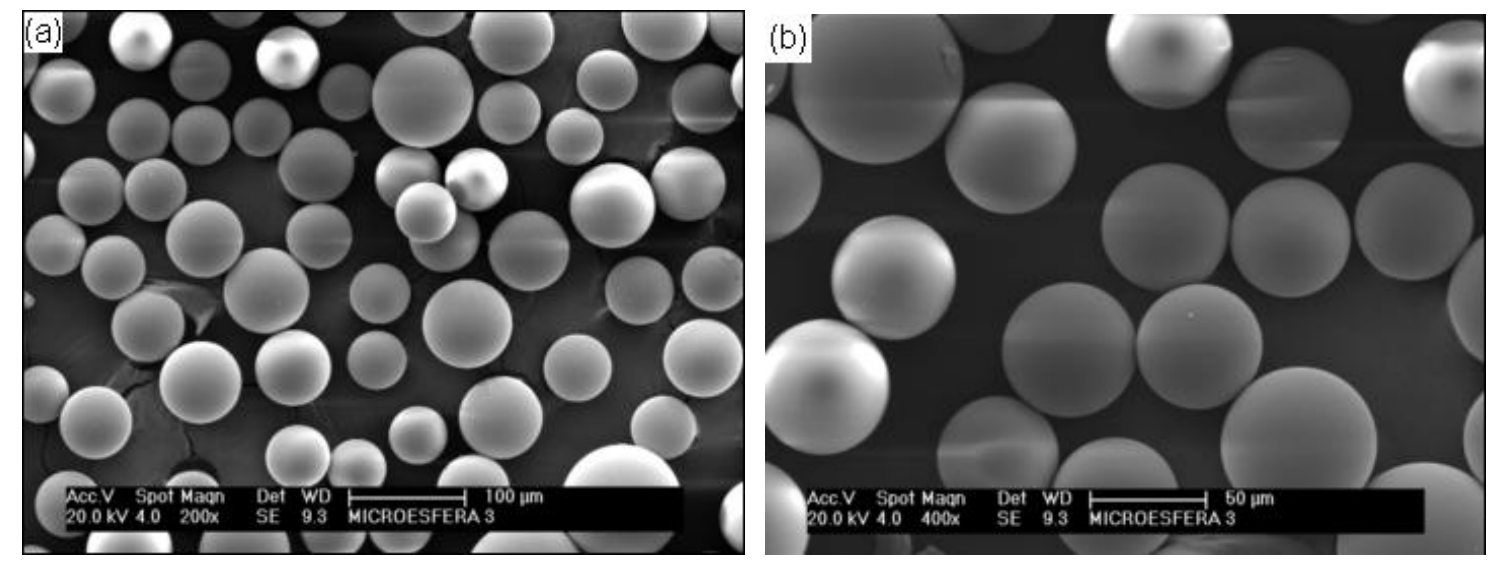

(c)

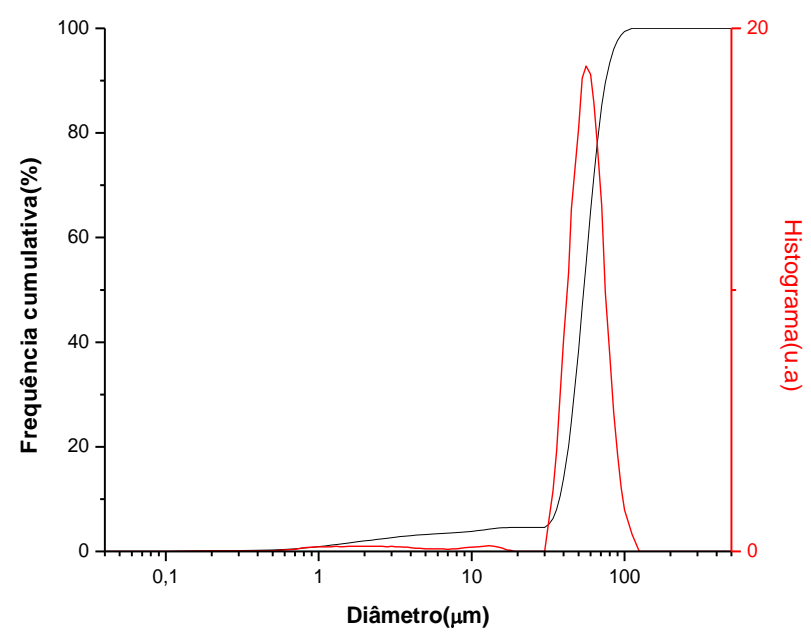

FIGURA 53 - Microesferas obtidas contendo $25 \%$ de óxido de hólmio em peso. (a) e (b) MEV (c) Distribuição granulométrica $<\Phi>=58 \mu \mathrm{m}$. 

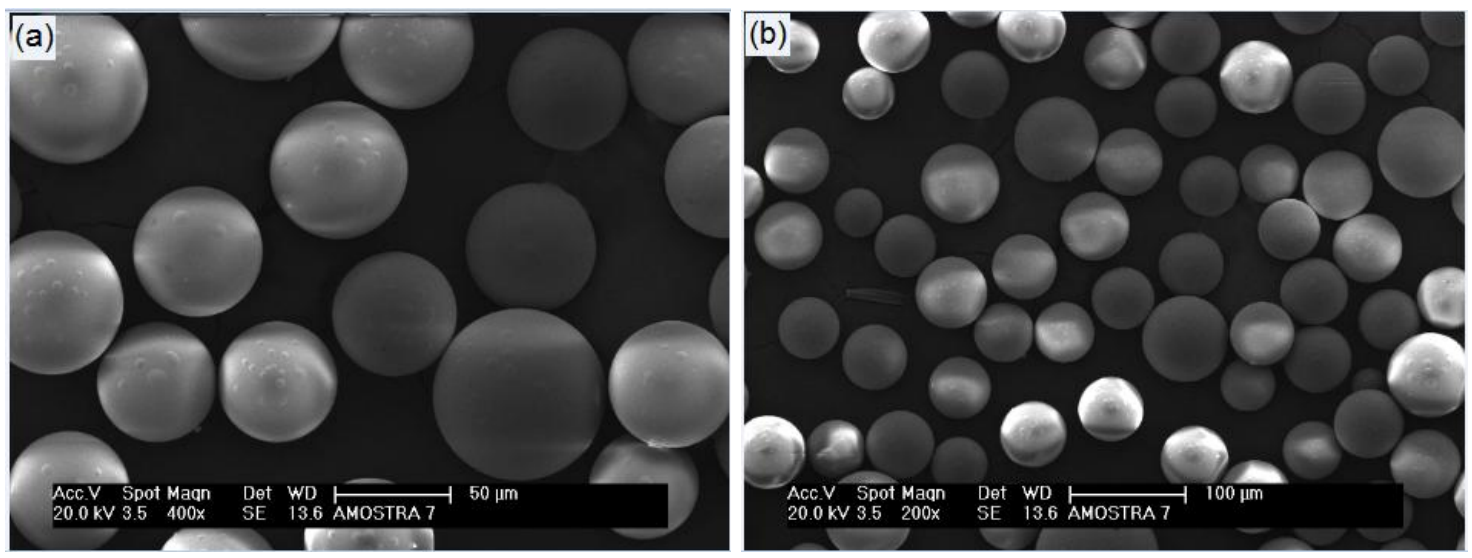

(c)

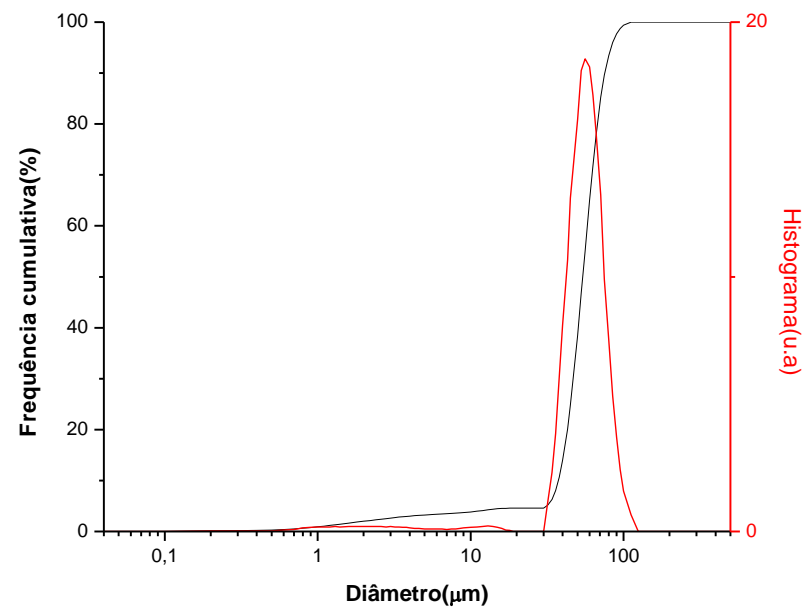

FIGURA 54 - Microesferas obtidas contendo 37\% de óxido de hólmio em peso. (a) e (b) MEV (c) Distribuição granulométrica $<\Phi>=54 \mu \mathrm{m}$.

Notou-se uma melhor fluidez do pó irregular de vidro contendo $25 \%$ e $37 \%$ em peso de óxido de hólmio em relação aquele contendo apenas $5 \%$ provavelmente devido à diminuição da higroscopicidade do vidro quando é aumentada a quantidade de óxido de hólmio. Isso proporcionou produzir microesferas mais homogêneas conforme mostrado nas micrografias das FIG. 53 e 54 e com diâmetro médio de $\langle\Phi\rangle=58 \mu \mathrm{m}$ (microesferas contendo $25 \% \mathrm{Ho}$ ) e $\langle\Phi\rangle=54 \mu \mathrm{m}$ (microesferas contendo $37 \% \mathrm{Ho}$ ). Essas microesferas com quantidades significativas de hólmio na estrutura do vidro podem proporcionar uma alta dose no tumor, tornando o tratamento mais efetivo. 


\subsection{Avaliação da durabilidade química em SBF por meio de MEV.}

As microesferas contendo 5, 25 e $37 \%$ em peso de óxido de hólmio foram observadas em um microscópio eletrônico de varredura visando a avaliação de sua superfície após período de 7 e 14 dias imersas em SBF. As micrografias são mostradas nas FIG. 55 a 57:
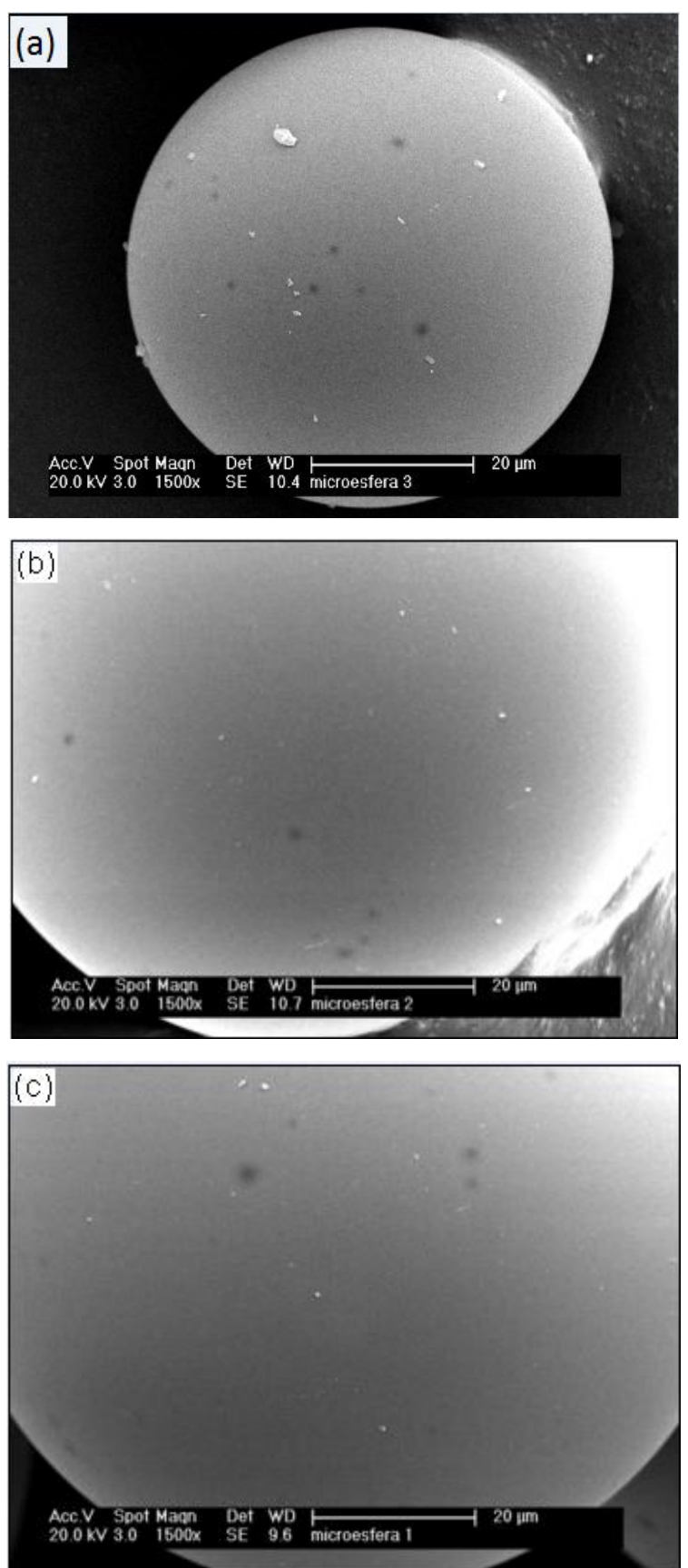

FIGURA 55 - Microesferas contendo 5\% de óxido de hólmio (a) antes da imersão (b) após 7 dias em SBF (c) após 14 dias em SBF. 

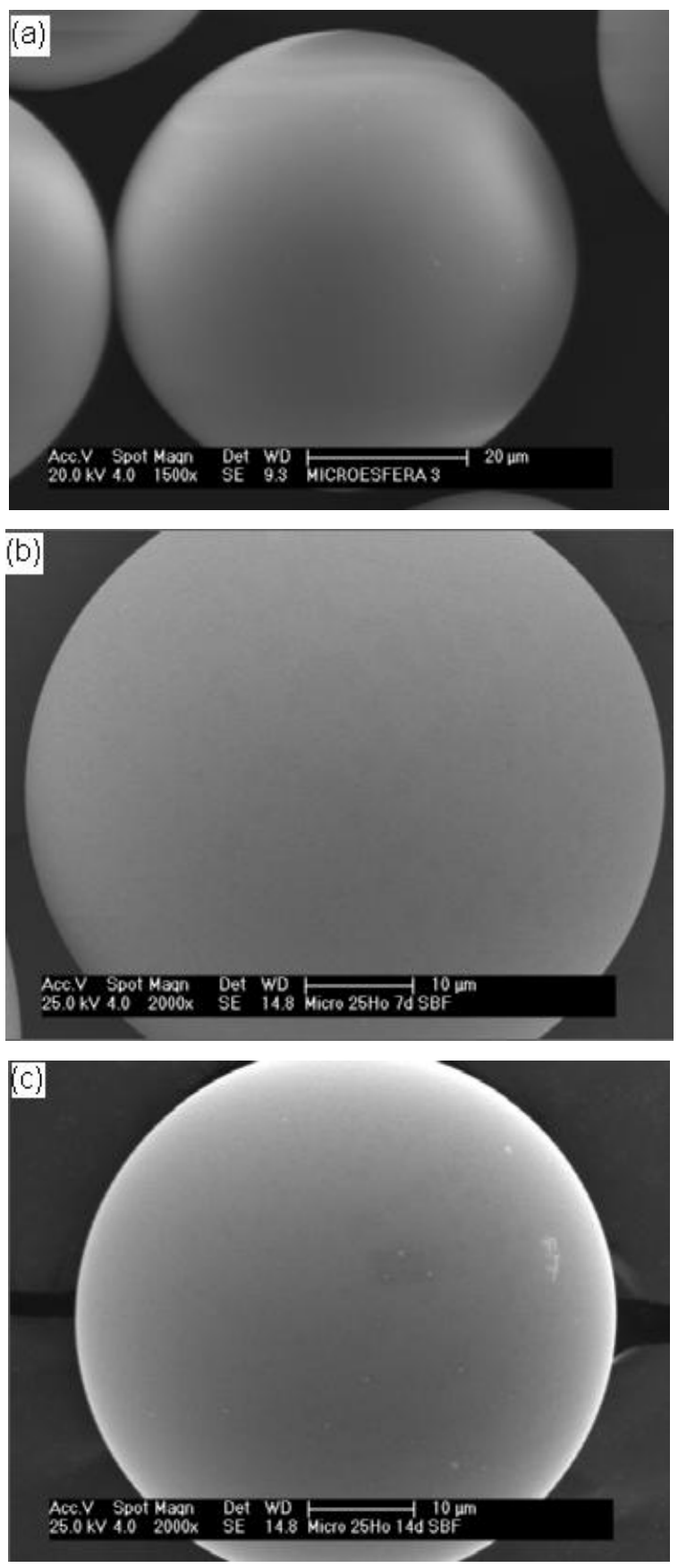

FIGURA 56 - Microesferas contendo 25\% de óxido de hólmio (a) antes da imersão (b) após 7 dias em SBF (c) após 14 dias em SBF. 

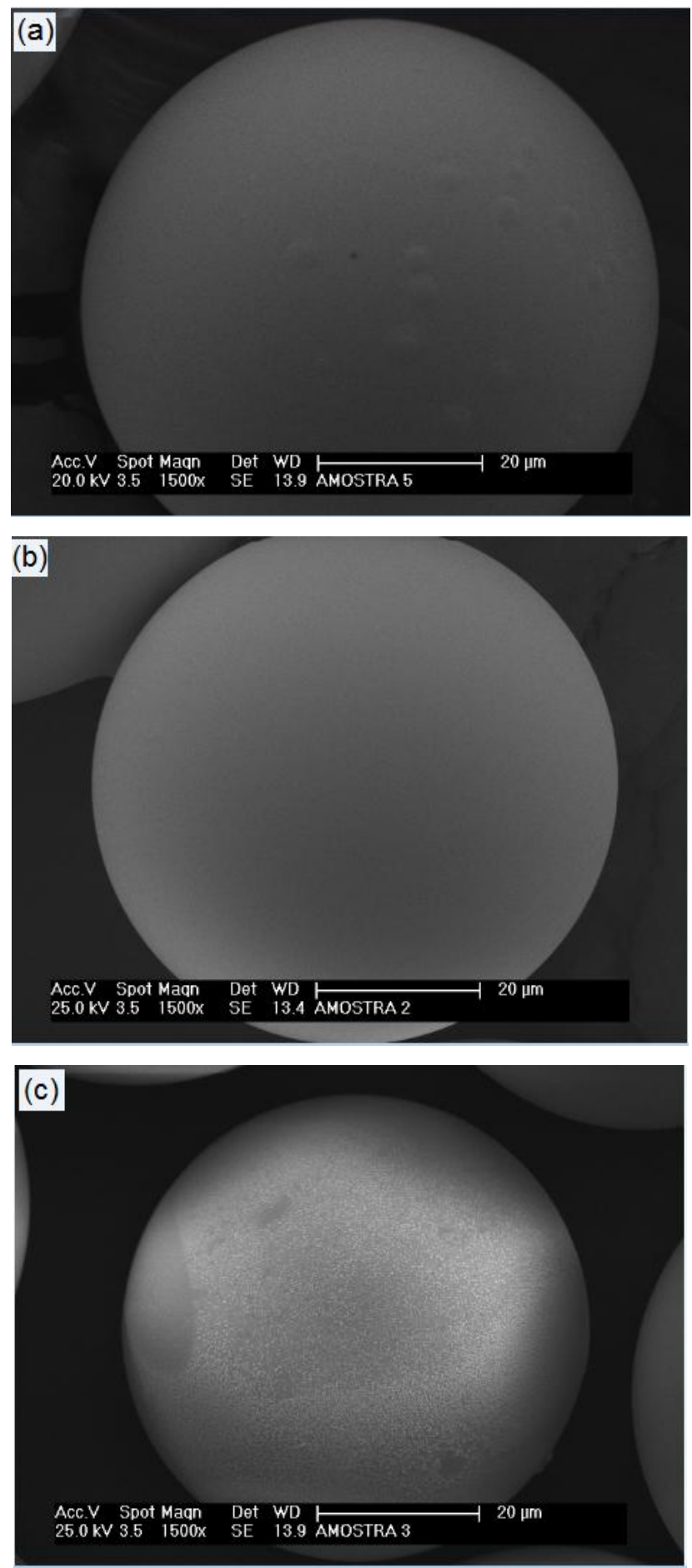

FIGURA 57 - Microesferas contendo 37\% de óxido de hólmio (a) antes da imersão (b) após 7 dias em SBF (c) após 14 dias em SBF. 
Os resultados obtidos demonstram que não houve ataque químico do SBF às microesferas e por isso podem ser consideradas potencialmente indicadas para radioterapia interna seletiva. Estes tipos de vidros possuem ligações químicas fortes influenciando suas propriedades como alta dureza, viscosidade e durabilidade química.

\subsection{Teste de durabilidade química}

A fim de confirmar a boa durabilidade química destes vidros aluminossilicatos, já reportados na literatura, testes de durabilidade química foram realizados para investigar se o hólmio contido na composição do vidro poderia alterar esta propriedade. Os resultados são apresentados na TAB. 11 e na FIG. 58:

TABELA 11: Taxa de dissolução de vidros aluminossilicatos contendo hólmio em função do tempo de imersão à $90^{\circ} \mathrm{C}$.

\begin{tabular}{clcl}
\hline \hline & & $\operatorname{Dr}\left(\mathrm{g} / \mathrm{cm}^{2} . \mathrm{min}\right)$ \\
\hline $\mathrm{t}$ (dias) & Ho 5\% & Ho 25\% & Ho 37\% \\
\hline 1 & $6,2(2) \times 10^{-7}$ & $8,4(3) \times 10^{-8}$ & $1,64(5) \times 10^{-8}$ \\
3 & $3,0(1) \times 10^{-6}$ & $1,20(5) \times 10^{-7}$ & $2,7(1) \times 10^{-8}$ \\
7 & $2,9(1) \times 10^{-6}$ & $2,6(1) \times 10^{-6}$ & $1,86(5) \times 10^{-8}$ \\
14 & $2,1(1) \times 10^{-6}$ & $9,6(3) \times 10^{-7}$ & $1,53(5) \times 10^{-8}$ \\
\hline \hline
\end{tabular}

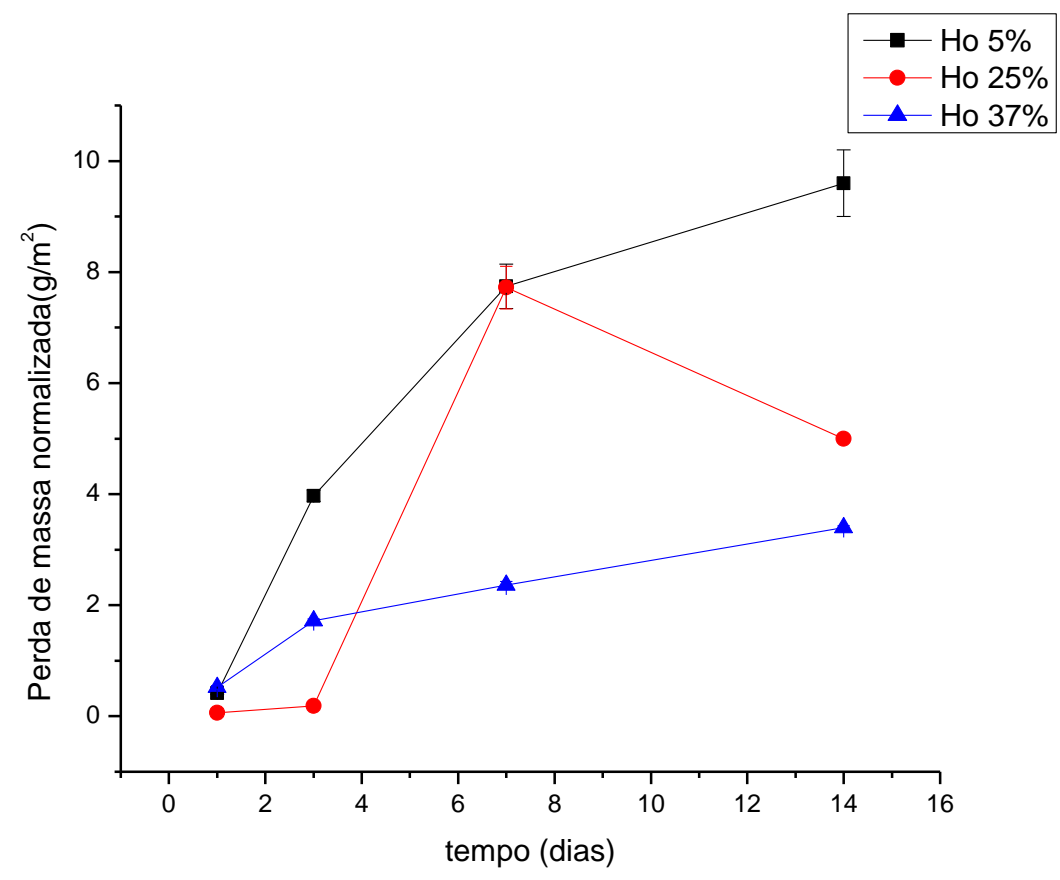

FIGURA 58: Perda de massa normalizada em função do tempo 
Estes resultados demonstram que estes vidros possuem durabilidade química alta comparados com os tradicionais vidros de janela (DR $\left.=10^{-5} \mathrm{~g} / \mathrm{cm}^{2} . \mathrm{min}\right) \mathrm{e}$ por isso são indicados para radioterapia interna seletiva. Também notou-se que o aumento da quantidade de hólmio no vidro aumenta sua durabilidade química, fazendo sua taxa de dissolução ser bastante baixa.

\subsection{Teste de Citotoxicidade}

Os testes de citotoxicidade foram realizados nos vidros contendo $5 \%, 25 \%$ e $37 \%$ de óxido de hólmio em sua composição nominal e os resultados são apresentados na FIG. 59 :

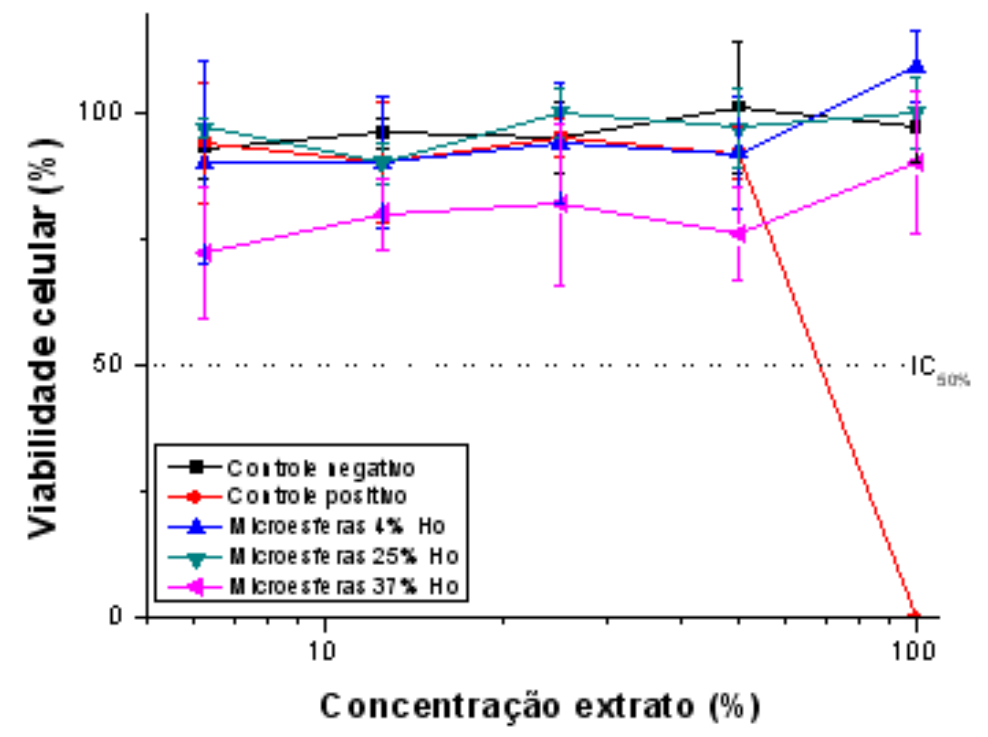

FIGURA 59: Viabilidade celular de amostras de microesferas de vidro aluminossilicatos contendo hólmio em função da concentração do extrato.

As microesferas com 5\%, 25\% e 37\% em peso de óxido de hólmio em sua composição não são citotóxicas, sendo indicadas para o uso em radioterapia interna seletiva. 


\section{CONCLUSÕES}

Foram produzidas microesferas de vidro aluminossilicato contendo hólmio pelos processos de esferolização por chama e por queda gravitacional a partir de partículas vítreas com formato irregular. Os vidros obtidos, tanto na forma de partículas, como microesferas, apresentam alta estabilidade contra a cristalização e alta viscosidade quando comparados a outros vidros. Não foram constatadas mudanças significativas na composição das microesferas e do material precursor após o processo de esferolização. As impurezas presentes representam menos de 1,5\% em massa da composição do vidro contendo $5 \%$ de óxido de hólmio em peso e podem ser reduzidas utilizando compostos com grau de pureza superior. Além disso, as impurezas presentes não inviabilizam o uso das microesferas na radioterapia pretendida, pois ou possuem baixa seção de choque para absorção de nêutrons ou os radiosótopos formados possuem meia vida curta. A densidade média das microesferas de vidro contendo hólmio é de $2,79(12) \mathrm{g} / \mathrm{cm}^{3}$ que é menor que as densidades apresentadas por microesferas de vidro comerciais contendo ítrio. Não se observou indícios da formação de fases cristalinas após o processo de esferolização. A princípio, a nucleação de fases cristalinas é considerada indesejada, pois poderia causar tensões mecânicas e prejudicar a performance das microesferas pela criação de ranhuras e outros defeitos.

Nos processos de esferolização por chama e por queda gravitacional, a distribuição granulométrica do material precursor mais adequada para a conformação em microesferas é $40 \mu \mathrm{m}<\Phi<53 \mu \mathrm{m}$, em que se obtiveram microesferas com diâmetro médio de $\langle\Phi\rangle=63 \mu \mathrm{m}$. O tipo de moagem considerado mais adequado é o moinho de facas onde se obteve um diâmetro médio das microesferas de $\langle\Phi\rangle=60 \mu \mathrm{m}$ quando o material precursor utilizado estava na faixa de $45 \mu \mathrm{m}<\Phi<63 \mu \mathrm{m}$.

No processo de esferolização por chama, as temperaturas da chama mais adequadas para conformação do vidro em microesferas são do tipo "quente", porém esta variável tem uma influência relativamente pequena sobre o diâmetro médio das 
microesferas, sendo praticamente equivalentes quando comparado a duas temperaturas "quentes" distintas. O tempo de voo adequado é do tipo "longo" em que as partículas foram coletadas na segunda metade do percurso total das microesferas mais afastadas em relação à chama. Houve uma redução de $10 \mu \mathrm{m}$ no diâmetro médio das microesferas mais afastadas com relação àquelas mais próximas da chama.

No processo de esferolização por queda gravitacional verificou-se que o fluxo de ar ascendente deve ser evitado, pois prejudica a morfologia das microesferas e, portanto, deve ser utilizado o fluxo "fraco". As temperaturas adequadas para conformação do vidro em microesferas são $1420^{\circ} \mathrm{C}, 1460^{\circ} \mathrm{C}$ e $1490^{\circ} \mathrm{C}$. As temperaturas de $1200^{\circ} \mathrm{C}$ e $1380^{\circ} \mathrm{C}$ foram consideradas inadequadas.

Comparando-se os dois processos de esferolização avaliados no presente trabalho, conclui-se que o processo que envolve a queda gravitacional apresenta um maior controle das variáveis de processamento e as microesferas obtidas são mais homogêneas e morfologicamente mais adequadas. Porém, este método é mais conveniente para estudos em escala laboratorial, pois o volume de microesferas gerado é relativamente pequeno para torná-lo viável economicamente. Por outro lado, o processo de esferolização por chama é capaz de gerar um volume maior de microesferas em função do tempo de operação.

O processo de eliminação de partículas satélites é eficaz e obtiveram-se microesferas com diâmetro médio de $\langle\Phi\rangle=60 \mu \mathrm{m}$ e boa homogeneidade das microesferas.

A irradiação por nêutrons não danifica a superfície das microesferas de vidro, mantendo suas características químicas, físicas e estruturais.

O aumento do teor de hólmio na estrutura do vidro melhora a fluidez do pó irregular (material precursor) durante a inserção das partículas na zona quente de ambos os processos de esferolização e aumenta a estabilidade do pó, sendo possível reduzir o diâmetro médio para $\langle\Phi\rangle=54 \mu \mathrm{m}$ quando as microesferas possuíam $37 \%$ de óxido de hólmio em sua constituição.

Não há indícios de alteração na superfície das microesferas após os testes de durabilidade química em SBF.

A taxa de dissolução dos vidros imersos em água destilada a $90^{\circ} \mathrm{C}$ é de $\sim 10^{-}$ ${ }^{8} \mathrm{~g} \cdot \mathrm{cm}^{-2} \cdot \mathrm{min}^{-1}$, inferior aos valores apresentados pelos tradicionais vidros de janela ( $10^{-5} \mathrm{~g} \cdot \mathrm{cm}^{-2} \cdot \mathrm{min}^{-1}$ ). Notou-se que a durabilidade química aumenta em função do teor de óxido de hólmio na composição dos vidros. 
Os testes de citotoxidade mostraram que as microesferas de vidro em estudo não são citotóxicas e podem ser usadas para o tratamento pretendido.

Propõe-se que as microesferas de vidro contendo hólmio possam ser utilizadas em testes "in vivo" visando a sua aplicação em radioterapia interna seletiva. 


\section{REFERÊNCIAS BIBLIOGRÁFICAS}

[1] Castro V. F., Celestino J., Queiroz A. A. A. de, Garcia F. G. - "Propriedades magnéticas e biocompatíveis de nanocompósitos para utilização em magnetohipertermia" - Revista Brasileira de Física Médica - p. 79-82 - 2010.

[2] "Human Health Series No 10- Trends and Practices in Diagnosis and Treatment of Hepatocellular Carcinoma" - IAEA - Vienna - 2010.

[3] MacMaster K. M., Vauthey J. N. - "Hepatocellular Carcinoma-Targeted Therapy and Multidisciplinary Care " - Springer - ISBN 978-1-60327-521-7 - 2010.

[4] Vente M. A. D. , Nijsen J. F. W., de Roos R., van Steenbergen M. J., Kaaijk C. N. J., Koster-Ammerlaan M. J. J., de Leege P. F. A. , Hennink W. E., van het Schip A. D. , Krijger G. C. - "Neutron activation of holmium poly(L-lactic acid) microspheres for hepatic arterial radioembolization: a validation study" - Biomed Microdevices - p. 763$772-2009$.

[5] Bult W., Seevinck P. R., Krijger G. C., Visser T., Kroon-Batenburg L. M. J., Bakker C. J. G., Hennink W. E., van het Schip A. D., Nijsen J. F. W. - "Microspheres with Ultrahigh Holmium Content for Radioablation of Malignancies" - Pharmaceutical Research Vol 26 - n.6 - p. 1371-1378 - 2009.

[6] Costa R. F., Azevedo M. B. M., Nascimento N., Sene F. F., Martinelli J. R., Osso J. A. - "Production of microsphere labeled with holmium-166 for liver cancer therapy: the preliminary experience at IPEN/CNEN" - 2009 International Nuclear Atlantic Conference - INAC 2009.

[7] Hench L. L., Day D. E., Ho“land W., Rheinberger V. M. - "Glass and Medicine" International Journal of Applied Glass Science - Vol. 1 - Num. 1 - p. 104-117 - 2010.

[8] Smits M. L. J., Nijsen J. F. W., van den Bosch M. A. A. J., Lam M. G. E. H., Vente M. A. D., Huijbregts J. E., van het Schip A. D., Elschot M., Bult W., de Jong H. W. A. M., Meulenhoff P. C. W., Zonnenberg B. A. - "Holmium-166 radioembolization for the treatment of patients with liver metastases : design of the phase I HEPAR trial".Journal of experimental and clinical cancer research - p. 29-70 - 2010.

[9] Andrä W., Nowak H. - "Magnetism in Medicine" - Wiley - 1998. 
[10] Martinelli J.R., Sene F.F., Kamikawachi C. N., Partiti C. S. de M., Cornejo D. R. "Synthesis and characterization of glass-ceramic microspheres for Thermotherapy" Journal of Non-Crystalline Solids - doi:10.1016/j.jnoncrysol.2010.05.006 - 2009.

[11] Hamoudeh M., Fessi H., Salim H., Barbos D. - "Holmium-Loaded PLLA Nanoparticles for Intratumoral Radiotherapy Via the TMT Technique: Preparation, Characterization, and Stability Evaluation after Neutron Irradiation"- Informa Health care - p.796-806 - ISSN: 0363-9045 - doi: 10.1080/03639040801918623 - 2008.

[12] Garin E., Rolland Y., Boucher E. , Ardisson V., Laffont S., Boudjema K. , Bourguet P. , Raoul J.-L. - "First experience of hepatic radioembolization using microspheres labelled with yttrium-90 (TheraSphere): practical aspects concerning its implementation" - Eur J Nucl Med Mol Imaging - p. 453-461 - doi 10.1007/s00259009-1279-6 - 2010.

[13] Mo L., Avci B., James D., Simpson B., Van Wyngaardt W.M., Cessna J.T., Baldock C. - "Development of activity standard for 90Y microspheres" - Applied Radiation and Isotopes - p. 193-199 - doi:10.1016/j.apradiso.2005.02.002 - 2005.

[14] Poobaygi H., Aghamiri S.M.R., Sheibani S., Kamali-Asl A., Mohagheghpoor E. "Production of glass microspheres comprising $90 \mathrm{Y}$ and $177 \mathrm{Lu}$ for treating of hepatic tumor with SPECT imaging capabilities " - Applied Radiation and Isotopes - Elsevier p. 1407-1414 - doi:10.1016/j.apradiso.2011.05.026 - 2011.

[15] Wang X. D. , Yang R. J., Cao X. C. , Tan J., Li B. - "Dose Delivery Estimated by Bremsstrahlung Imaging and Partition Model Correlated with Response Following Intra-arterial Radioembolization with ${ }^{32} \mathrm{P}$-Glass Microspheres for the Treatment of Hepatocellular Carcinoma"- Journal Gastrointest. Surg. - p. 858-866 - doi 10.1007/s11605-010-1180-4-2010.

[16] Goh A. S-W., Chung A. Y.-F., Lo R. H.-G., Lau T.-N., Yu S. W.-K., Chng M., Satchithanantham S., Loong S. L.-E., Chee-Eng NG D., Lim B.-C., Connor S., Chow P. K.-H., "A novel approach to brachytherapy in hepatocellular carcinoma using a phospherius 32 brachytherapy delivery device - A first-in-man study"- Int. J. Radiation Oncology Biol. Phys - 2006.

[17] G. Wunderlich, J. Pinkert, M. Stintz, J. Kotzerke - "Labeling and biodistribution of different particle materials for radioembolization therapy with ${ }^{188} \mathrm{Re}$ " - Applied Radiation and isotopes -2004 .

[18] Nijsen J.F.W., van Steenbergen M.J., Kooijman H., Talsma H., Kroon-Batenburg L.M.J., van de Weert M., van Rijk P.P., de Witte A., van het Schip A.D., Hennink W.E. - "Characterization of poly(L-lactic acid) microspheres loaded with holmium acetylacetonate" - Biomaterials 22 - p. 3073-3081-2001.

[19] Dasa T., Chakrabortya S., Sarmab H. D., Venkatesha M., Banerjeea S. "Preparation of 166Ho-oxine-lipiodol and its preliminary bioevaluation for the potential application in therapy of liver cancer" - Nuclear Medicine Communications - p. 362367 - doi: 10.1097/MNM.0b013e328329981a - 2009. 
[20] Costa R. F. - "Desenvolvimentos de métodos de preparação de microesferas de polímeros e resinas marcadas com hólmio-166" - Dissertação de Mestrado - IPEN-USP -2008 .

[21] Vente M. A. D., de Wit T. C., van den Bosch M. A. A. J., Bult W., Seevinck P. R., Zonnenberg B. A., de Jong H. W. A. M., Krijger G. C., Bakker C. J. G., van het Schip A. D., Nijsen J. F. W. - "Holmium-166 poly (L-lactic acid) microsphere radioembolization of the liver: technical aspects studied in a large animal model" - Eur. Radiol. - p. 862-869 - doi. 10.1007/s00330-009-1613-1 - 2010.

[22] Nijsen J.F.W., Van Het Schip A.D., Van Steenbergen M.J., Zielhuis S.W., KroonBatenburg L.M.J., Van de Weert M., Van Rijk P.P., Hennink W.E. "Influence of neutron irradiation on holmium acetylacetonate loaded poly(l-lactic acid) microspheres" - Biomaterials - p. 1831-1839-2001.

[23] Sreekumar K.P., Saxena S.K., Kumar Y., Thiyagarajan T.K., Dash A., Ananthapadmanabhan P.V., Venkatesh M. - "Studies on the preparation and plasma spherodization of yttrium aluminosilicate glass microspheres for their potential application in liver brachytherapy" - Journal of physics - doi.10.1088/17426596/208/1/012117 - 2010.

[24] Alves O. L., Menezes I. de F., Mazali I. O. - "Vidros" - Cadernos Temáticos Química Nova na Escola - p. 9-20 - 2001.

[25] Shelby J. E. - "Introduction to Glass Science and Technology" - The Royal Society Chemistry - 1997.

[26] Navarro J.M.F. - "E1 Vidrio" - CSIC - 1991.

[27] Zarzycki J. - "Glasses and the Vitreous State"- Cambridge University Press - 1991.

[28] Wheeler E.L. - "Scientific Glassblowing” - Interscience Publishers Inc. - 1958.

[29] Pulker H. K. - "Coating on Glass" - Elsevier - 2 edição - 1999.

[30] Bach H., Neuroth N. - "The Properties of Optical Glass" - Springer - 1998.

[31] Candido C.M.N. - "Propriedades Ópticas de Vidros Oxifluoroboratos de Chumbo dopados com DY3+" - Dissertação de Mestrado-IFSC-USP-2001.

[32] Varshneya A.K. - " Fundamentals of Inorganic Glasses" - Academic Press - 1994.

[33] http://www.astm.org acessado em 05/03/2011.

[34] Fokin V. M. , Zanotto E. D. , Yuritsyn N. S. , Schmelzer J. W. P. - "Homogeneous crystal nucleation in silicate glasses: A 40 years perspective" - Jornal of Non-Cristalline Solids - p. 2681-2714 - doi:10.1016/j.jnoncrysol.2006.02.074 - 2006. 
[35] Vieira H. - "Avaliação da cristalização e durabilidade química de vidros niobofosfatos visando à imobilização de rejeitos radioativos" - Dissertação de Mestrado - IPEN-USP-2008.

[36] Jones G.O. - "Glass" - John Wiley and sons, INC - 1956.

[37] Elliot S.R. - "Physics of Amorphous Materials" . Longman Scientific and Technical $-2^{\circ}$ edição -1990.

[38] Zachariasen W. H. - "The Atomic Arrangement in Glass" - Ryerson Physical Laboratory - Vol. 54 - p. 3841-3851 - 1932.

[39] Ghussn L. - "Síntese e Caracterização de Vidros Niobofosfatos e Ferrofosfatos Utilizados como Meio para Imobilização de U3O8" - Tese de Doutorado - IPEN-USP -2005 .

[40] Saddeek Y. B. - "Structural interpretations of aluminosilicate glasses" - Physica B - p. 19-24 - doi:10.1016/j.physb.2005.02.029 - 2005.

[41] Mclellan G. W., Shand E. B. - "Glass Engineering Handbook" - McGraw-Hill Book Company - 1984.

[42] Lee S. K., Sung S. - "The effect of network-modifying cations on the structure and disorder in peralkaline $\mathrm{Ca}-\mathrm{Na}$ aluminosilicate glasses: O-17 3QMAS NMR study" Chemical Geology - p. 326-333 - doi:10.1016/j.chemgeo.2008.07.019 - 2008.

[43] Lee S. K., Stebbins J. F. - "Effects of the degree of polymerization on the structure of sodium silicate and aluminosilicate glasses and melts: An 17O NMR study" Geochimica et Cosmochimica Acta - p. 1109-1119 - doi:10.1016/j.gca.2008.10.040 2009.

[44] Pozdnyakova I., Sadiki N., Hennet L., Cristiglio V., Bytchkov A., Cuello G.J., Coutures J.P., Price D.L. - "Structures of lanthanum and yttrium aluminosilicate glasses determined by X-ray and neutron diffraction" - Journal of Non-Crystalline Solids - $\mathrm{p}$. 2038-2044 -doi:10.1016/j.jnoncrysol.2007.11.012doi:10.1016/j.jnoncrysol.2007.11.012 -2008 .

[45] Silich L.Y., Bobkova B.M. - "Spectroscopic studies of the alkali - free aluminosilicate glass structure" - Journal of Molecular Structure - p. 243-246 - 1986.

[46] Lee S. K. , Stebbins J. F., "Al - O - Al and Si - O - Si sites in framework aluminosilicate glasses with Si/Al.1: quantification of framework disorder" - Journal of Non-Crystalline Solids - p. 260-264 - 2000.

[47] White F. M. "Fluid mechanics" - McGraw - Hill - 1999.

[48] Atkins P., De Paula J.- "Físico - Química Vol.2” - LTC - 2002. 
[49] Pellicer J., Morales V. G., Hernandez M. J. - "On the demonstration of the YoungLaplace equation in introductory physics courses" - TEACHING PHYSICS - p. 126$129-2000$.

[50] Potter M. C., Wiggert D. C.- "Mecânica dos Fluidos" - Thomson - 2002.

[51] Reed J. S. "Introduction to the Principles of Ceramic Processing" - John Wiley sons -1988 .

[52] Yoshimura E. M. - "Física das radiações: interação da radiação com a matéria" Revista brasileira de física médica - p. 57-67 - 2009.

[53] Eisberg R., Resnick R. - "Física Quântica: átomos, moléculas, sólidos, núcleos e partículas" - Campus - 1988.

[54] Feynman R. P. - "Notas de aula de Física Nuclear Teórica” redigidas por G.

Rawitscher - Livraria da física - 2005.

[55] Magill J., Galy J.- "Radioactivity Radionuclides Radiation” - Springer - 2005.

[56] Kuckuk T. M. - "Física Nuclear: Uma introdução" - Fundação Calouste Gulbenkian - 1984 .

[57] Kaplan I. - "Nuclear Physics" - Addison-Wesley Publishing Company, Inc - 1955.

[58] Bitelli T. - "Dosimetria e higiene das radiações" - Gremio Politécnico - 1982.

[59] Turner J. E. - “Atoms, Radiation and Radiation Protection” - Wiley VCH - 2007.

[60] Richet P., Roskosz M., Roux J. - "Glass formation in silicates: Insights from composition” - Chemical Geology - 2006.

[61] http://www.lenntech.es/periodica/elementos/ho.htm acessado em 06/04/2011.

[62] Yntema L. F., Hopkins B. S. - "Observations on the rare earths. VII the separation of holmium" - Contribution from the chemical laboratory of the university of Illinois 1918.

[63] James C., Grant A. J. - "The separation of the rare earths giving the more soluble double sulfates from brazilian monazite sand" - Contribution from the school of chemistry of university of Pittsburgh - 1915.

[64] Hubicka H., Drobeck D. - "Anion-exchange method for separation of ytterbium from holmium and erbium" - Hidrometarllugy - 1997.

[65] Bates S., Patterson C., Mcintery G. J., Palmer S. B., Mayer A., Cowley R. A., Melville R. - "The magnetic structure of holmium" - J. Phus C: Solid States Phys 1988. 
[66] Koehler W. C., Cable J. W., Wilkinson M. K., Wollan E. O. - "Magnetic Structure of Holmium. The Virgin state" - Physical Review - Vol. 151 - num. 2 - p. 414-424 1966.

[67] Strandburgh D. L., Legvolg S., Spedding F. H. - "Electrical and Magnetic properties of holmium single crystals" - Physical Review - vol. 127 - num. 6 - p. 2046$2051-1962$.

[68] Rhodes B. L., Legvolg S., Spedding F. H. - "Magnetic properties of Holmium and Thulium metals" - Physical Review - vol.109 - num.5 - p. 1547-1550 - 1957.

[69] Feynman R. P., Leighton R. B., Sands M. - "The Feynman Lectures on Physics Vol. II" - Bookman - 2008.

[70] Nijsen J. F. W., Seppenwoolde J. H., Havenith T., Bos C., Bakker C. J. G., Schip A. D. V. H. - "Liver Tumors: MR Imaging of radioactive holmium microsphere Phantom and rabbit study" - Radiology - vol. 231 - num. 2 - p. 491-499 - 2004.

[71] Seppenwoolde J. H. , Nijsen J. F. W., Bartels L. W., Zielhuis S. W., Van het Schip A. D., Bakker C. J. G. - "Internal Radiation Therapy of Liver Tumors: Qualitative and Quantitative Magnetic Resonance Imaging of the Biodistribution of Holmium-Loaded Microspheres in Animal Models" - Magnetic Resonance in Medicine - p.76-84 - 2005.

[72] http://www.nndc.bnl.gov/nudat2/ acessado em 06/10/2011.

[73] Simon N. - "Intra-Arterial Irradiation" - Bulletin of the New York Academy of Medicine - vol. 4 - num. 4 - p.358-372 - 1969.

[74] Hilgard P., Müller S., Gerken G., Antoch G. - "Radioembolisation with Yttrium-90 Microspheres for Hepatocellular Carcinoma - Method and Results" - European gastroenterology and hepatology review - p.82-88 - 2010.

[75] Salem R., Kulik L., Murthy R. - "Radioembolization with Yttrium-90 Microspheres for the Treatment of Hepatocellular Carcinoma and Liver Metastases" US Gastroenterology - p. 50-52 - 2007.

[76] http://www.nordion.com/therasphere/physicians_us/about therasphere.asp acessado em 04/07/2011.

[77] Arakin N., Nagata Y., Fujiwara K., Aoki T., Mitsumorim M., Kimura H., Itasaka S., Saitou H., Hiraoka M., Kawashita M., Kokubo T. - "Evaluation of glass microspheres for intra-arterial radiotherapy in animal kidneys" - Int. J. Radiation Oncology Biol. Phys - vol. 49 - num. 2 - p. 459-463 - 2001.

[78] Mantravadi R.V., Spigos D. G., Tan W.S, Felix E.L.- "Intraarterial yttrium 90 in the treatment of hepatic malignancy" - Radiology - vol. 142 - p. 783-786 - 1982. 
[79] Liu D. M., , Salem R., Bui J. T., Courtney A., Barakat O., Sergie Z., Atassi B., Barrett K., Gowland P., Oman B., Lewandowski R. J., Gates V. L., Thurston K. G., Wong C. O., - "Angiographic Considerations in Patients Undergoing Liver-directed Therapy" - J. Vasc. Interv. Radiol. - 2005.

[80] Lafave J. W. , Grotenhuis L., Kim Y. S., Maclean L.D., Perry J . F.

Jr. - "Y90- tagged microspheres in adjuvant tumor theraphy" - Surgery - vol. 53 - p. $778-783-1963$.

[81] Salem R., Hunter R. - "Yttrium-90 microspheres for the treatment of hepatocellular carcinoma: a review" - Int. J. Radiation Oncology Biol. Phys. - 2006.

[82] Nolan T.R., Grady E.D. - "Intravascular particulate radioisotope therapy; clinical observations of 76 patients with advanced cancer treated with 90-yttrium particles" Am. Surg. - 1969.

[83] http://www.sirtex.com/ acessado em 04/07/2011.

[84] http://www.factsage.com/ acessado em 05/05/2011.

[85] MCC-1P Static Leach Test Method, Nuclear Waste Materials Handbook, Waste Form Test Methods (1981)

[86] ISO document 10 993-5, 2009 Biological evaluation of medical devices, Part 5, Tests for cytotoxicity: in vitro methods.

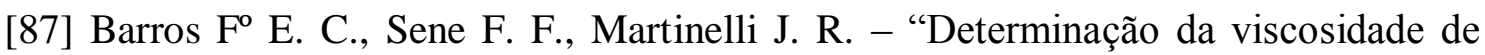
vidros por meio da medida do prolongamento de fibras" - Seminário Anual de iniciação científica PIBIC/PROBIC - 2006.

[88] Sandhu A. K., Singh S., Pandey O. P. - "Neutron irradiation effects on optical and structural properties of silicate glasses" - Materials Chemistry and Physics - p. 783-788 - doi:10.1016/j.matchemphys.2009.02.032 - 2009. 